\title{
Electrical Model Development and Validation for Distributed Resources
}

Subcontract Report NREL/SR-581-41109

April 2007

M.G. Simões, B. Palle, S. Chakraborty, and C. Uriarte

Colorado School of Mines

Golden, Colorado

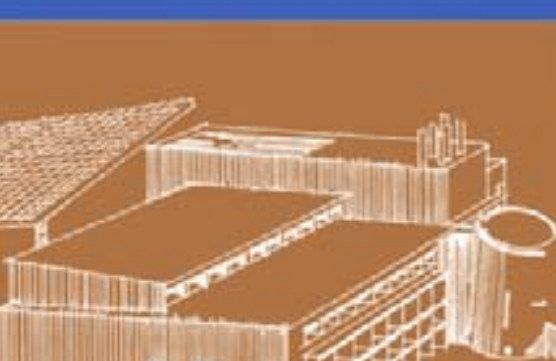




\section{Electrical Model Development and Validation for Distributed Resources}

M.G. Simões, B. Palle, S. Chakraborty, and $\mathrm{C}$. Uriarte

Colorado School of Mines

Golden, Colorado

NREL Technical Monitor: Benjamin Kroposki

Prepared under Subcontract No(s). XAT-5-55150-01

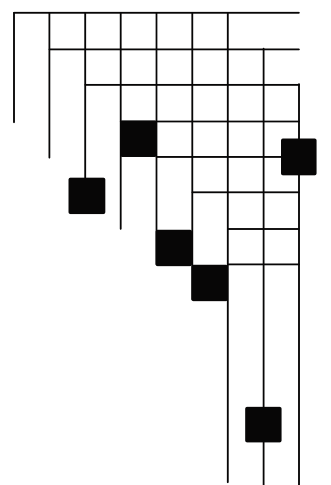




\section{NOTICE}

This report was prepared as an account of work sponsored by an agency of the United States government. Neither the United States government nor any agency thereof, nor any of their employees, makes any warranty, express or implied, or assumes any legal liability or responsibility for the accuracy, completeness, or usefulness of any information, apparatus, product, or process disclosed, or represents that its use would not infringe privately owned rights. Reference herein to any specific commercial product, process, or service by trade name, trademark, manufacturer, or otherwise does not necessarily constitute or imply its endorsement, recommendation, or favoring by the United States government or any agency thereof. The views and opinions of authors expressed herein do not necessarily state or reflect those of the United States government or any agency thereof.

Available electronically at http://www.osti.gov/bridge

Available for a processing fee to U.S. Department of Energy and its contractors, in paper, from:

U.S. Department of Energy

Office of Scientific and Technical Information

P.O. Box 62

Oak Ridge, TN 37831-0062

phone: 865.576 .8401

fax: 865.576 .5728

email: mailto:reports@adonis.osti.gov

Available for sale to the public, in paper, from:

U.S. Department of Commerce

National Technical Information Service

5285 Port Royal Road

Springfield, VA 22161

phone: 800.553 .6847

fax: 703.605.6900

email: orders@ntis.fedworld.gov

online ordering: http://www.ntis.gov/ordering.htm

This publication received minimal editorial review at NREL 


\section{Table of Contents}

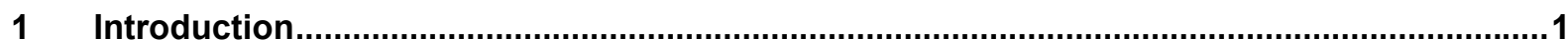

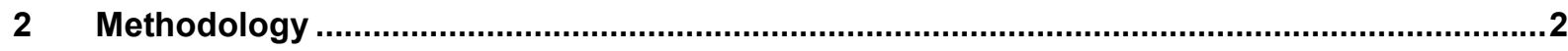

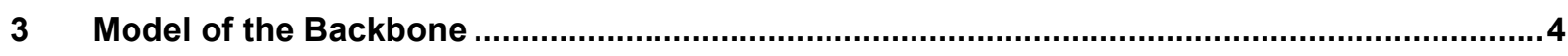

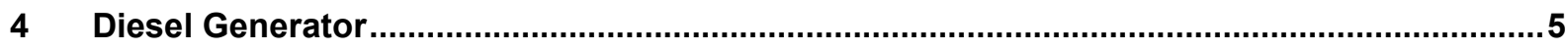

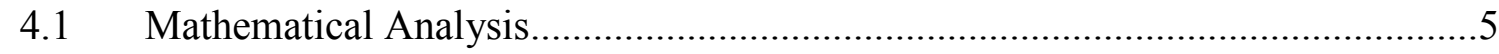

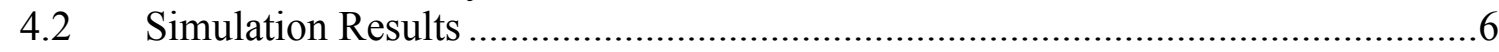

$5 \quad$ Wind Turbine

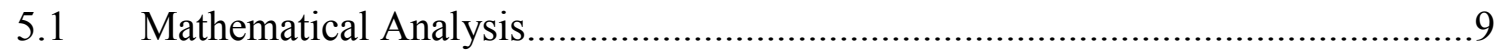

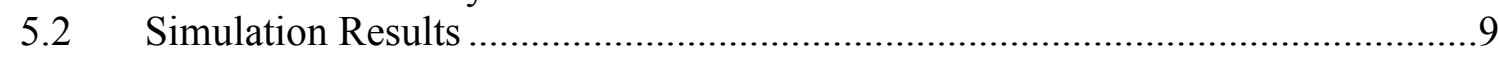

$6 \quad$ Inverter

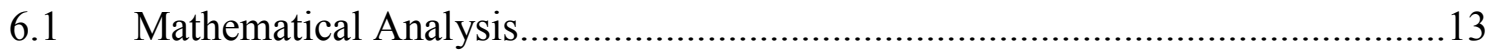

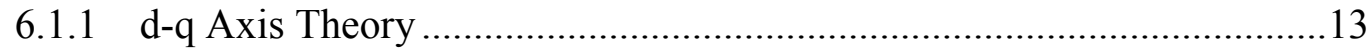

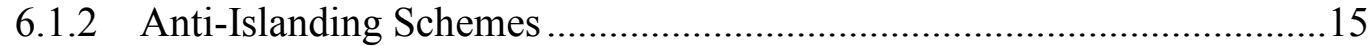

6.1.3 Constant Current Control ........................................................................16

6.1.4 Constant Power Control ..................................................................... 18

6.2 Simulation Results .............................................................................. 18

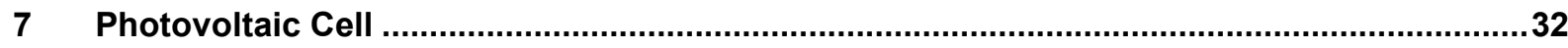

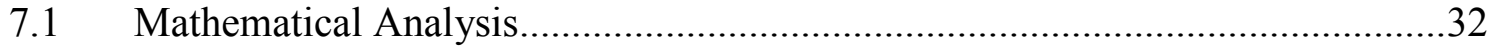

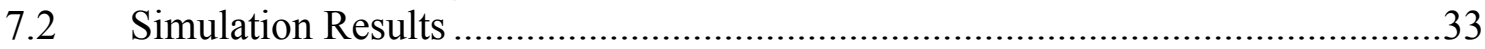

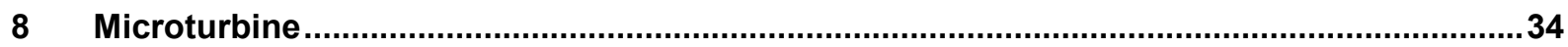

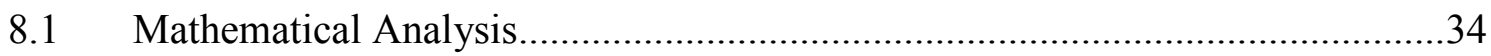

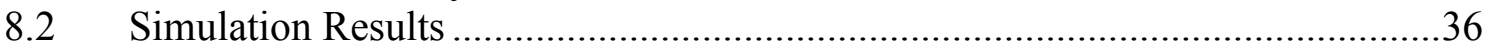

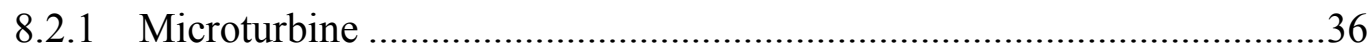

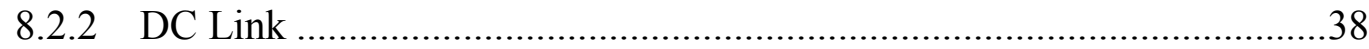

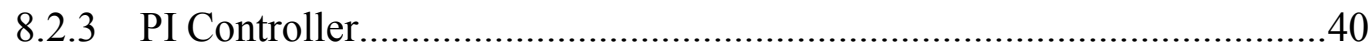

8.2.4 Grid Connection .........................................................................4 40

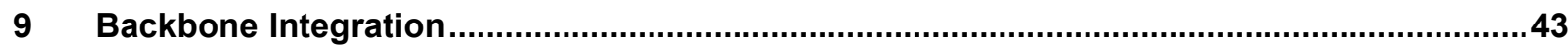

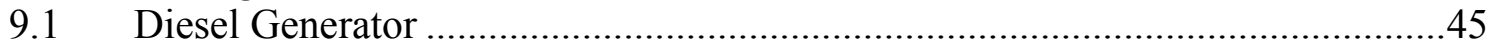

9.2 PV Cell Grid Connection ..........................................................................46

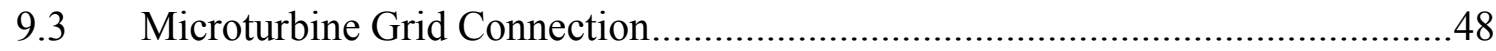

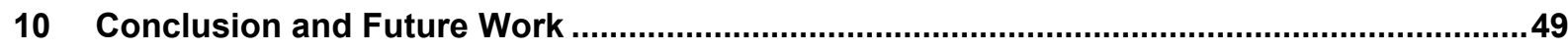

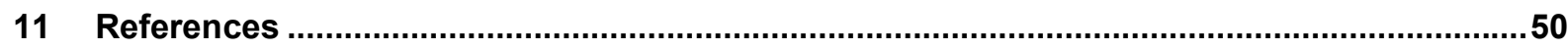




\section{List of Figures}

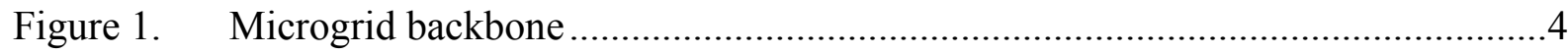

Figure 2. Diagram of the three-phase and d-q windings ...................................................5

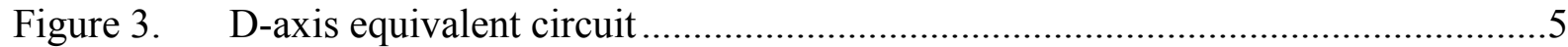

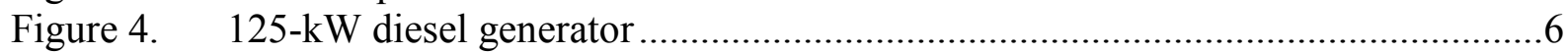

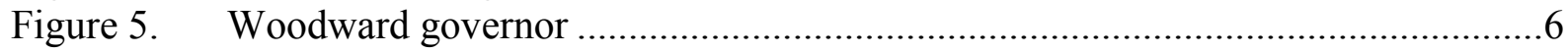

Figure 6. Output of diesel generator without mechanical dynamics.....................................

Figure 7. Output of diesel generator with mechanical dynamics .......................................... 8

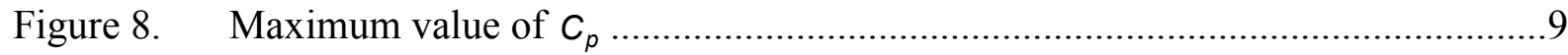

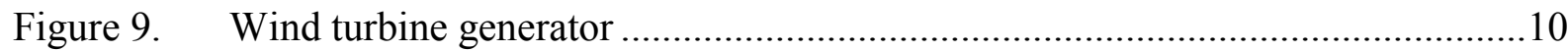

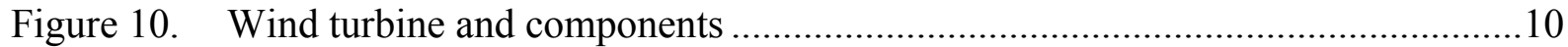

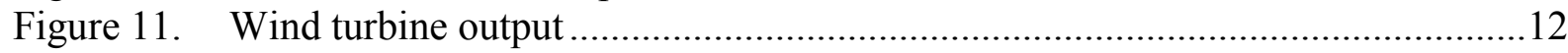

Figure 12. Schematic of the GE inverter system ...............................................................13

Figure 13. Physical distribution of three stationary axes and a quadrature stationary axis ..14

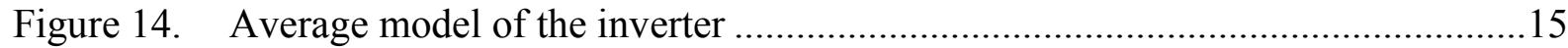

Figure 15. Constant current control with voltage feedback .................................................17

Figure 16. Constant current control with frequency feedback ...............................................17

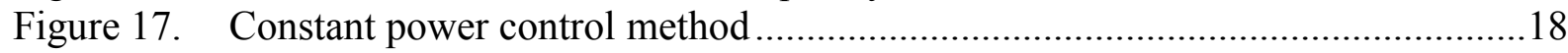

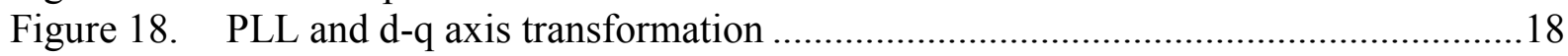

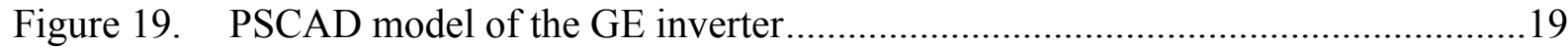

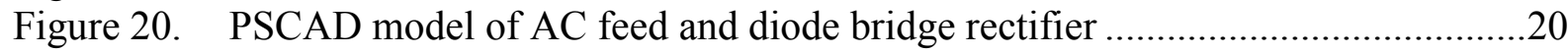

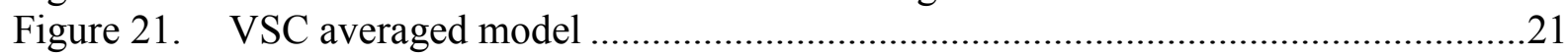

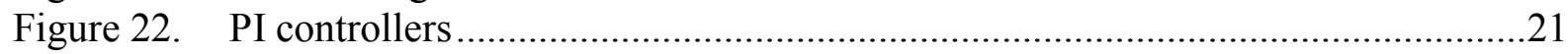

Figure 23. Compensation term for inverter voltage and frequency control ...........................22

Figure 24. Commands for the VSC averaged inverter ......................................................22

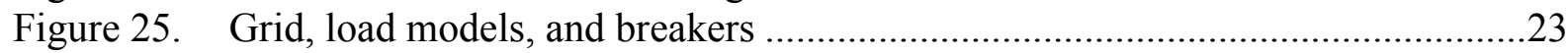

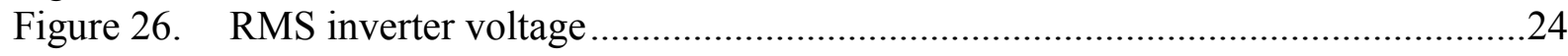

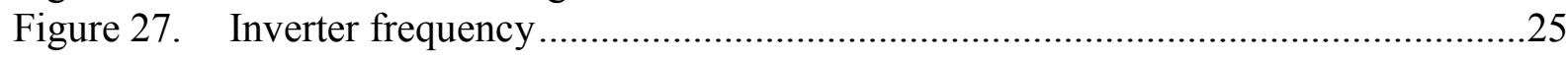

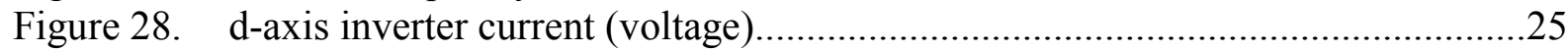

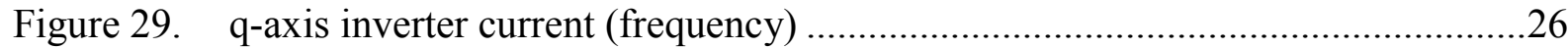

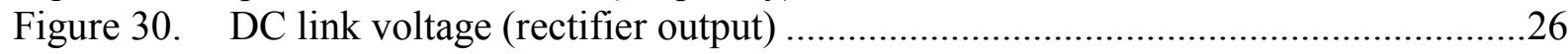

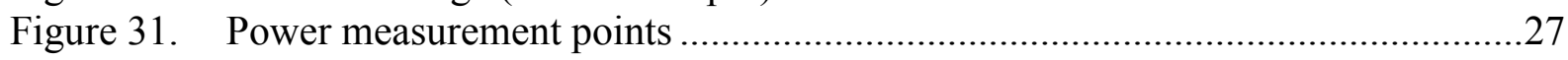

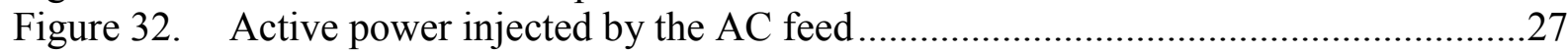

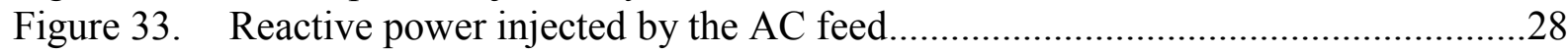

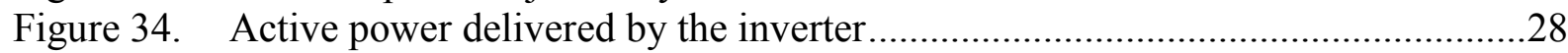

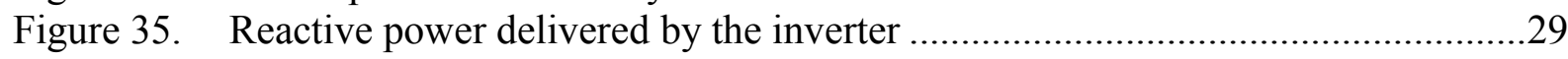

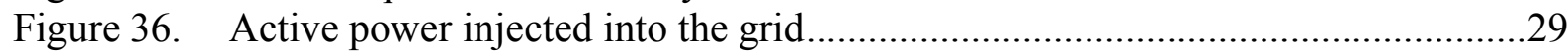

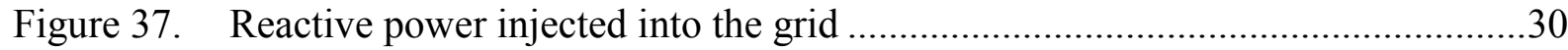

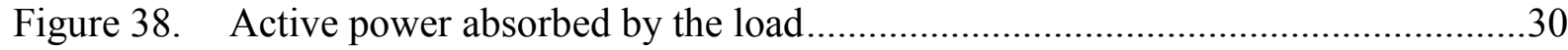

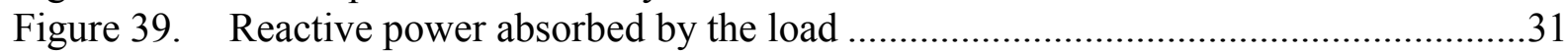

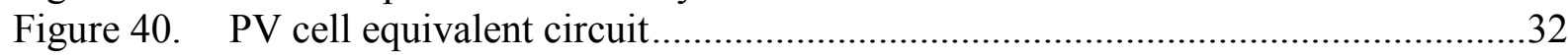

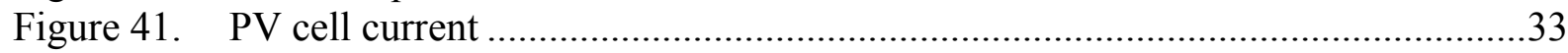

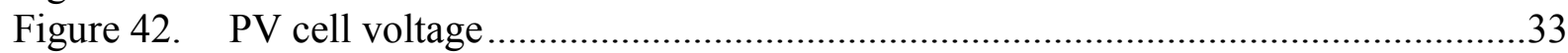

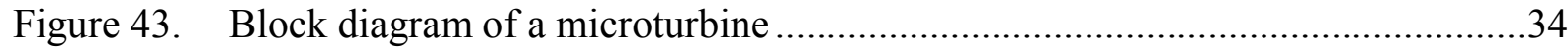

Figure 44. Total system ................................................................................................. 


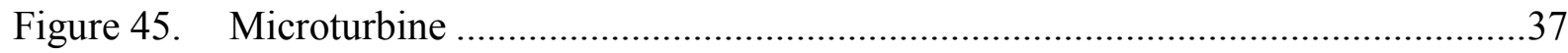

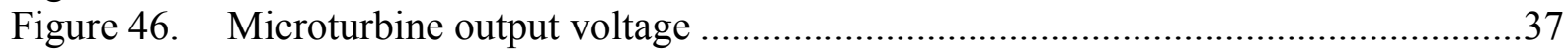

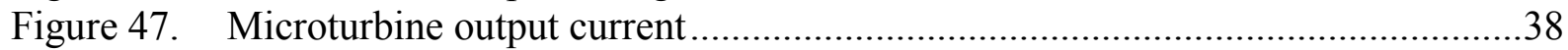

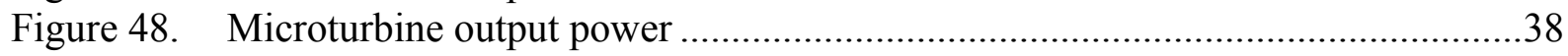

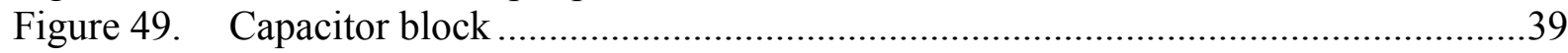

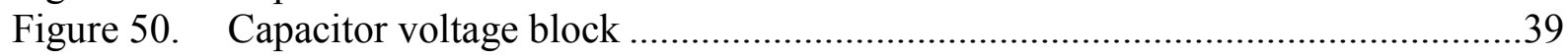

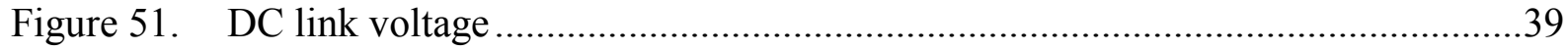

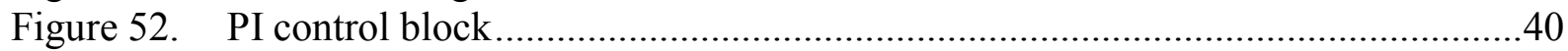

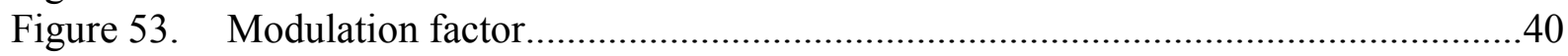

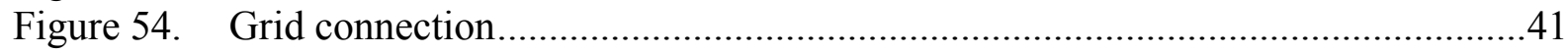

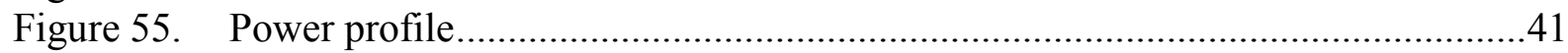

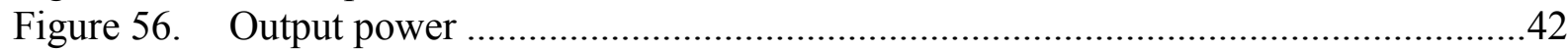

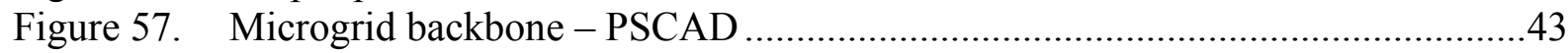

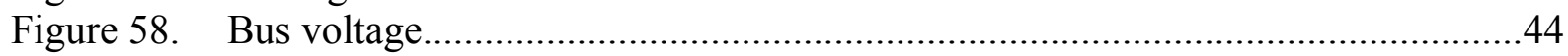

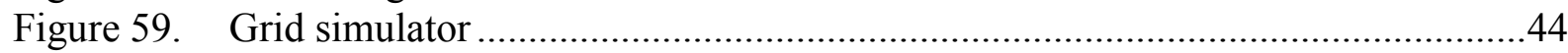

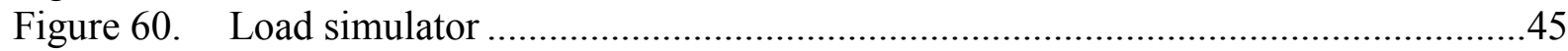

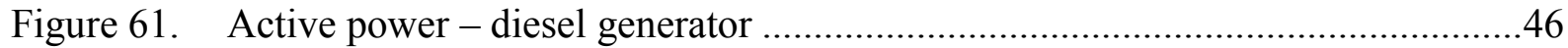

Figure 62. Reactive power - diesel generator ...........................................................46

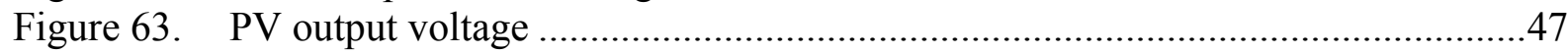

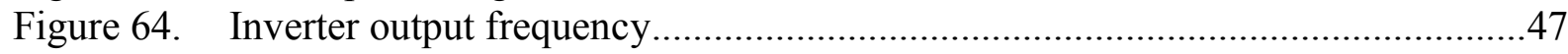

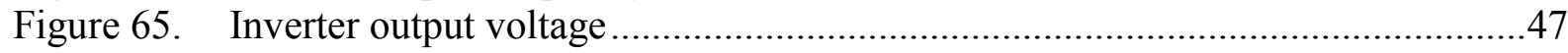

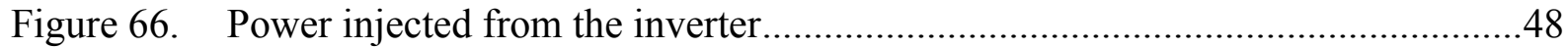

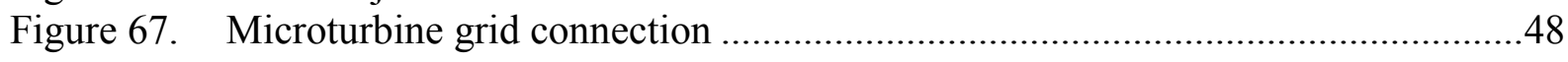

\section{List of Tables}

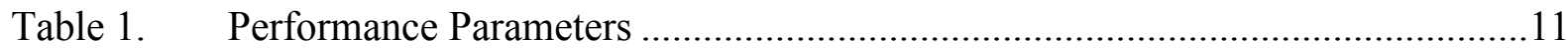

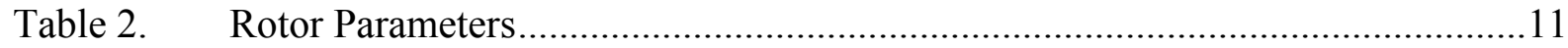

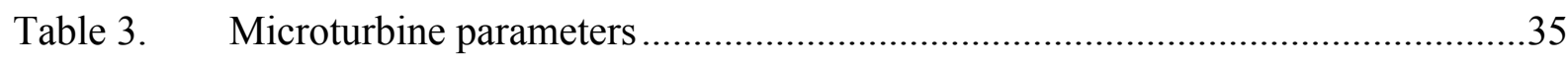




\section{Introduction}

This project focuses on the development of electrical models for small (1-MW) distributed resources (DR) at the National Renewable Energy Laboratory's (NREL's) Distributed Energy Resources Test Facility (DERTF). DR include all generation (e.g., photovoltaics, wind turbines, fuel cells, microturbines, and engines) and storage (e.g., batteries and flywheels) located at or near loads. The DERTF includes a Hybrid Power Test Bed, to which multiple DR are connected. These devices include wind turbines, a diesel generator, a microturbine, two village simulator load banks, and one alternating current-source (AC-source) grid simulator.

The purpose of this project is to provide NREL with the ability to conduct electrical power system modeling and analysis on the distribution system. This capability will allow NREL to examine the effects of multiple distributed generation units at various penetration levels on the electrical power system.

The first step of the project was to discuss which DR would be integrated into the microgrid. After that was defined, a mathematical analysis was performed for each component. Most of the modeling was based on the information contained in [1].

Before modeling the microgrid, it was necessary to determine which simulation software would be most appropriate. Of the software packages tested and analyzed, it was determined that PSCAD would be most suitable for this task.

With the mathematical analysis done and the appropriate software chosen, the modeling of the backbone of the microgrid began. The purpose was to analyze the system and the interactions of the DR with one another. Each machine was modeled individually and then inserted onto the grid. Interactions between models and the microgrid could then be monitored and adjusted to match their physical counterparts at the NREL testing facility.

The next step of this research is to model a fuel cell and integrate it into the microgrid. In addition, validation of the developed models through actual testing of multiple types of DR must be done to examine the electrical impacts of multiple DR on the electrical power system. 


\section{Methodology}

NREL, in collaboration with the Colorado School of Mines, developed advanced models for multiple DR. The work developed in this project can be used to understand and model the electrical effects of multiple DR on the distribution system and to determine the effects of large penetrations of DR.

The following methodology was adopted for this project:

1. DR model literature search

A literature search for available DR electrical models was conducted for inverters, synchronous generators, microturbines, photovoltaic (PV) cells, and wind turbines and induction generators $[1,2,4,6,7]$. This task helped bring together in a central location the current electrical models for the various types of DR. Most of the models came from [1], but the PV model was based on [2].

2. Electrical system modeling software evaluation

This part of the project involved selecting the best simulation software for analysis of electrical power systems. The software chosen was PSCAD.

PSCAD is a power-system simulator for the design and verification of power quality studies, power electronic design, distributed generation, and transmission planning. It was developed by the Manitoba HVDC Research Center and has been in use since 1975. PSCAD is a graphical front end to EMTDC for creating models and analyzing results. In PSCAD, one combines blocks to form a power network. These blocks are actually FORTRAN code, which call for an EMTDC code library to combine them into executable files. Running these files runs the simulations, and the results can be picked up by PSCAD on the run.

PSCAD is suitable for the NREL DERTF for several reasons. PSCAD has fully developed models of various devices used in the NREL facility. The library includes models of synchronous and induction machines, transformers, three-phase converters, relays, breakers, cables, wind turbines, and transmission lines. Saturation, magnetizing, and leakage inductances can be disabled or enabled in the rotating machine models. If enabled, up to 10 saturation curve points can be given. PSCAD also offers tools to simulate various faults on the power system. Turbine models - including wind turbines, governor, and other miscellaneous models - are also in the PSCAD library. In addition, PSCAD has models that generate wind speed for the wind turbine.

In PSCAD, systems may consist of electrical and control-type components, which may be interconnected to allow for an all-inclusive simulation study. The control systems modeling function section of the PSCAD library provides a complete set of basic linear and nonlinear control components. These components can be combined into larger, more elaborate systems. Outputs from control components can be used to 
control voltage and current sources, switching signals, and firing pulses for thyristors, gate turn-off thyristors, and insulate gate bipolar transistors. Control components can also be used for signal analysis, and outputs may be directed to online plots or meters. In addition, PSCAD has an inbuilt model for a six-pulse SCR converter. Converter models with other switching devices and firing circuits can be built using the control systems modeling function library. Models of fuel cells or other devices not available in PSCAD can be built using this library and be added to the master library. Users can write subroutines for any unavailable components in FORTRAN or $\mathrm{C}(\mathrm{C}++)$.

As in Simulink, multiple modules can be built inside a single project, and each module can contain other modules. This provides a hierarchical modeling capability. PSCAD has an interface to Simulink, but it is not suitable for continuous and simultaneous simulations. PSCAD calls Simulink, which runs a whole simulation and then returns the result to PSCAD.

Modeling in the PSCAD environment is not as intuitive as it is in circuit simulators such as PSIM. However, once one gets used to wiring and other simulation controls, building models in PSCAD is relatively easy.

PSCAD has complete models of most of the devices used in the NREL facility. Models of other devices [such as fuel cells and pulse-width modulated (PWM) inverters] that are not available in PSCAD can be built by the user. PSCAD has the tools to implement control algorithms such as peak-power tracking for PV cells or wind turbines. Graphing, plotting, and exporting results are easy. Therefore, PSCAD is suitable for this simulation study.

3. DR model development

Under this task, models of DR such as microturbines, PV cells, and diesel generators were developed. Electrical models of inverters were also developed. Each model was developed and tested individually and then connected to a three-phase distribution system.

4. Validation testing of developed models

This step is yet to be implemented. It consists of using the models developed in Step 3 to simulate the electrical configurations of DR at the NREL DERTF. Testing will verify the model transient and steady-state models of electrical power flow.

5. Final report and presentation

This report details the research conducted under this project. It includes information about the availability of models and software to conduct analysis of the electrical impacts of distributed generation on the electrical power system and the selection of a specific modeling program. It also reports on the models that were developed. Validation under actual test conditions is yet to be conducted. 


\section{Model of the Backbone}

Figure 1 shows the microgrid at the NREL DERTF. The main components of the system are a 250-kVA grid simulator; a 120:480-V, 250-kVA transformer; a 480-V bus; a 165-kW-404kVAR variable R-L-C load bank; a $125-\mathrm{kW}$ diesel generator; a $60-\mathrm{kW}$ wind turbine; a $33-\mathrm{kW}$ microturbine; and a few three-phase and single-phase PWM inverters to inject power into the bus from direct current (DC) sources.

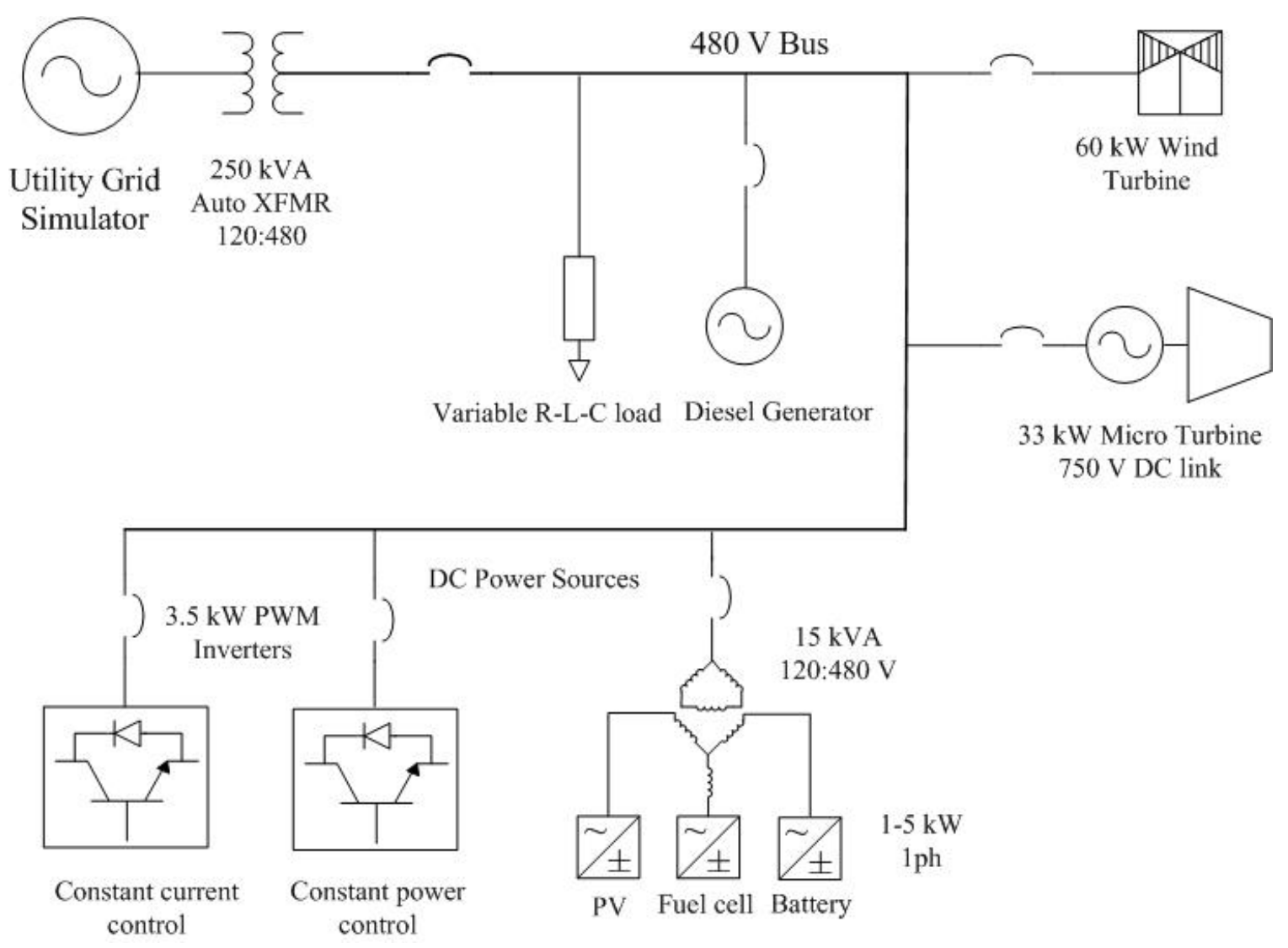

Figure 1. Microgrid backbone

The following sections discuss each DR. 


\section{Diesel Generator}

\subsection{Mathematical Analysis}

The diesel generator used a synchronous machine model available in the PSCAD library.

Equation 1 shows the transformation of the stator windings into equivalent windings, using the dq0 transformation, as follows:

$$
\left[\begin{array}{l}
U_{d} \\
U_{q} \\
U_{0}
\end{array}\right]=\left[\begin{array}{ccc}
\cos (\theta) & \cos \left(\theta-120^{\circ}\right) & \cos \left(\theta-240^{\circ}\right) \\
\sin (\theta) & \sin \left(\theta-120^{\circ}\right) & \sin \left(\theta-240^{\circ}\right) \\
1 / 2 & 1 / 2 & 1 / 2
\end{array}\right] \cdot\left[\begin{array}{c}
V_{a} \\
V_{b} \\
V_{c}
\end{array}\right]
$$

The three-phase rotor winding may be transformed into a two-phase equivalent winding, with additional windings added to each axis, as shown in Figure 2.

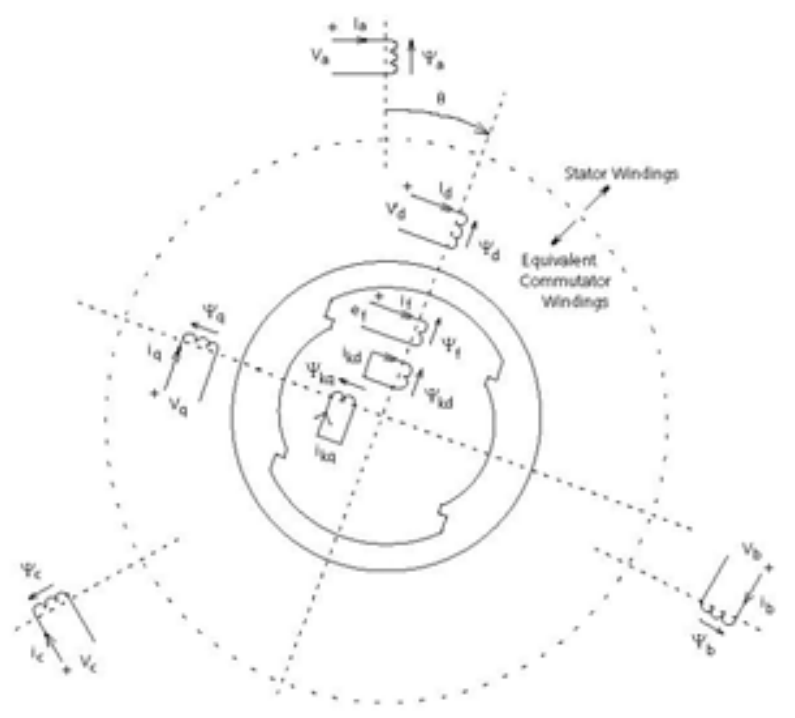

Figure 2. Diagram of the three-phase and d-q windings [3]

The d-axis equivalent circuit for the generalized machine is shown in Figure 3.

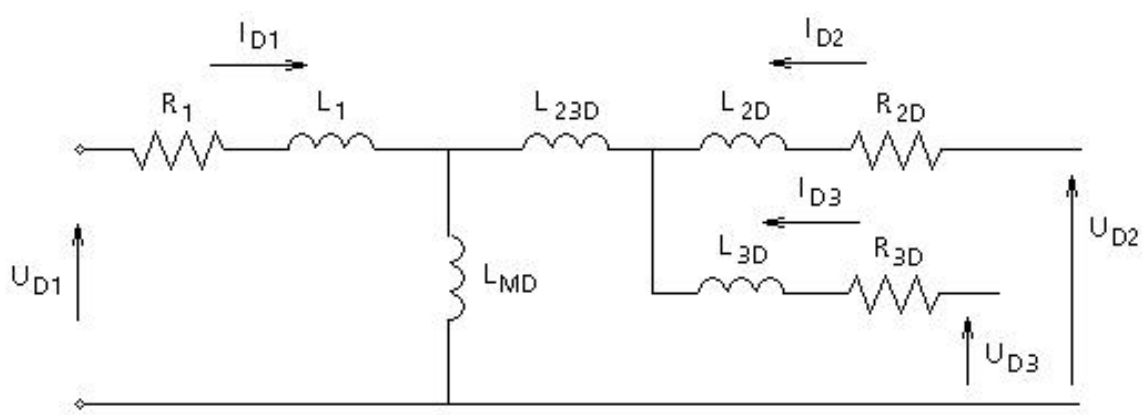

Figure 3. D-axis equivalent circuit [3] 
The mechanical torque is calculated by Equation $2[3,11]$.

$$
\begin{aligned}
& \mathbf{T}=\Psi_{\mathbf{q}} \mathbf{I}_{\mathbf{D} 1}-\Psi_{\mathbf{d}} \mathbf{I}_{\mathbf{Q} 1} \\
& \Psi_{\mathrm{q}}=\mathbf{L}_{1} \mathbf{I}_{\mathbf{Q} 1}+\mathbf{L}_{\mathbf{M Q}}\left(\mathbf{I}_{\mathbf{Q} 1}+\mathbf{I}_{\mathbf{Q} 2}+\mathbf{I}_{\mathbf{Q} 3}\right) \\
& \Psi_{\mathbf{d}}=\mathbf{L}_{1} \mathbf{I}_{\mathbf{D} 1}+\mathbf{L}_{\mathbf{M D}}\left(\mathbf{I}_{\mathbf{D} 1}+\mathbf{I}_{\mathbf{D} 2}+\mathbf{I}_{\mathbf{D} 3}\right)
\end{aligned}
$$

\subsection{Simulation Results}

Figure 4 is the $125-\mathrm{kW}$ synchronous generator driven by a diesel engine. Included in this schematic is the synchronous generator with exciter and timers with an AC source on the right side representing an infinite bus to maintain voltage and a $50-\mu \mathrm{F}$ capacitor for power correction. L2N and S2M send a signal to the generator at 10 and $9.5 \mathrm{~s}$, respectively, to allow it to operate as a machine with mechanical dynamics rather than as a simple AC source. This model is a better representation of a real-time system. The signal BRK is used to close the breaker at $0.5 \mathrm{~s}$ to allow power flow through the system.

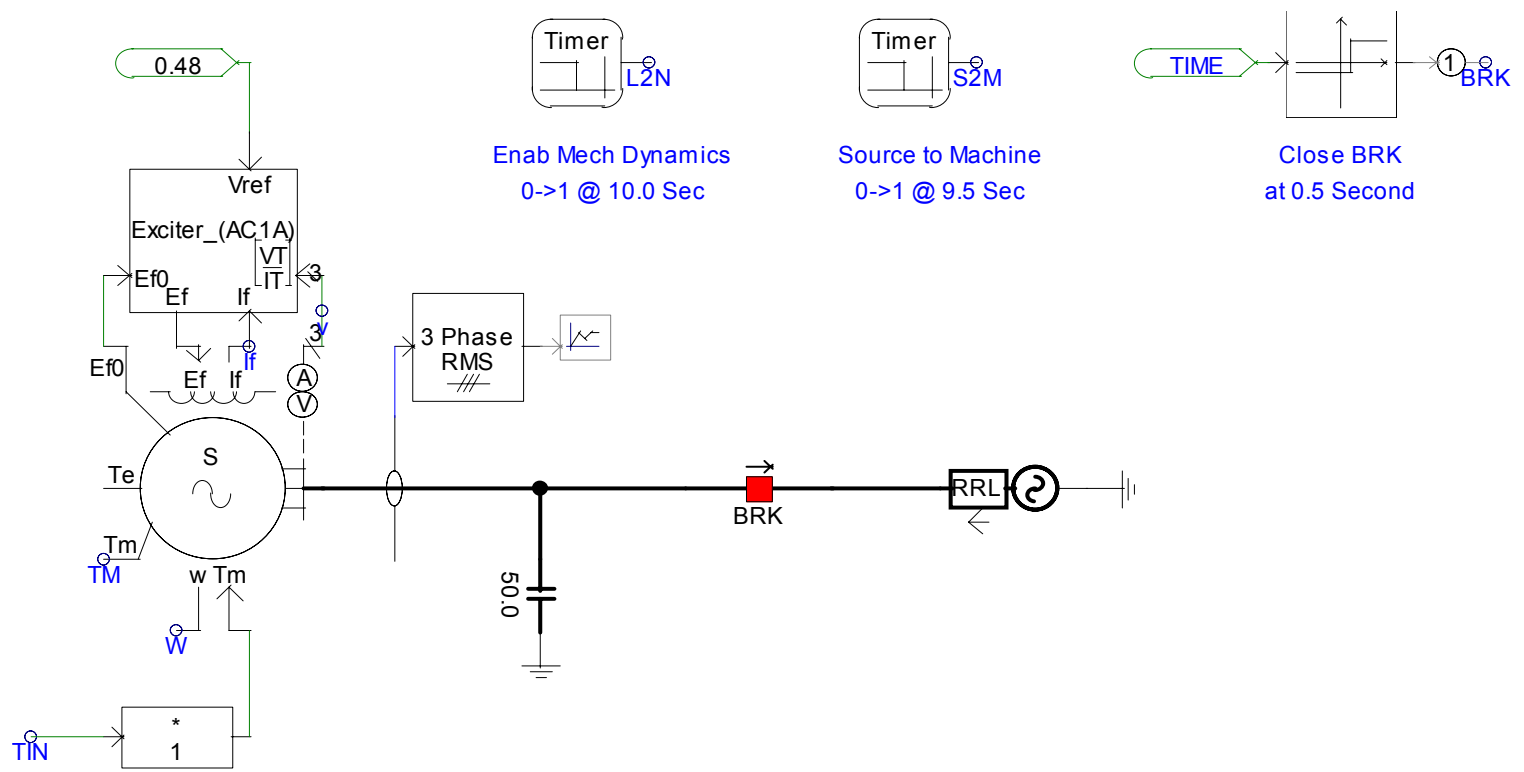

Figure 4. 125-kW diesel generator

Below is the control system, also known as the Woodward governor, for the diesel engine. It consists of a set of controls - whose input is the offset of the actual speed and the reference speed - that control the actual diesel engine (labeled IC engine) and result in a controlled output torque that is sent to the input torque of the synchronous generator.

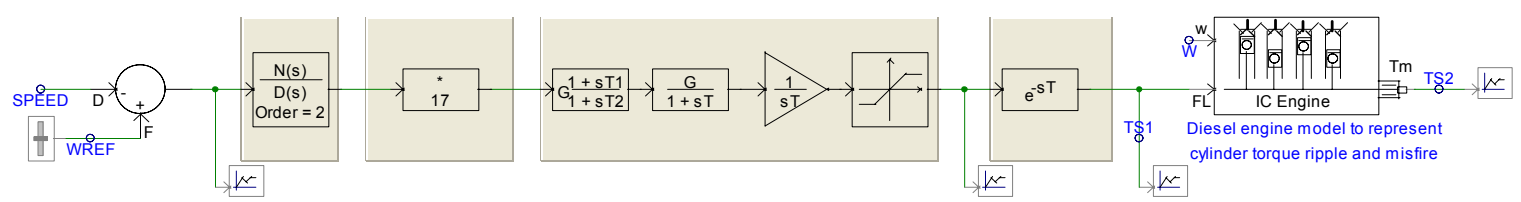

Figure 5. Woodward governor 
Output real power, reactive power, and terminal voltage are measured at the generator's output. Below are output graphs of the synchronous machine running solely as a source without transitioning to machine with the rotor unlocked and the mechanical dynamics enabled. Figure 6 provides the output graphs of the generator. The desired output of $125 \mathrm{~kW}$ is achieved as is the desired terminal voltage, which at $1 \mathrm{p}$.u. is equal to $480 \mathrm{~V}$. The blue output represents the diesel generator; the green line represents the AC source. The negative power output of the AC source represents power supplied to the source from the diesel generator.

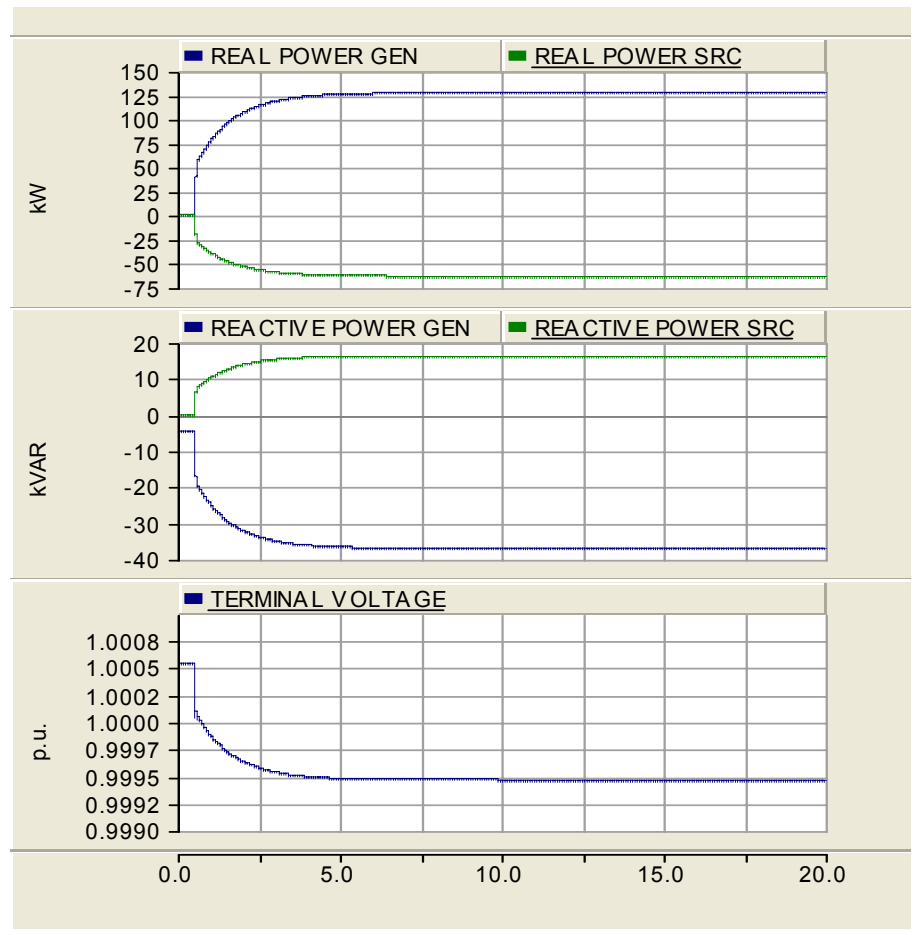

Figure 6. Output of diesel generator without mechanical dynamics

Figure 7 displays the output when the machine transitions from a source to a machine at $\mathrm{t}=$ $9.5 \mathrm{~s}$ and the rotor is unlocked at $\mathrm{t}=10 \mathrm{~s}$, enabling machine dynamics. In the following graphs, it is clear the machine is experiencing transient problems in the large power output sine wave. 


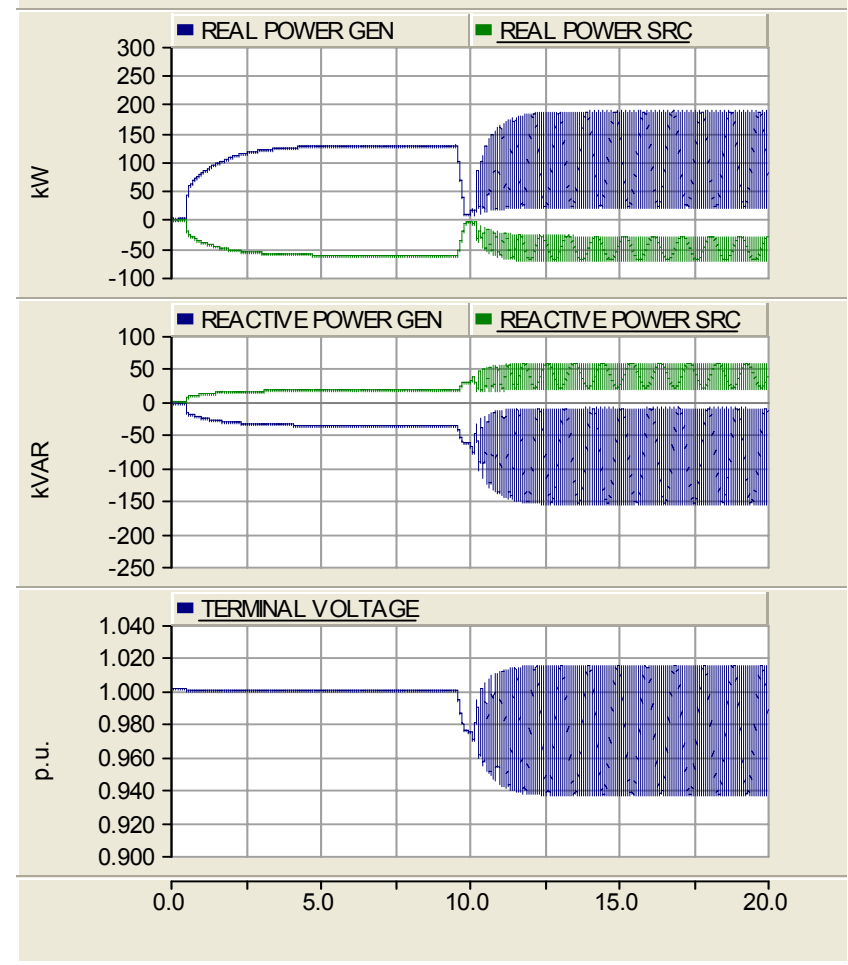

Figure 7. Output of diesel generator with mechanical dynamics 


\section{$5 \quad$ Wind Turbine}

\subsection{Mathematical Analysis}

The wind turbine also used a model in the PSCAD library. One way to control the active power of a wind turbine is to regulate the power coefficient, $C_{p}$, of the rotor turbine. $C_{p}$ can be calculated by [4]:

$$
\begin{aligned}
& C_{p}(\beta, \lambda)=0.22\left(\frac{116}{\lambda_{i}}-0.4 \beta-5\right) \cdot e^{\frac{-12.5}{\lambda_{i}}} \\
& \frac{1}{\lambda_{i}}=\frac{1}{\lambda+0.08 \beta}-\frac{0.035}{\beta^{3}+1}
\end{aligned}
$$

Where:

$\lambda=$ tip speed ratio

$\beta=$ pitch angle.

The maximum power coefficient can be determined graphically. An example is given in Figure 8. With the maximum $\mathrm{C}_{\mathrm{p}}$ value, it is possible to determine the optimum tip speed, where there is maximum power capture. With this, the optimum turbine speed curve is obtained and used as a reference in active power control.

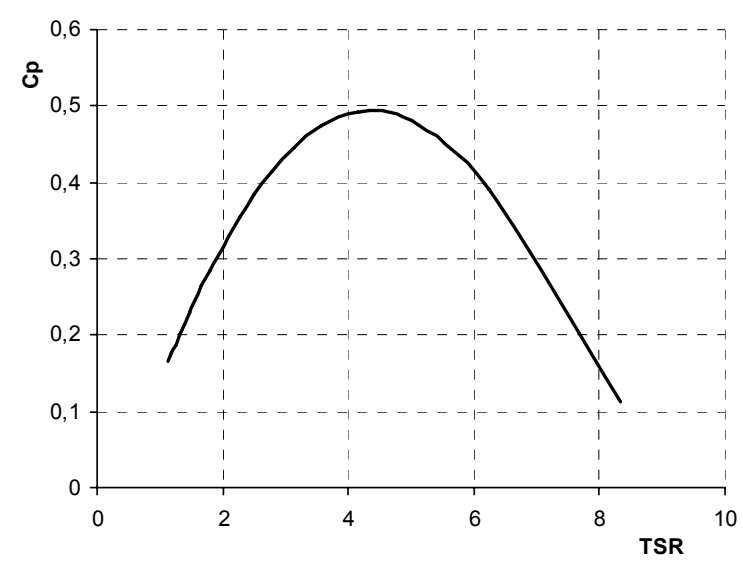

Figure 8. Maximum value of $C_{p}$ [1]

\subsection{Simulation Results}

The 65-kW Northern Power wind turbine also used a model available in PSCAD. Figure 9 is the synchronous generator that closely resembles the actual wind turbine generator. Included in the schematic is the exciter, the generator, an infinite bus with an $\mathrm{AC}$ source, and a $50-\mu \mathrm{F}$ capacitor for power factor correction. The input, $\mathrm{T}_{\mathrm{m}}$, is at the bottom of the synchronous machine. The input torque - which usually is driven by a turbine, engine, or in this case, a windmill—enters here. 


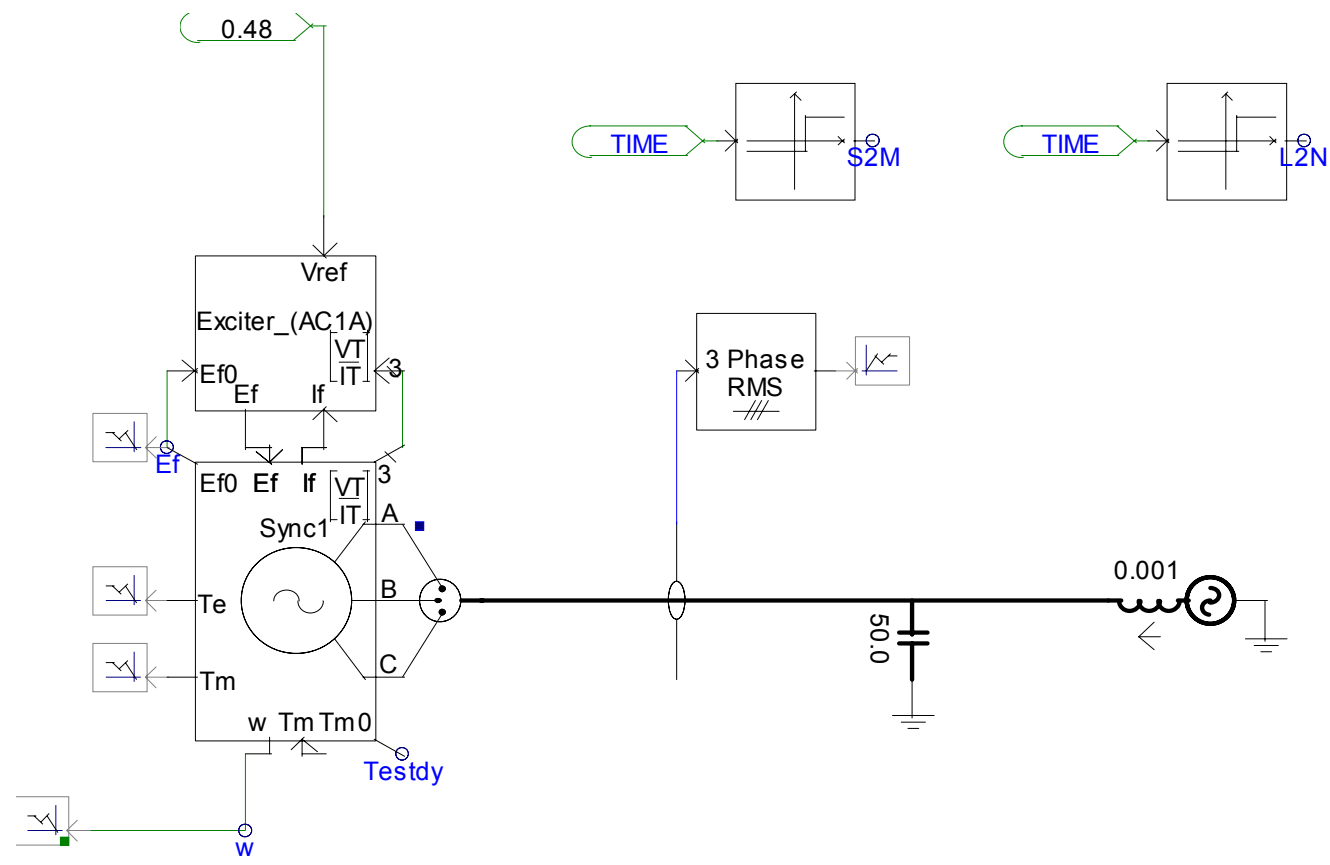

Figure 9. Wind turbine generator

Figure 10 is a schematic of the wind turbine and its components, including an input wind speed that may be adjusted to ramp, gust, or create wind noise and a blade angle pitch dynamics control.

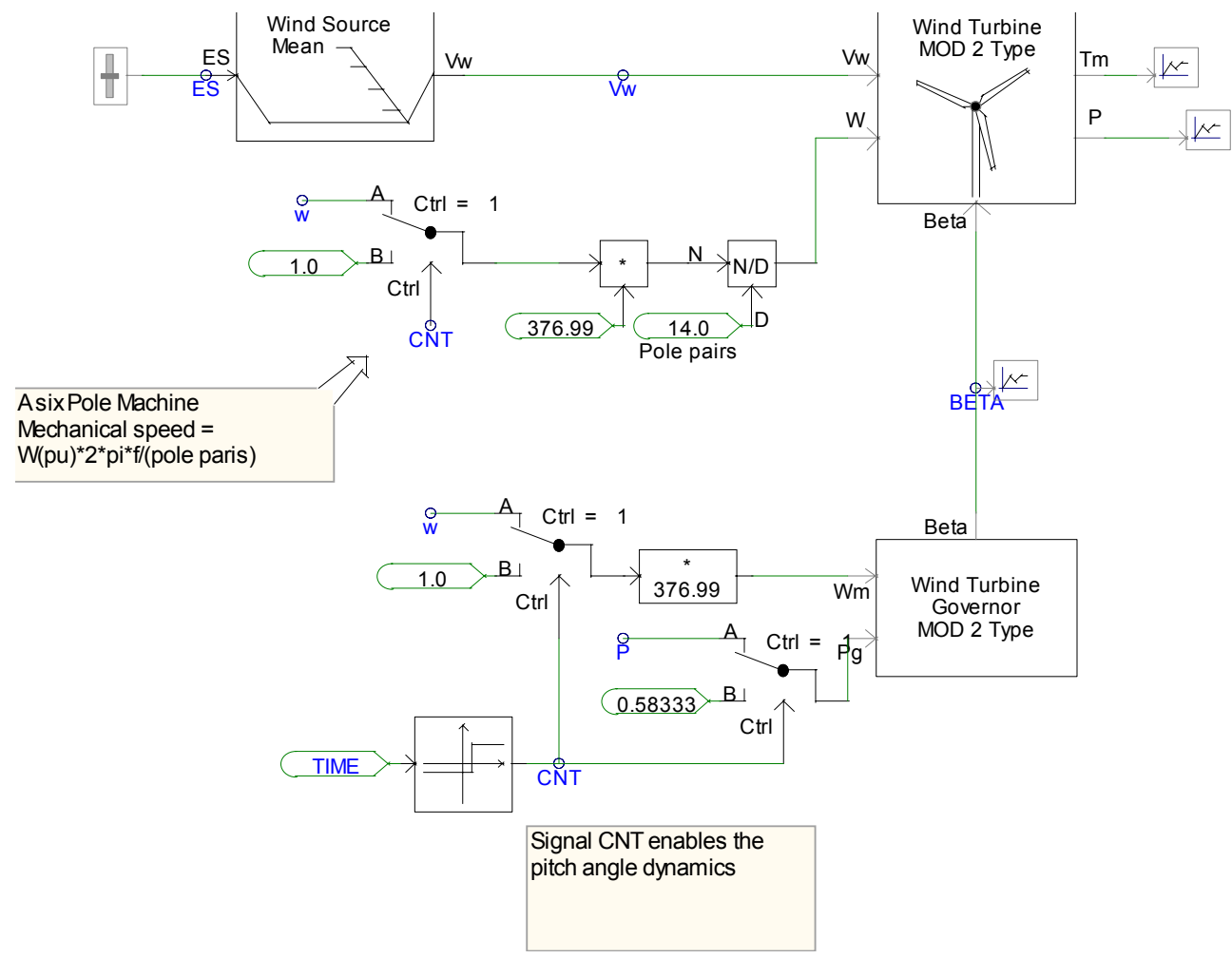

Figure 10. Wind turbine and components 
To make the simulation as close as possible to the real turbine, actual values were taken from the Northern Power wind turbine Operation and Maintenance Manual. The extracted values are provided in tables 1 and 2 .

Table 1. Performance Parameters

\begin{tabular}{ll}
\hline Performance Parameters & \\
\cline { 2 - 2 } Nominal power rating & $100 \mathrm{~kW}$ \\
Rated wind speed & $14 \mathrm{~m} / \mathrm{s}$ \\
Cut-in wind speed & $4 \mathrm{~m} / \mathrm{s}$ \\
Cut-out wind speed & $25 \mathrm{~m} / \mathrm{s}$ \\
Survival wind speed & $70 \mathrm{~m} / \mathrm{s}$
\end{tabular}

Table 2. Rotor Parameters

Rotor

Rotor diameter $19.1 \mathrm{~m}$

Swept area $\quad 287 \mathrm{~m}^{2}$

Rotational speed $63.5 \mathrm{rpm}$

Figure 11 depicts the output of the Northern Power wind turbine. For simple analysis, the wind speed was set at a constant $14 \mathrm{~m} / \mathrm{s}$, and pitch angle dynamics were disabled to allow study of the effects of a constant wind speed without change in wind direction. The fluctuation of real power and machine speed $(\omega)$ is due to the synchronous machine enabling mechanical dynamics and unlocking the rotor, which results in a large out flux of output power. After about $10 \mathrm{~s}$, the machine settles to a constant speed of $377 \mathrm{rad} / \mathrm{s}(60 \mathrm{~Hz})$. 


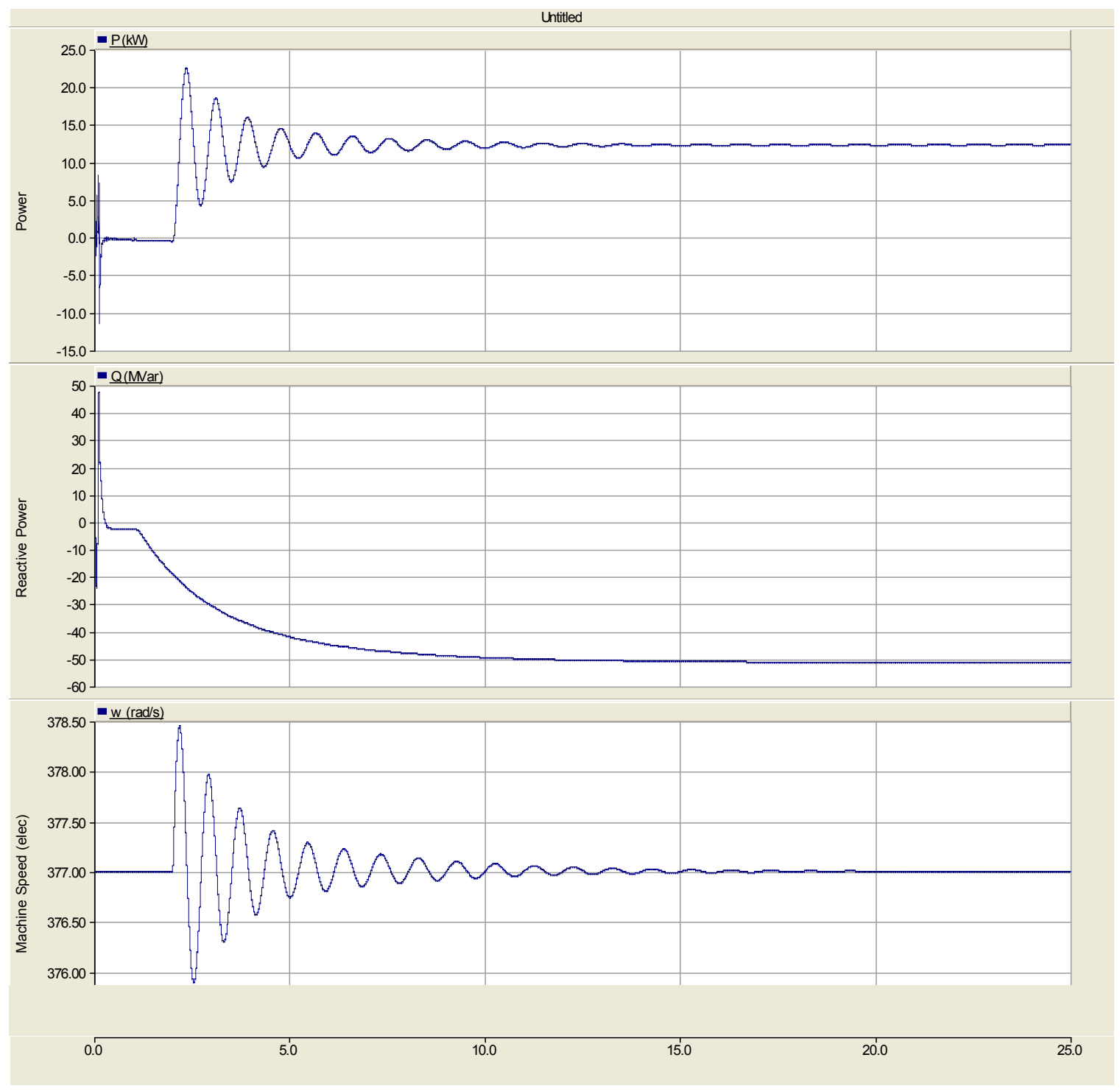

Figure 11. Wind turbine output 


\section{Inverter}

\subsection{Mathematical Analysis}

Figure 12 shows the main schematic of the inverter model. The main components of the system are a 480-V AC feed, a 489:575 star-delta transformer, a three-phase diode bridge rectifier, a three-phase PWM inverter modeled using controlled current sources, a three-phase balanced R-L-C load, and breakers for connecting the system to load and utility. The modeling of each of these components in PSCAD is explained in later sections.

A d-q axis reference frame is used to control the inverter voltage and frequency by controlling the d-axis and q-axis currents, respectively. Initial results from the original simulation model are shown in the results section. Later in the results section, power measurements taken at various points in the schematic are presented. The p.u. system of units was used to display some of the results. Base value for voltage is $0.2771 \mathrm{kV}$ (phase), and base current is 0.1208 $\mathrm{kA}$ (phase).

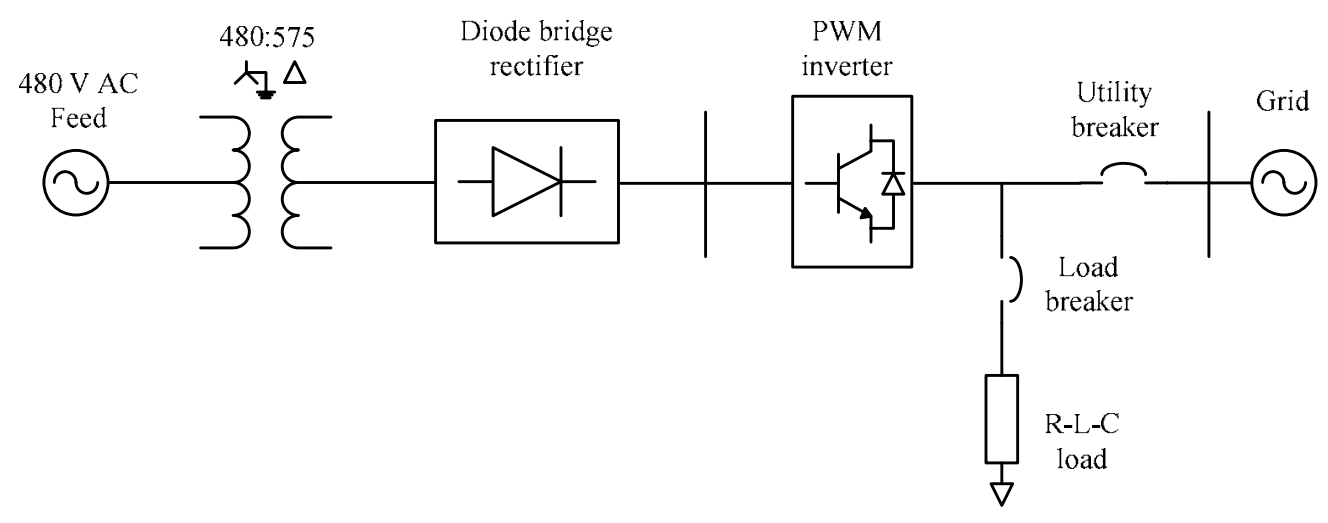

Figure 12. Schematic of the GE inverter system

\subsection{1 d-q Axis Theory}

Figure 13 shows a physical distribution of the three stationary axes $a^{s}, b^{s}$, and $c^{s}$, which are $120^{\circ}$ apart from one another, and of the Cartesian axes, where $q^{s}$ is a horizontal axis aligned with phase $a^{s}$ and a vertical axis rotated by $-90^{\circ}$ is indicated by $d^{s}$. Three-phase voltages varying in time along the axes $a^{s}, b^{s}$, and $c^{s}$ can be algebraically transformed onto two-phase voltages varying in time along the axes $d^{s}$ and $q^{s}[10]$. 


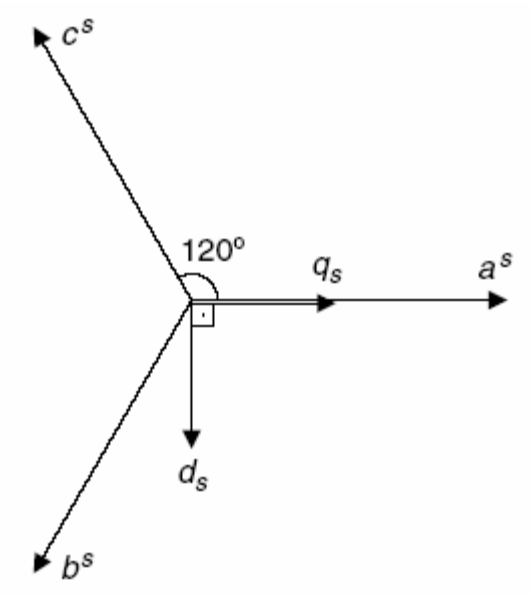

Figure 13. Physical distribution of three stationary axes and a quadrature stationary axis

The transformations are shown in Equation 4.

$$
\begin{aligned}
& {\left[\begin{array}{c}
\mathbf{V}_{\text {as }} \\
\mathbf{V}_{\mathrm{bs}} \\
\mathbf{V}_{\mathrm{cs}}
\end{array}\right]=\left[\begin{array}{ccc}
1 & 0 & 1 \\
-\frac{1}{2} & -\frac{\sqrt{3}}{2} & 1 \\
-\frac{1}{2} & \frac{\sqrt{3}}{2} & 1
\end{array}\right] \cdot\left[\begin{array}{c}
\mathbf{V}_{\mathrm{qs}}^{\mathrm{s}} \\
\mathbf{V}_{\mathrm{ds}}^{\mathrm{s}} \\
\mathbf{V}_{0 \mathrm{~s}}^{\mathrm{s}}
\end{array}\right]} \\
& {\left[\begin{array}{c}
\mathbf{V}_{\mathrm{qs}}^{\mathrm{s}} \\
\mathbf{V}_{\mathrm{ds}}^{\mathrm{s}} \\
\mathbf{V}_{0 \mathrm{ss}}^{\mathrm{s}}
\end{array}\right]=\left[\begin{array}{ccc}
1 & 0 & 0 \\
0 & -\frac{\sqrt{3}}{3} & \frac{\sqrt{3}}{3} \\
\frac{1}{2} & \frac{1}{2} & \frac{1}{2}
\end{array}\right] \cdot\left[\begin{array}{c}
\mathbf{V}_{\mathrm{as}} \\
\mathbf{V}_{\mathrm{bs}} \\
\mathbf{V}_{\mathrm{cs}}
\end{array}\right]}
\end{aligned}
$$

Three methods commonly used to control a grid-connected inverter feeding power from a DG source are [12]:

- Constant current control

- Constant power control

- Constant DC bus voltage control.

This report presents the first two inverter control methods with anti-islanding schemes. The control block diagrams presented used the average model of the PWM inverter. The average model is usually preferred over the switching model for simulation purposes because the average model needs less computation time. In addition, small signal analysis can be performed on the average model. The average model of the inverter with controlled voltage and current sources is shown in Figure 14. 


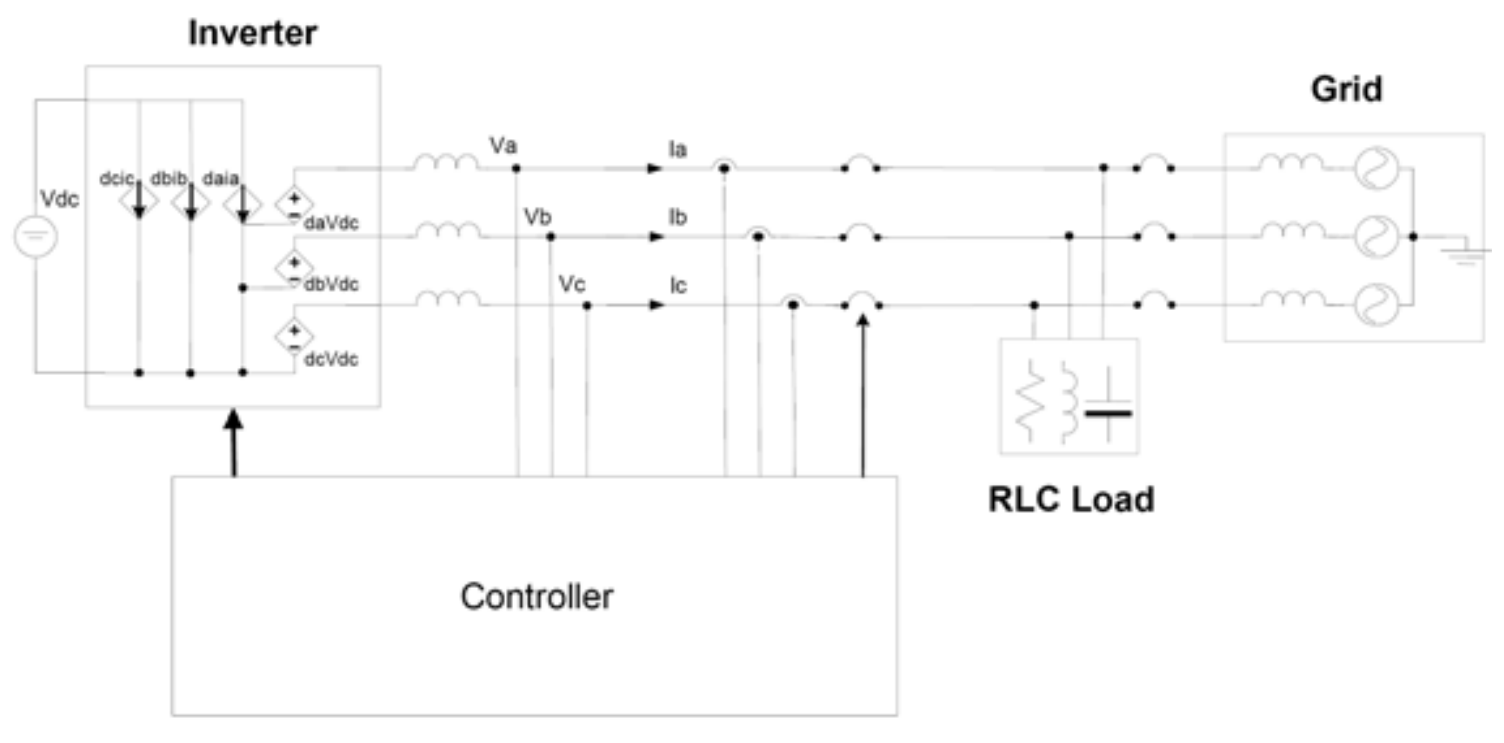

Figure 14. Average model of the inverter

\subsubsection{Anti-Islanding Schemes}

Various methods to detect islanding of a DG inverter connected to a grid are discussed in [5]. However, the most commonly used methods are passive inverter-resident methods, active inverter-resident methods, active methods not resident in the inverter, and the use of communications between the utility and the inverter.

A report published by GE [6] showed that active inverter-resident methods have advantages over other methods. Active inverter-resident methods use a variety of schemes to cause an abnormal condition in the inverter voltage and/or frequency that can be detected to prevent islanding. The anti-islanding scheme proposed by [6] is based on d-q implementation of the positive feedback concept. The following equations explain the basics of the positive feedback concept with d-q axis modeling.

Considering an R-L-C load, active and reactive power can be defined as:

$$
P=\frac{V^{2}}{R} \quad \text { and } \quad Q=V^{2}\left(\omega C-\frac{1}{\omega L}\right)
$$

The proposed islanding scheme creates abnormal voltage and frequency conditions (force voltage and frequency of the nominal ranges) to detect islanding. In the voltage feedback method, when the controller detects a change in the d-axis output voltage, it commands an increase in active power, which results in a further increase in d-axis voltage and eventually forces the voltage out of the nominal range. Thus, islanding can be detected. 


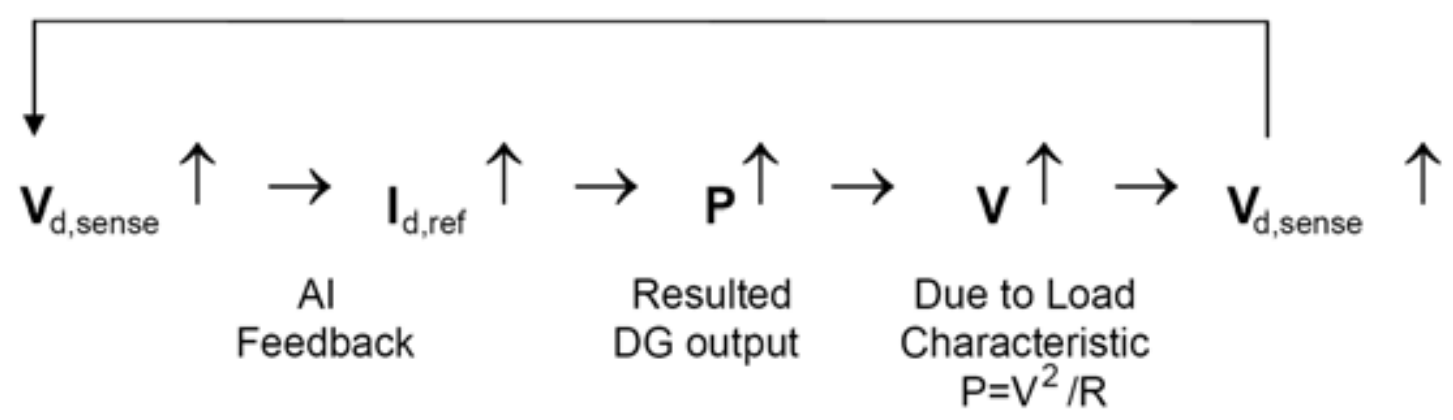

The same analysis can be applied to frequency feedback methods. When the controller detects a change in frequency, it forces the reactive power and results in a further increase or decrease of inverter frequency in the same direction. These two islanding detection schemes can be implemented in the two control methods, as described in the next section.

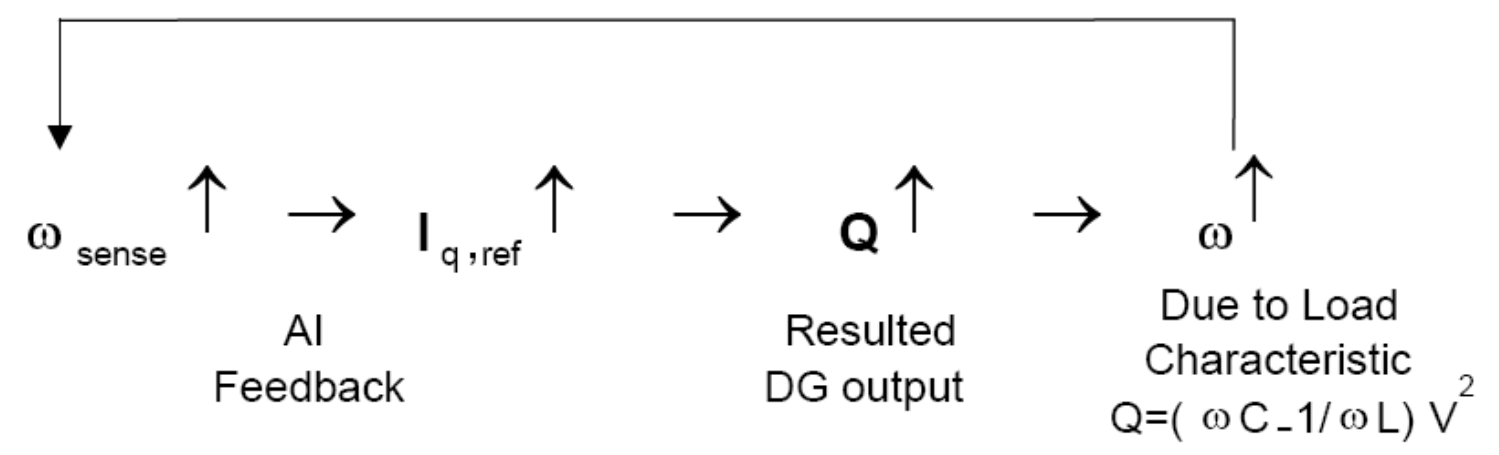

\subsubsection{Constant Current Control}

In this method, the inverter output currents are controlled to the given reference currents. The error between the measured and reference currents is processed by PI controllers to generate commands for the PWM converter.

Block diagrams of the control method are shown in figures 15 and 16. In the first figure, the voltage feedback loop is implemented. In Figure 16, the frequency feedback loop is implemented. These are added as feed-forward terms to the d-axis and q-axis reference currents, respectively. The measured voltage and frequency are passed through a band pass filter operating at a very narrow frequency band, a gain, and a limiter to become a current variation, $\Delta \mathrm{i}$, that is added to Idref or Iqref. 


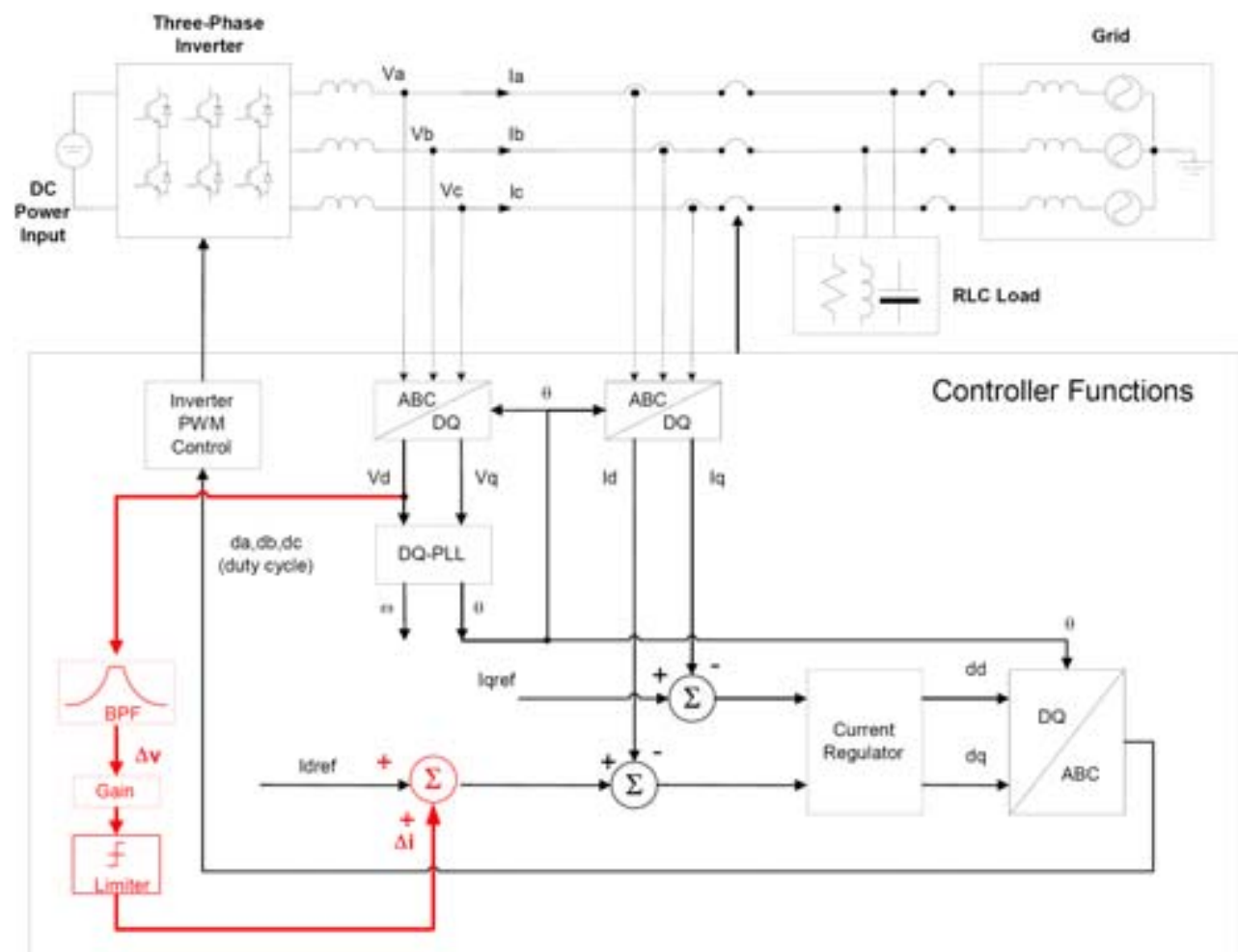

Figure 15. Constant current control with voltage feedback

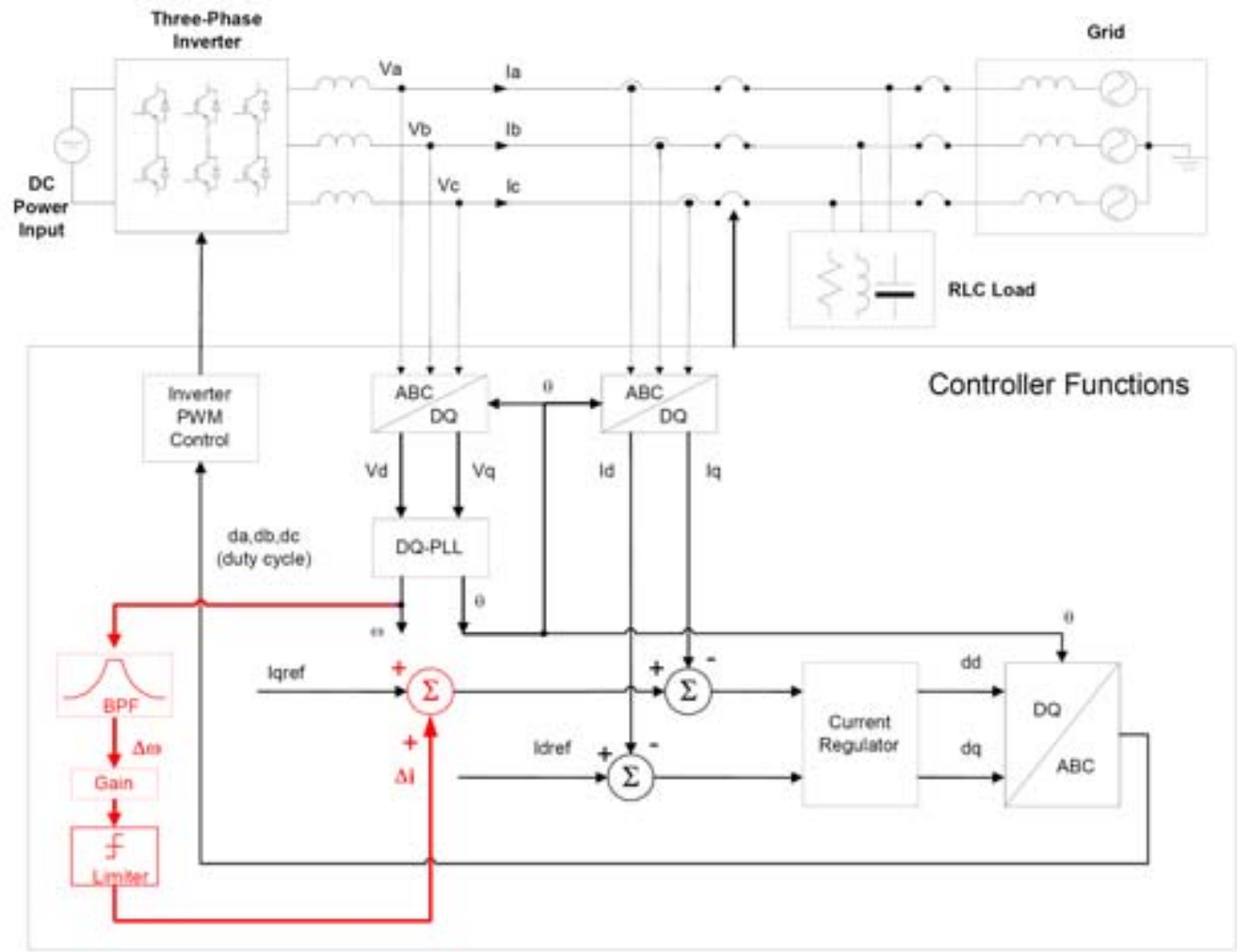

Figure 16. Constant current control with frequency feedback 


\subsubsection{Constant Power Control}

In this method, the active and reactive powers supplied by the inverter are controlled to the given reference values. The error between the measured and reference powers are processed to generate reference current commands. Feed-forward terms for islanding detection similarly can be added to the control scheme.

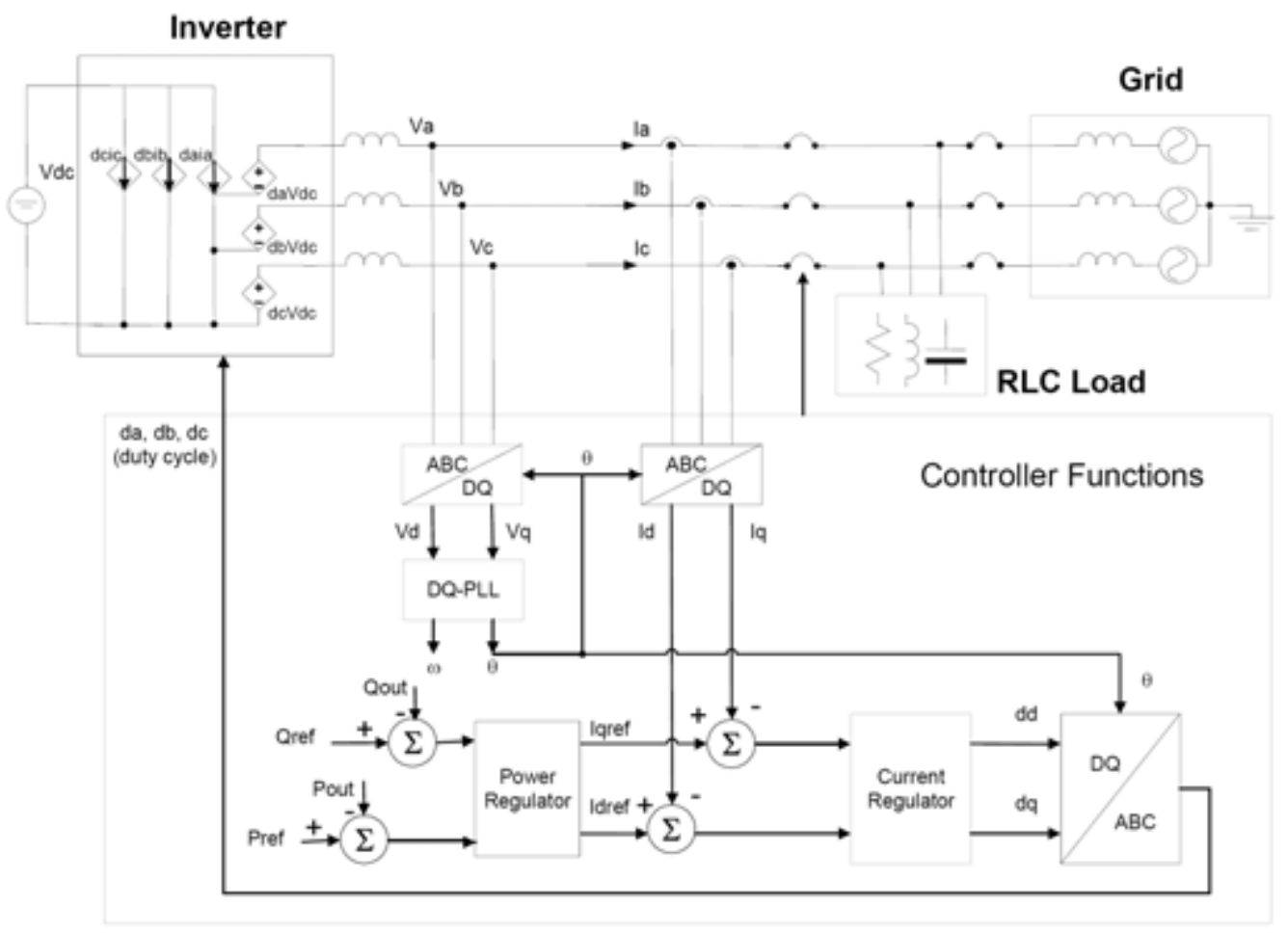

Figure 17. Constant power control method

\subsection{Simulation Results}

The "abc to dqo" component in the PSCAD library performs the transformation of threephase stationary frame components to synchronously rotating two-phase reference frame components. The $\mathrm{d}-\mathrm{q}$ transformation in PSCAD is modified so that $\mathrm{q}$ axis leads $\mathrm{d}$ axis by $90^{\circ}$, as shown in Figure 18. A vector control scheme with the d-axis reference frame oriented along the "Phase a" voltage vector is used. Direct axis current is used to control the magnitude of the inverter voltage, and quadrature axis current is used to control the frequency. Voltage angle is derived from the "PLL" block in the PSCAD library. This angle is modified so the waveform described by the cosine (angle) is in phase with "Phase a" voltage. Figure 19 shows the complete PSCAD model.

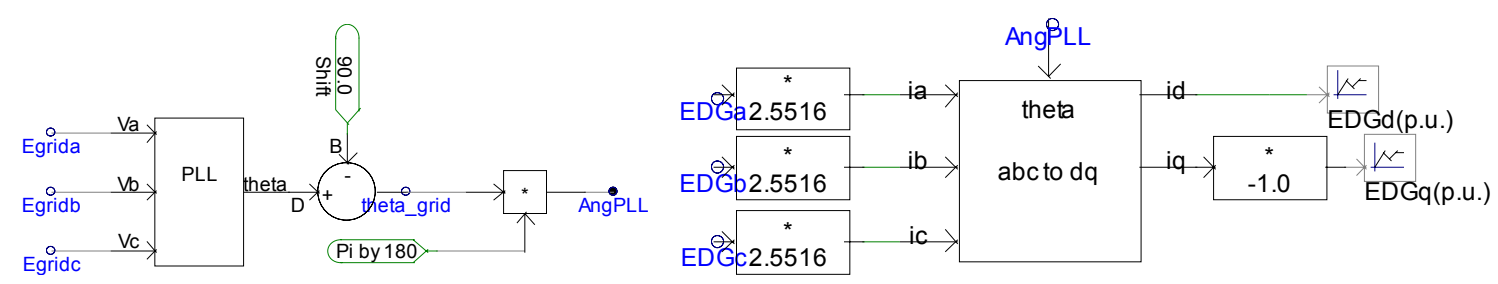

Figure 18. PLL and d-q axis transformation 


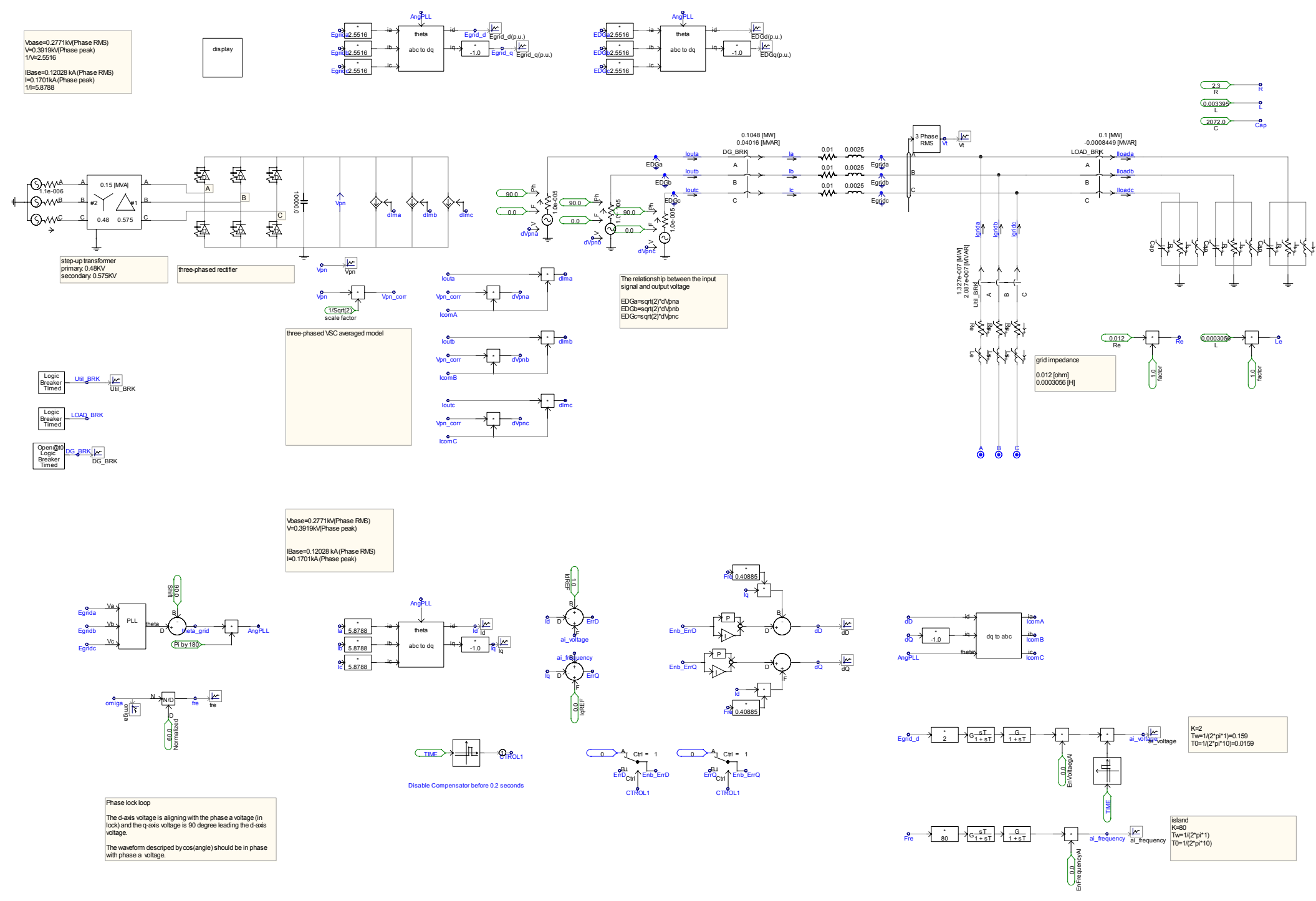

Figure 19. PSCAD model of the GE inverter 
Inverter modeling included:

- 480-V feed, transformer, and diode bridge rectifier

Figure 20 shows the PSCAD model of a 480-V AC source with a transformer feeding the diode bridge rectifier. The transformer is a grounded star-delta rated at $150 \mathrm{kVA}$ with a turn ratio of 480:575. Diode models in PSCAD are arranged to form a threephase diode bridge rectifier. A large $(1 \mathrm{mF})$ capacitor is connected across the DC side of the rectifier.

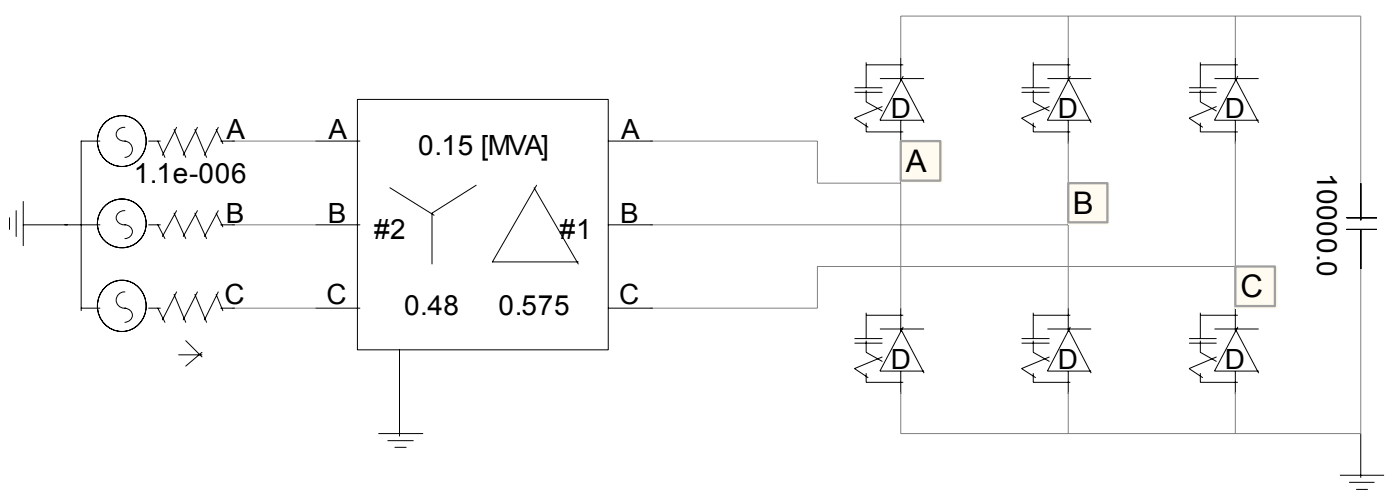

Figure 20. PSCAD model of AC feed and diode bridge rectifier

- Inverter model

A three-phase voltage source converter (VSC) averaged model was used to model a PWM converter, as shown in Figure 21. The commands for the PWM converter are generated by two PI control loops that control the voltage magnitude and frequency at the converter output. Ia, Ib, and Ic and Egrida, Egridb, and Egridc are transformed to $\mathrm{d}-\mathrm{q}$ quantities for the PI control loops, as shown in Figure 22. IdREF is the reference value for the d-axis inverter current, and IqREF is the reference value for the q-axis inverter current. These are compared with the actual currents, and the error signals are passed into two PI controllers. Figure 18 shows that a feed-forward term is being added to the error signals. The two feed-forward terms, ai_voltage and ai_frequency, are generated from the actual inverter voltage and frequency. However, these signals are currently disabled in the model, and the simulation would not run if these signals were enabled. Compensation terms are added to the PI controller outputs for crosscoupling effect. The controllers are disabled for the first $0.2 \mathrm{~s}$. 

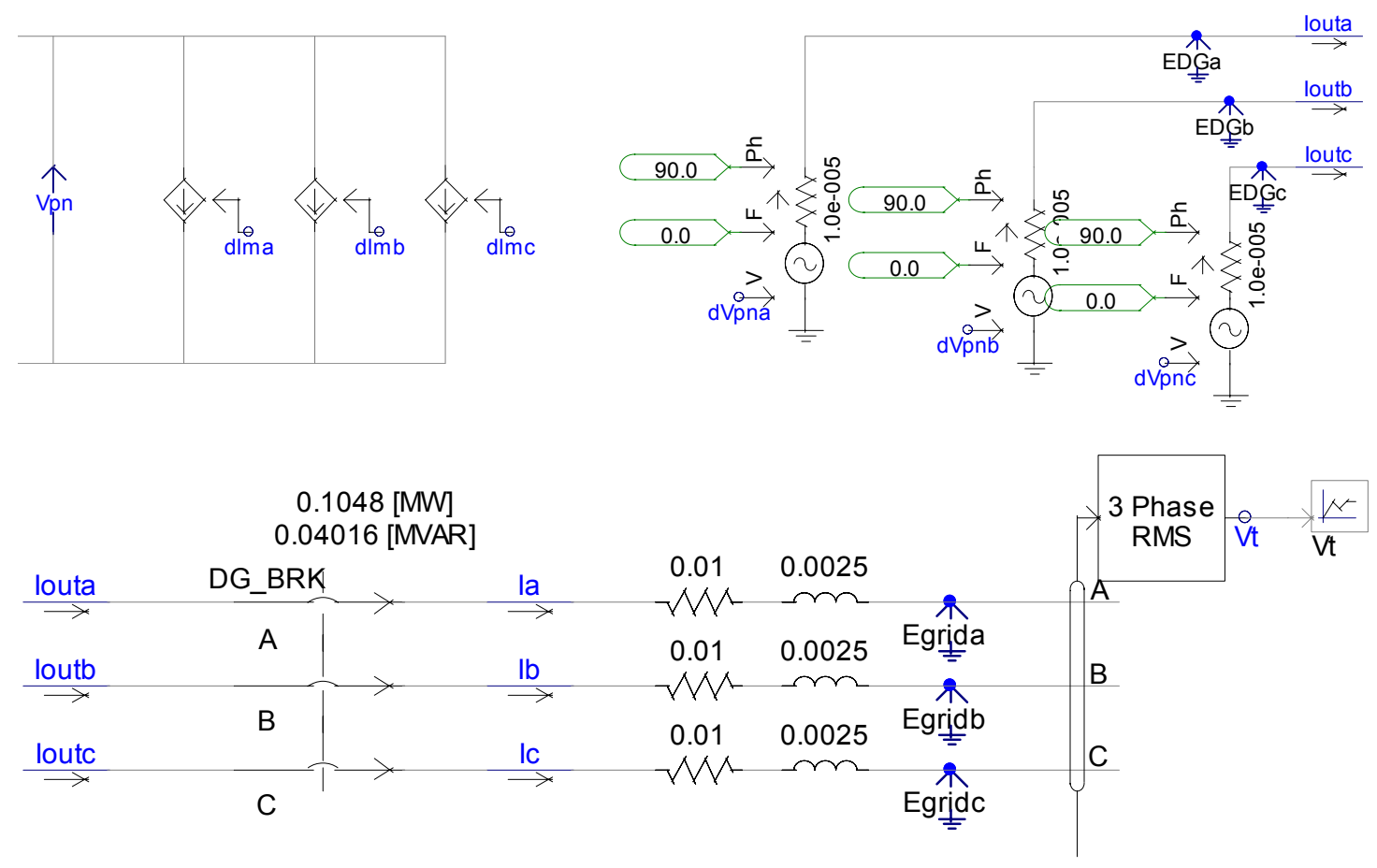

Figure 21. VSC averaged model

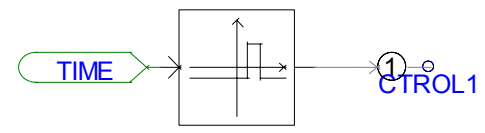

Disable Compensator before 0.2 seconds

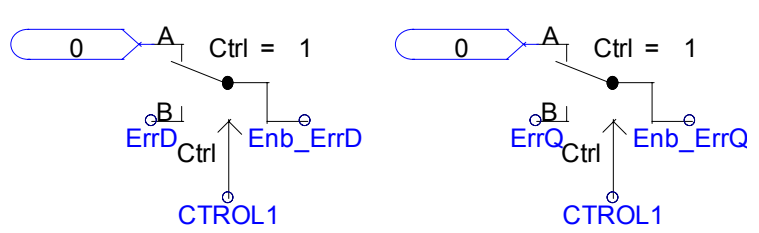

CTROL1
CTROL1
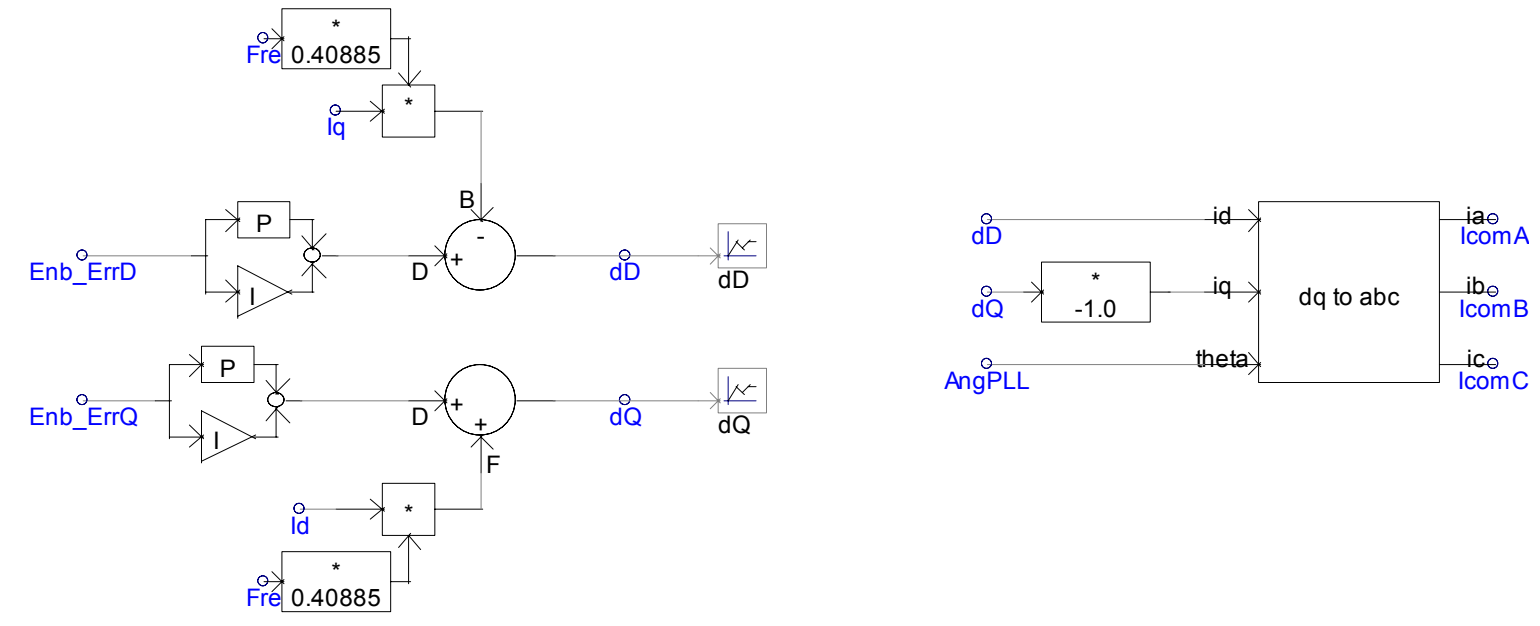

Figure 22. PI controllers 
Figure 23 shows how the compensation terms ai_voltage and ai_frequency are generated. The terms are supposedly being used to provide better tracking of inverter voltage magnitude and frequency. However, as these signals are multiplied by zero, the voltage and frequency are not tracked directly. The results section shows that the PI controller does not keep the inverter voltage and frequency constant when the grid or load is disconnected from the inverter system.

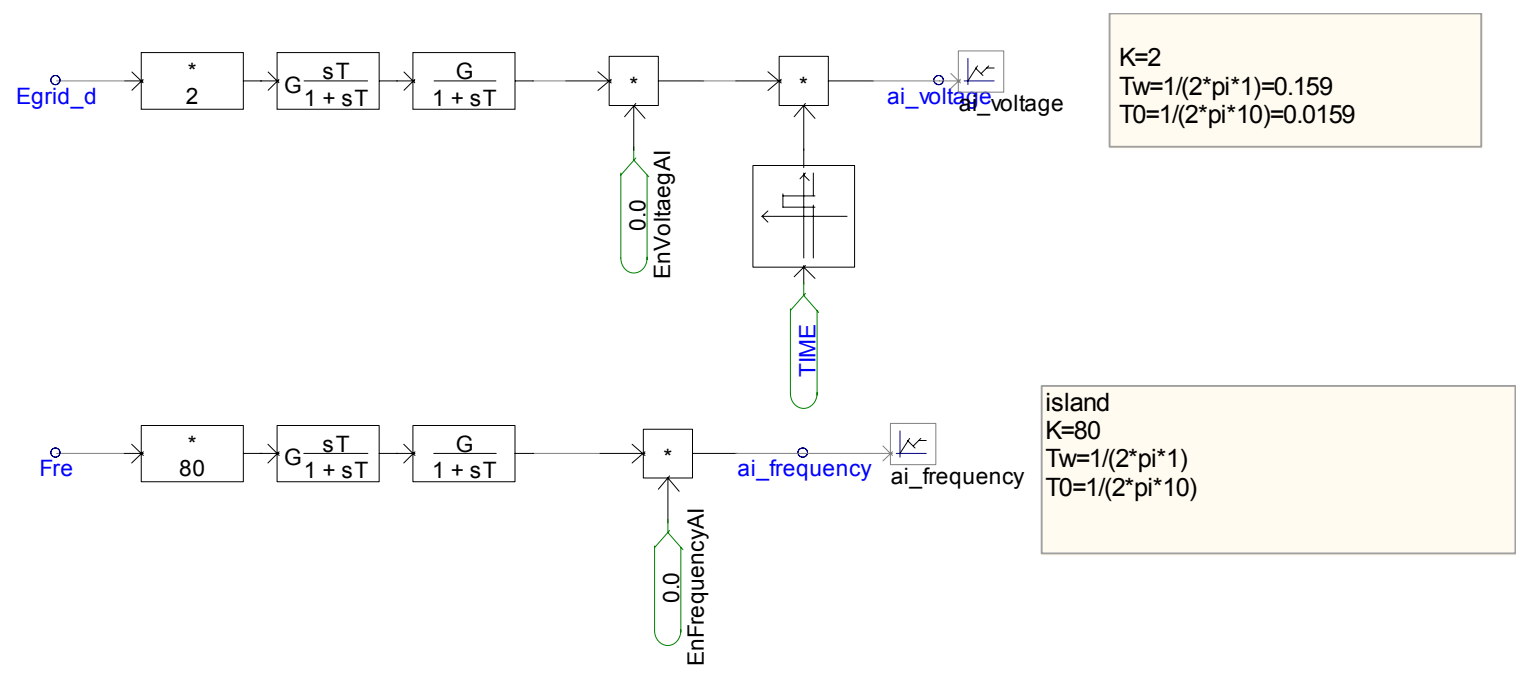

Figure 23. Compensation term for inverter voltage and frequency control

The d-q outputs from the PI controllers are transformer back to a-b-c to generate the commands for the PWM converter. The inverter commands dlma, dlmb, and dlmc and dVpna, dVpnb, and dVpnc shown in Figure 24 are obtained as follows.
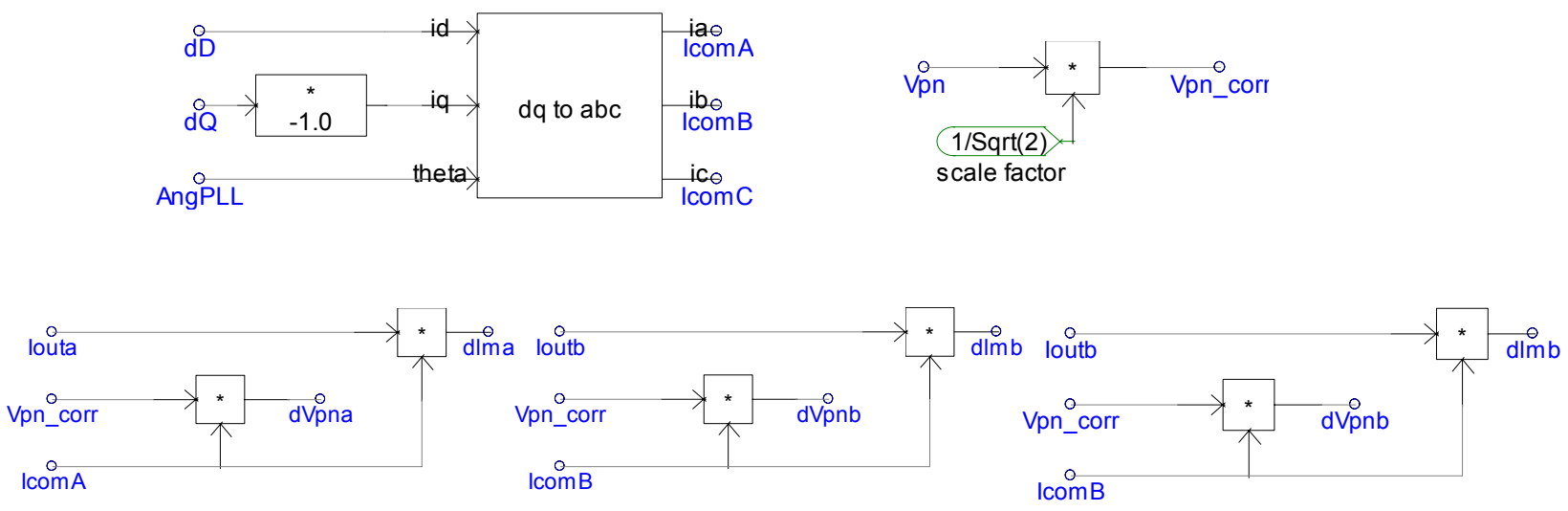

Figure 24. Commands for the VSC averaged inverter 
- Grid and load connections

The three-phase inverter outputs are connected to the grid and a variable R-L-C load through two breakers, as shown in Figure 25. These breakers are operated using the "timed breaker logic" block in PSCAD. The behavior of the inverter simulation model when these breakers are described is shown in the results section.

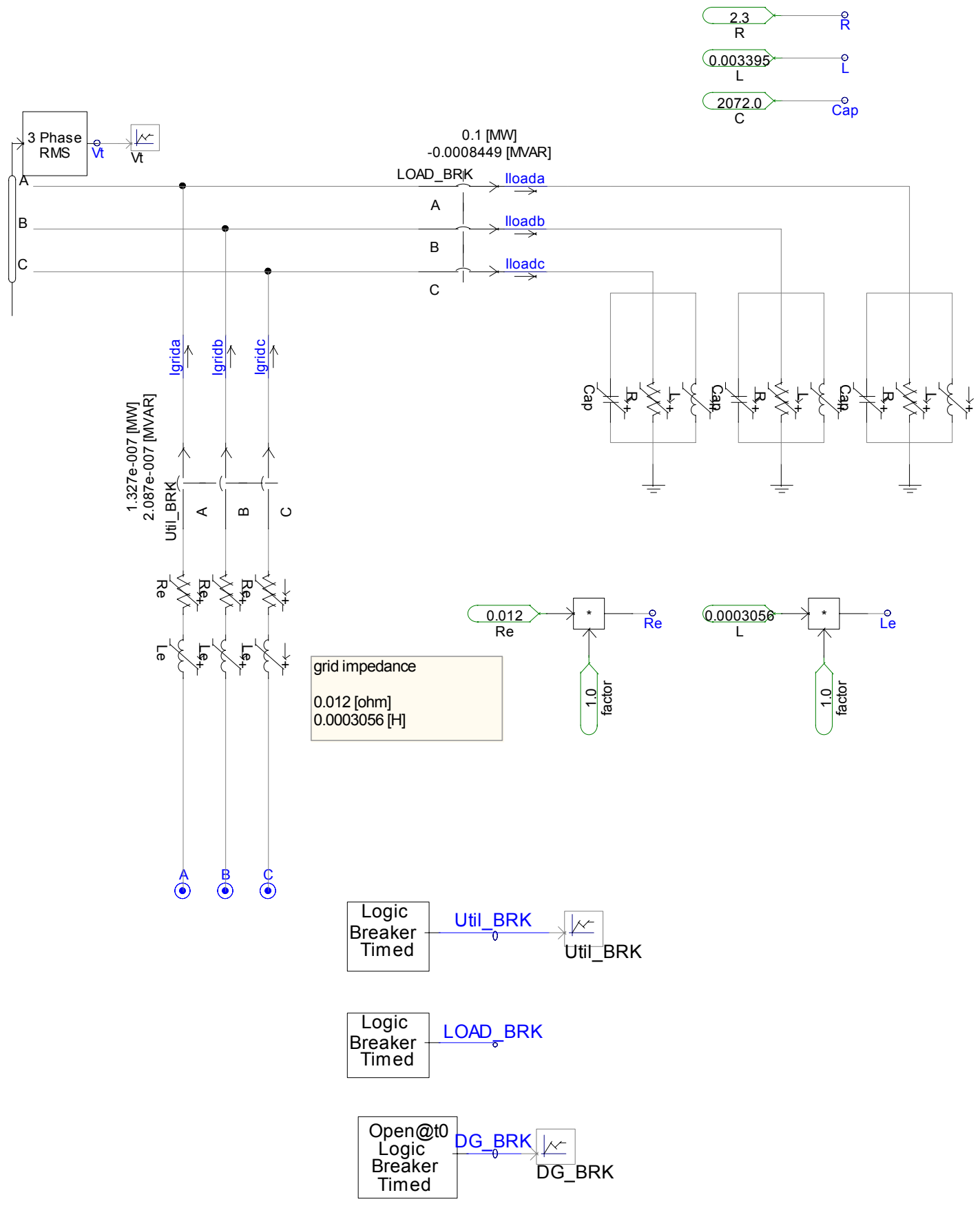

Figure 25. Grid, load models, and breakers 
The three breakers shown in Figure 25 are operated at the following times:

○ DG_BRK is closed at $0.2 \mathrm{~s}$ to connect the inverter to the grid and load.

- Util_BRK is opened at $4 \mathrm{~s}$ to disconnect the inverter from the grid.

- LOAD_BRK is opened is $10 \mathrm{~s}$ to disconnect the R-L-C load from the inverter.

Figure 26 and Figure 27 show the inverter RMS output voltage and frequency during the breaker operations. Inverter voltage is expressed in the p.u. system with a base value of $0.2771 \mathrm{kV}$ (phase). Figure 27 shows that the inverter frequency gradually increases when the system is disconnected from the grid. Voltage remains pretty constant during this period. However, when load is disconnected from the system at 10 $\mathrm{s}$, both frequency and voltage change rapidly. This is probably due to the averaged model of the inverter, which has three controlled current sources in the three inverter legs.

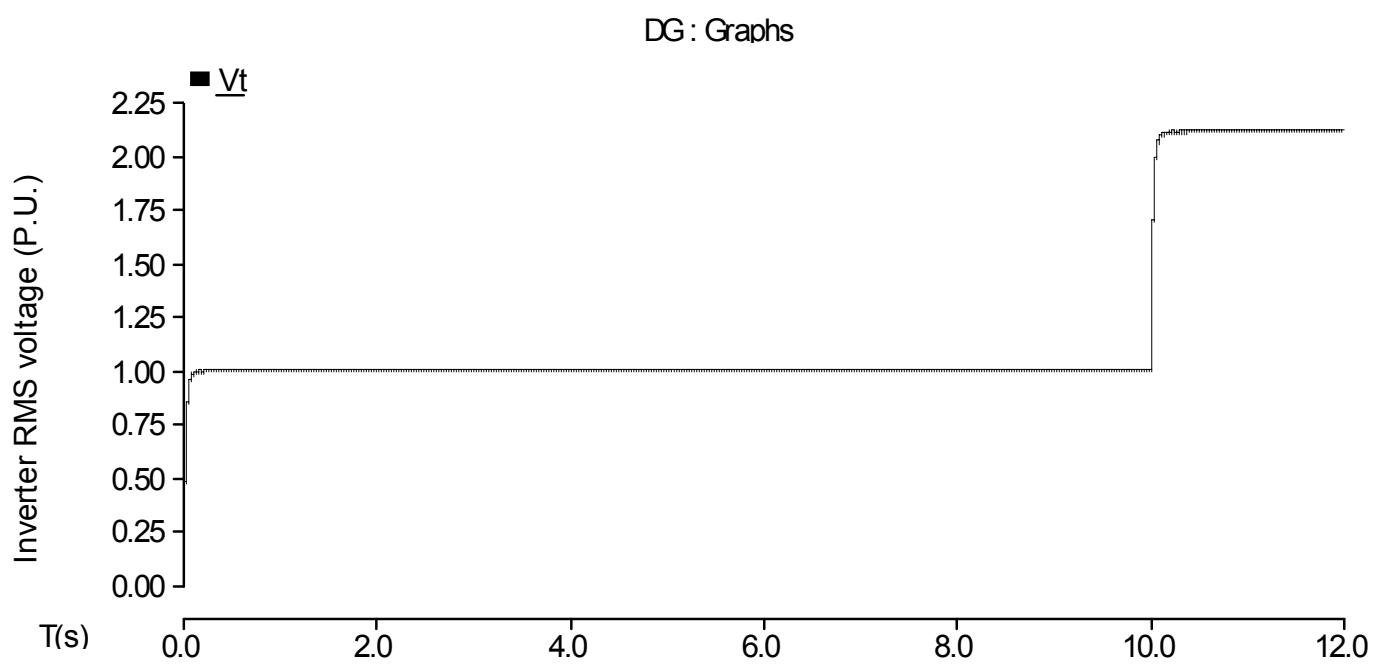

Figure 26. RMS inverter voltage 


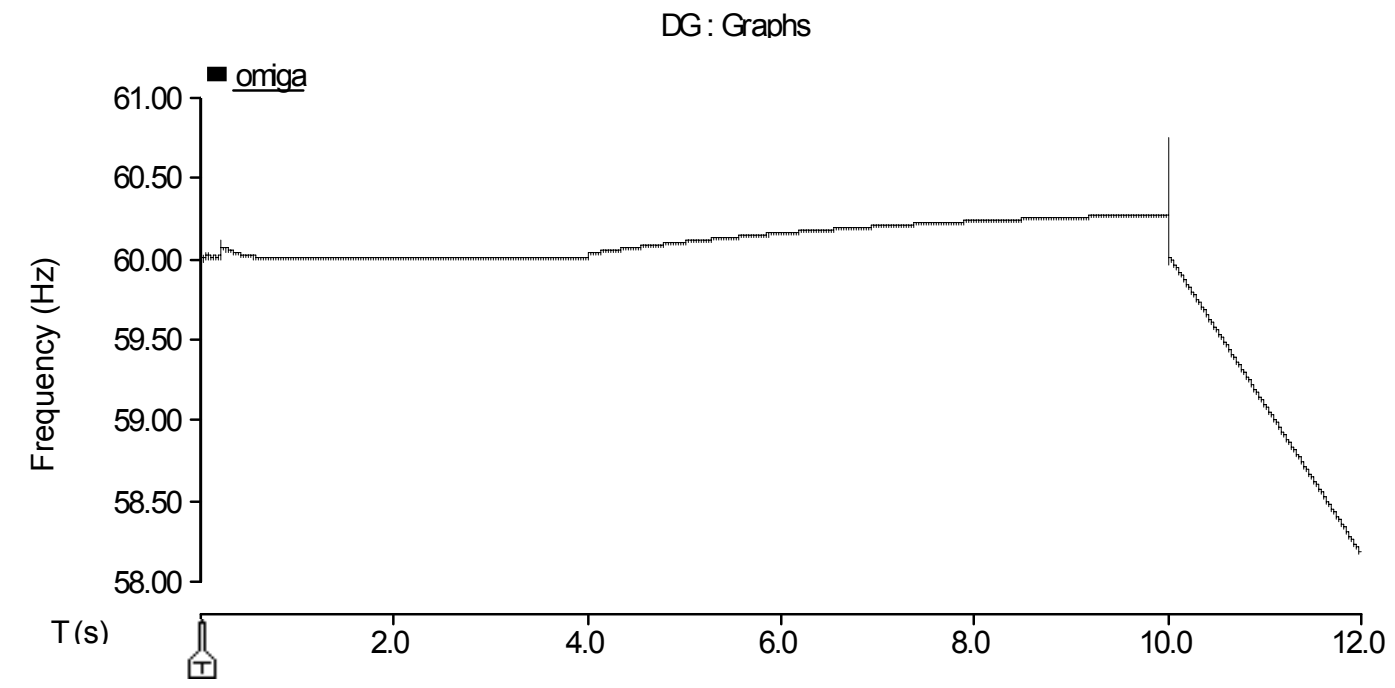

Figure 27. Inverter frequency

Figures 28 and 29 show the d-axis and q-axis inverter currents, respectively. The reference value for $\mathrm{d}$-axis current is 1.0 (P.U), and the reference value for q-axis current is 0.0 (p.u.). The PI controllers do a good job tracking these reference values until the instant when load is disconnected from the system. The magnitude of the DC link voltage is shown in Figure 30.

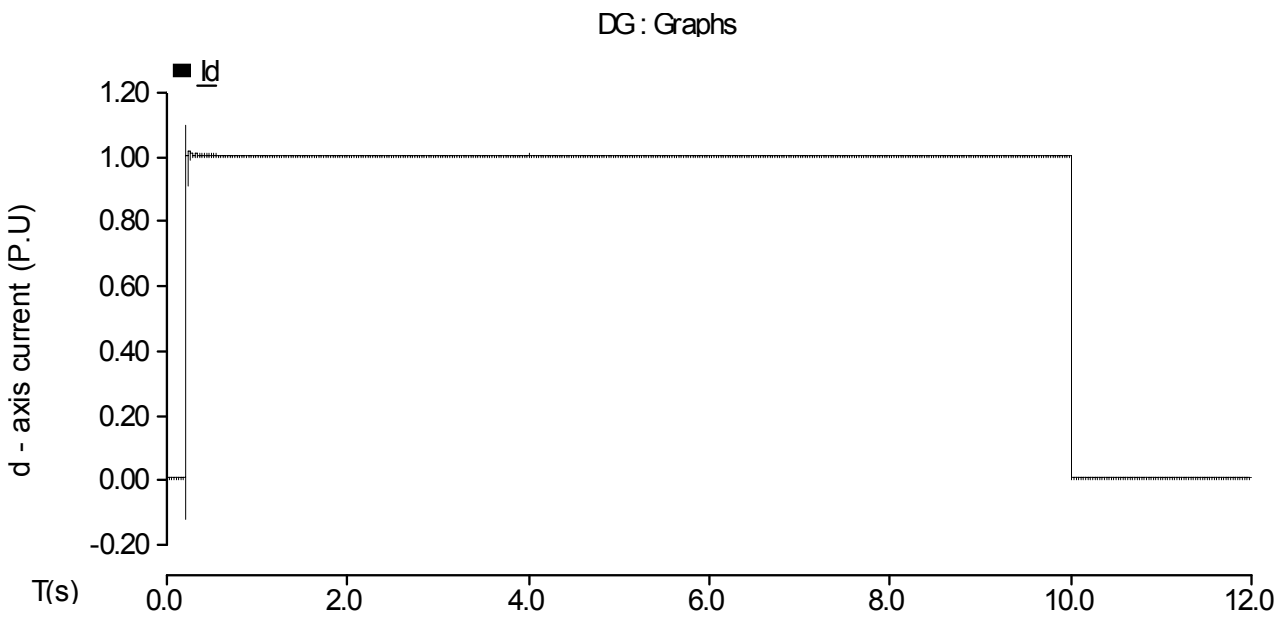

Figure 28. d-axis inverter current (voltage) 


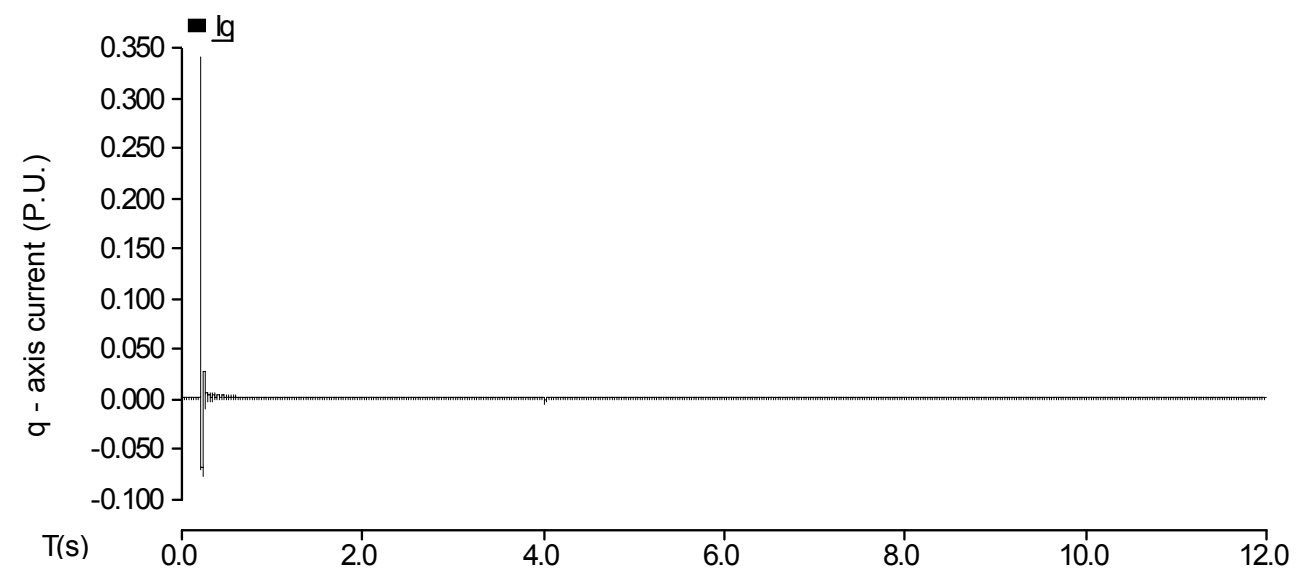

Figure 29. q-axis inverter current (frequency)

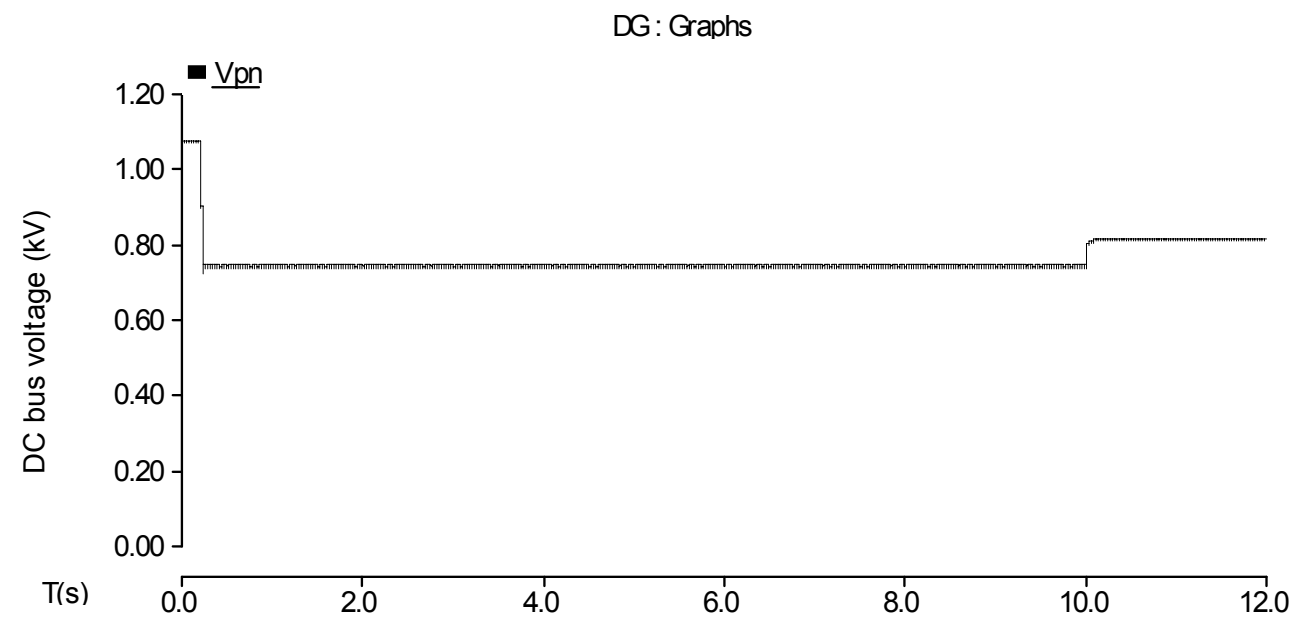

Figure 30. DC link voltage (rectifier output)

Active and reactive power measurement points in the schematic are shown in Figure 31 . Figure 32 and Figure 33 show the active and reactive power injected by the $480-\mathrm{V}$ $\mathrm{AC}$ feed into the system. It delivers about $105 \mathrm{~kW}$ of active power and $32 \mathrm{kVAR}$ of reactive power when the R-L-C $(23 \Omega-3.395 \mathrm{mH}-2072 \mu \mathrm{F})$ load is connected at the inverter output. Figure 34 and Figure 35 show the active and reactive power delivered by the inverter. The magnitudes are slightly lower than the power delivered by the AC feed, which can be attributed to the switching losses in the diode bridge rectifier and the PWM converter. (The AC sources used in the average model have a small series resistance). Figure 36 and Figure 37 show the active and reactive powers injected into the grid. Both of these are close to zero, which means that no real amount of power is being injected into the grid. Active and reactive power absorbed by the R-L-C load are shown in Figure 38 and Figure 39. The magnitudes of these powers are very close to the power measured at the inverter output. 


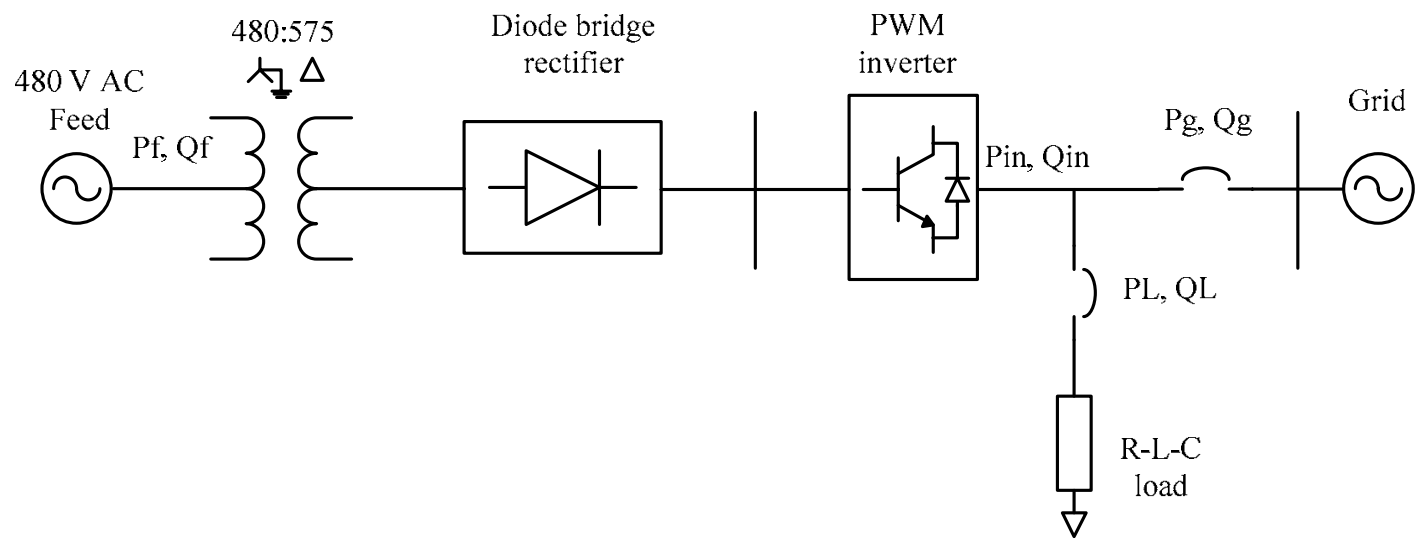

Figure 31. Power measurement points

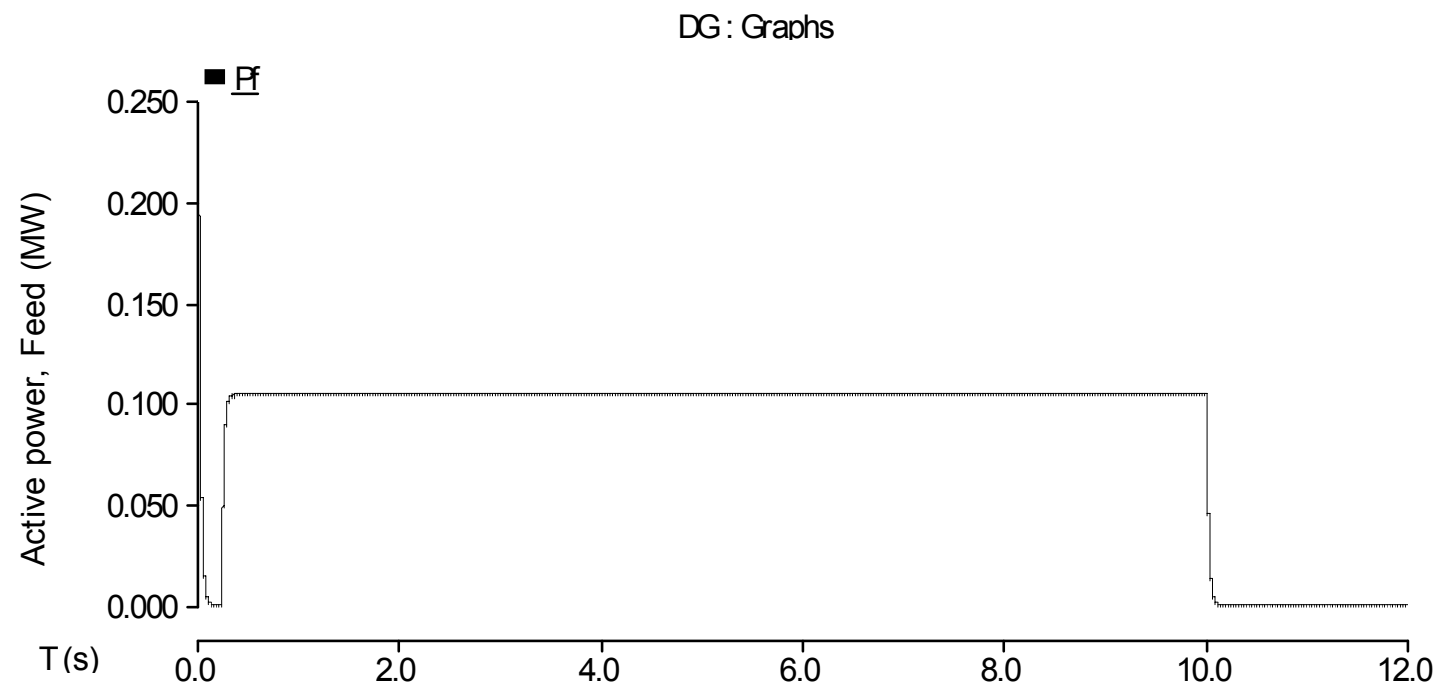

Figure 32. Active power injected by the AC feed 


\section{DG : Graphs}

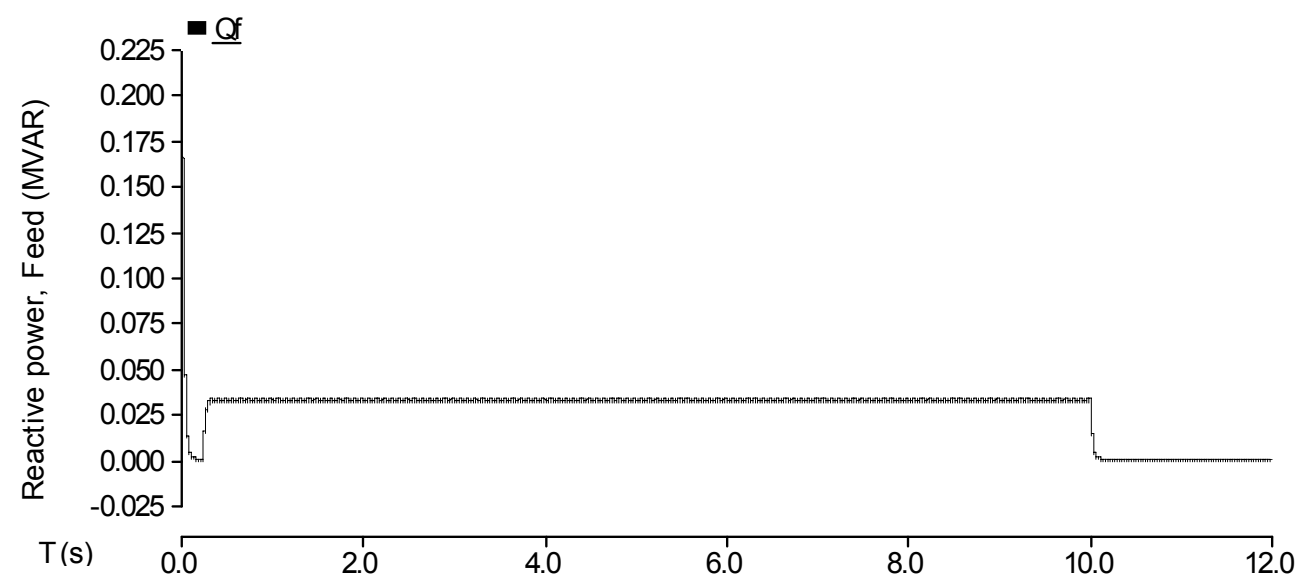

Figure 33. Reactive power injected by the AC feed

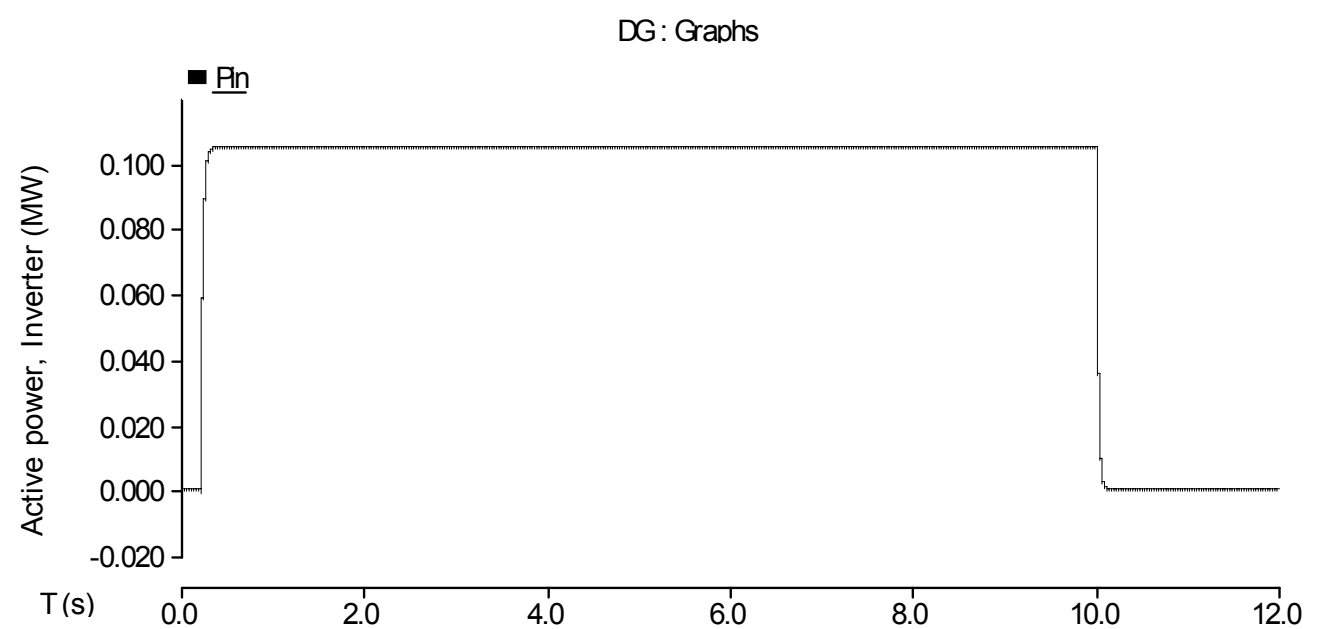

Figure 34. Active power delivered by the inverter 
DG: Graphs

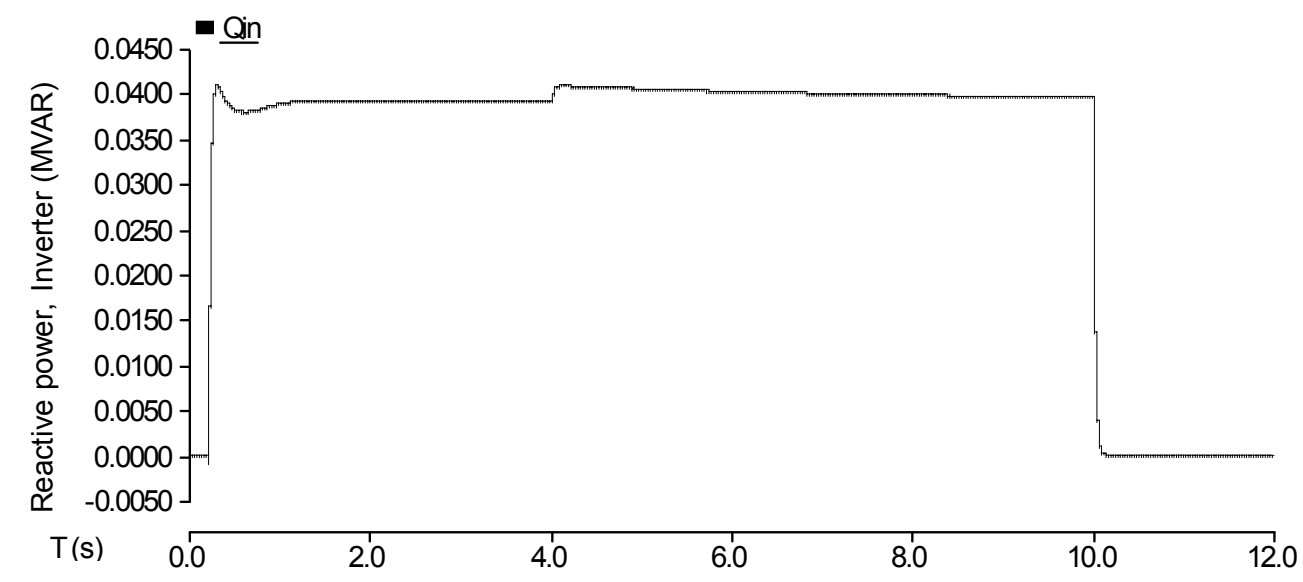

Figure 35. Reactive power delivered by the inverter

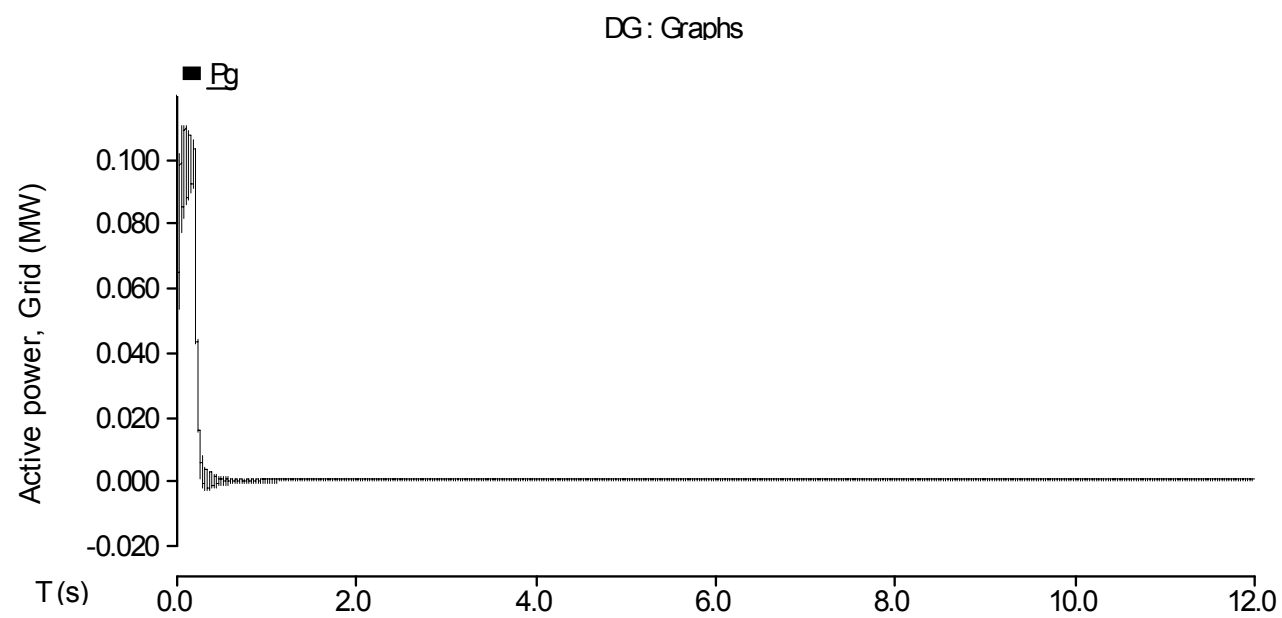

Figure 36. Active power injected into the grid 


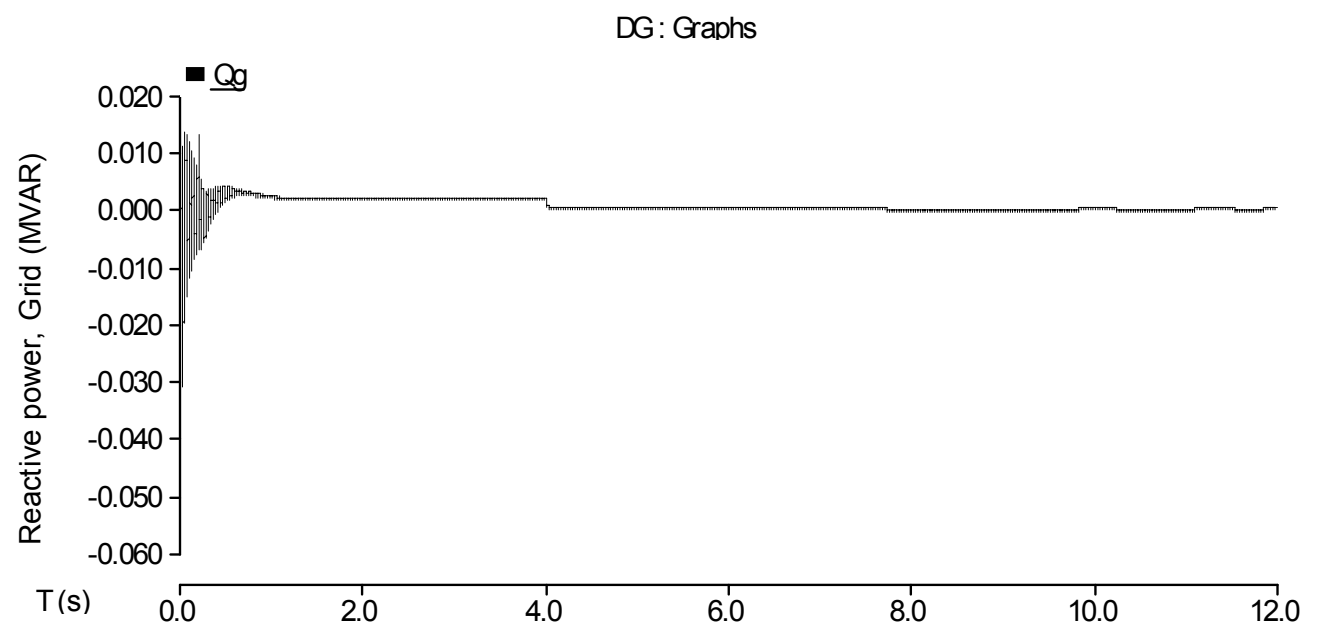

Figure 37. Reactive power injected into the grid

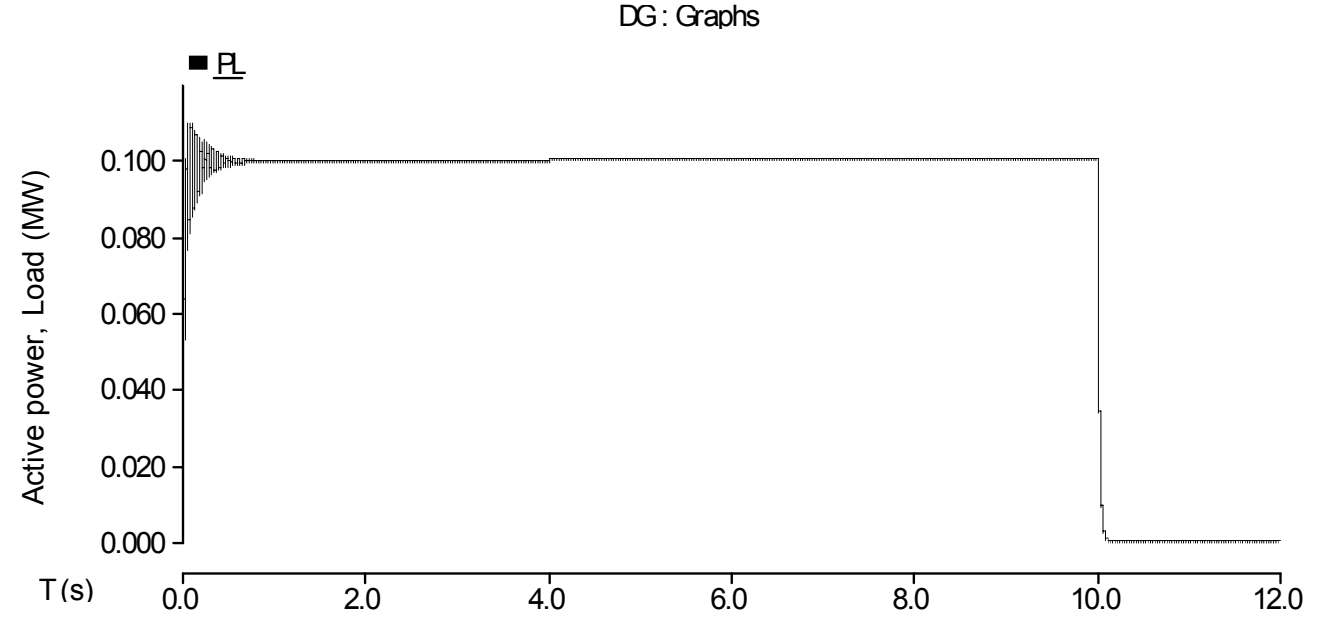

Figure 38. Active power absorbed by the load 


\section{DG: Graphs}

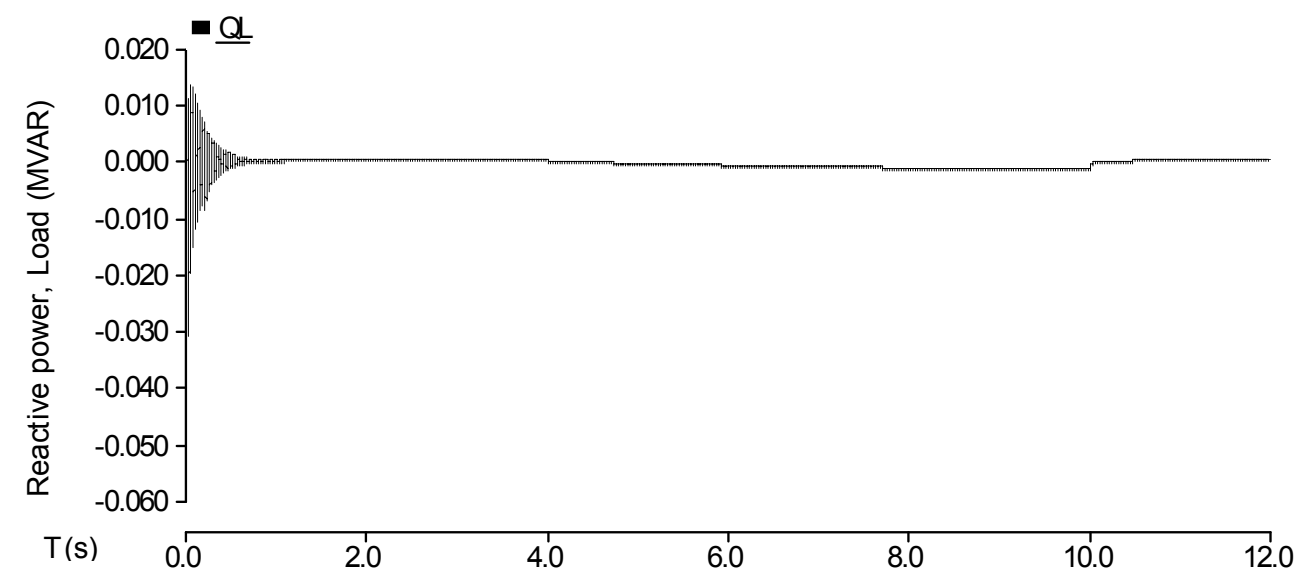

Figure 39. Reactive power absorbed by the load 


\section{$7 \quad$ Photovoltaic Cell}

\subsection{Mathematical Analysis}

The simulation model of the PV cell is based on the circuit-based model developed in [2]. The schematic of the circuit-based model is shown in Figure 40. The schematic is based on the double exponential equation, which models a PV cell, derived from the physics of the p-n junction.

$$
I=I_{p h}-I_{s}\left(e^{\frac{e\left(V+I R_{s}\right.}{A k T}-1}\right)-\frac{V+I R_{s}}{R_{p}}
$$
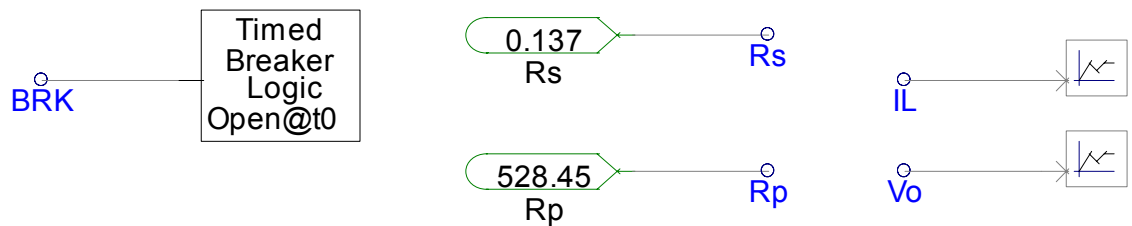

$\mathrm{Rp}$

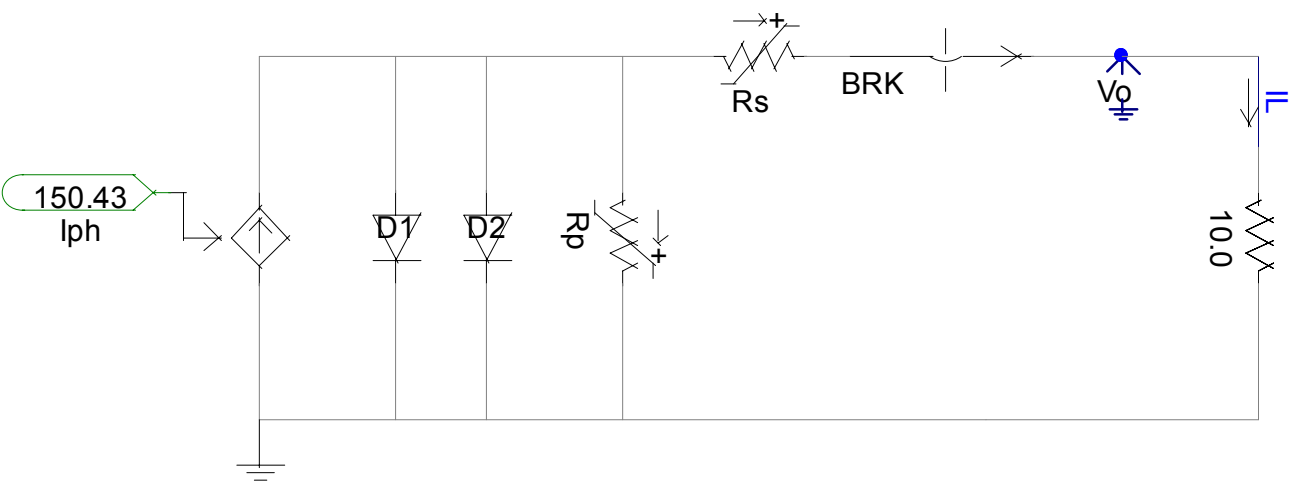

Figure 40. PV cell equivalent circuit

The parameters in the equivalent circuit are derived from the environmental parameters of temperature and irradiance. They are related as shown below.

$$
\begin{aligned}
& I_{p h}=K_{0} E\left(1+K_{1} T\right) \\
& R_{s}=K_{8}+\frac{K_{9}}{E} K_{10} T \\
& R_{p}=K_{11} e^{\left(K_{12} T\right)}
\end{aligned}
$$

Where:

$\mathrm{E}$ is the irradiance in $\mathrm{W} / \mathrm{m}^{2}$

$\mathrm{T}$ is temperature in Kelvin

$\mathrm{K}_{0-12}$ are constants specific to a given cell. 
These constants are derived from the I-V curve of the PV cell.

\subsection{Simulation Results}

The following are the simulation results, with the parameters shown in Figure 1. The temperature used was $25^{\circ} \mathrm{C}$. All other parameters were taken from [2]. Figure 41 and Figure 42 show the response of the PV cell to load changes.

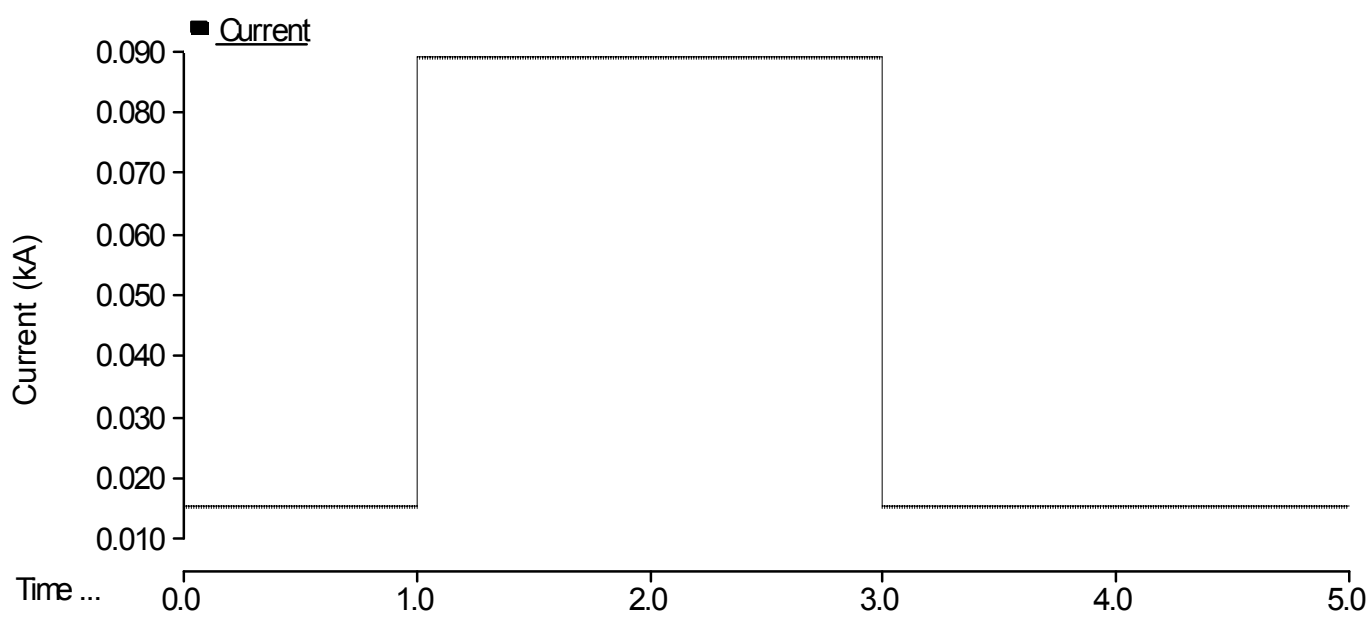

Figure 41. PV cell current

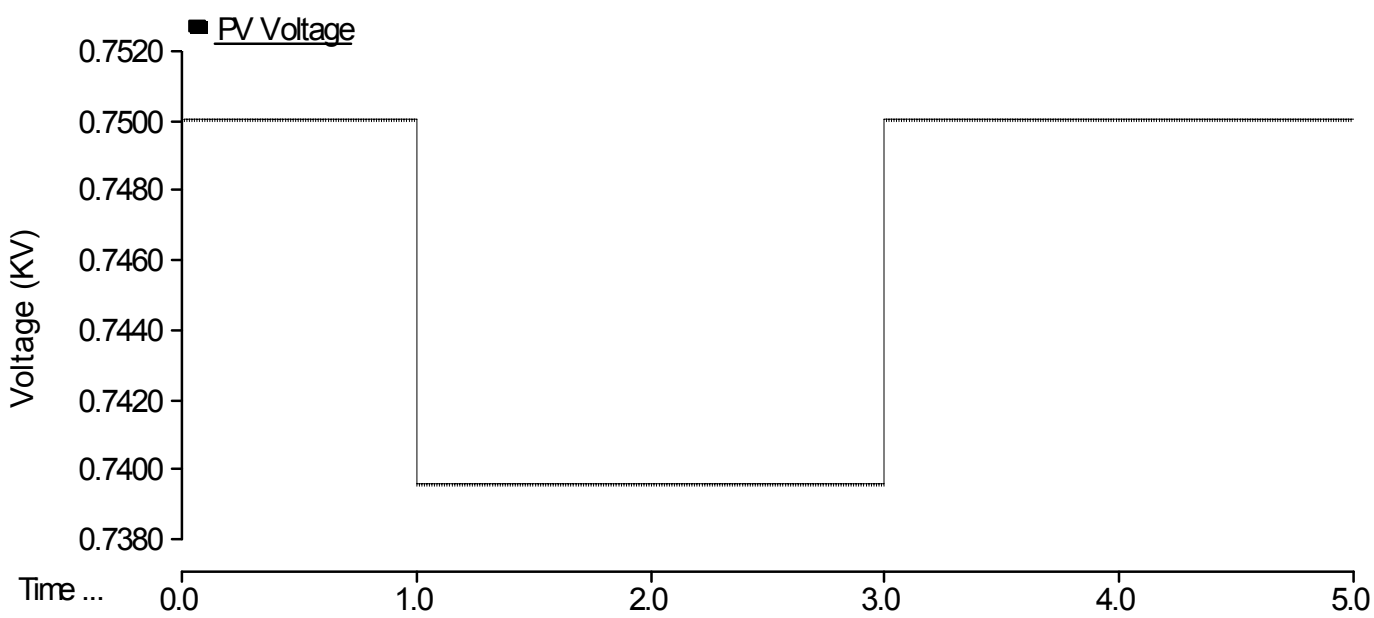

Figure 42. PV cell voltage 


\section{Microturbine}

The microturbine model is connected to the grid through an inverter and a DC link capacitor. A PI controller is used to set the inverter output voltage to match the desired power profile from the microturbine.

\subsection{Mathematical Analysis}

The microturbine model was based on the system of Figure 42 from [1].

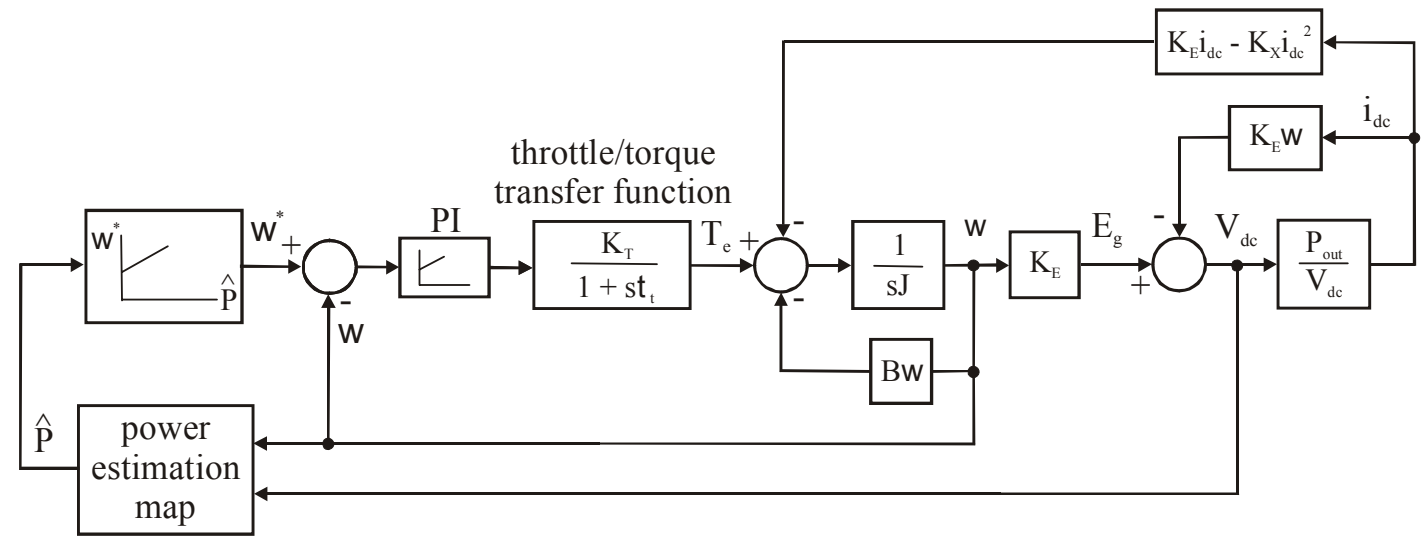

Figure 43. Block diagram of a microturbine

This model assumes that the torque response is a first-order system. The model was modified to accept a constant input shaft speed. Also, the $\mathrm{K}_{\mathrm{e}}{ }^{*} \omega * \mathrm{i}_{\mathrm{dc}}$ feedback was eliminated because it does not give a voltage value. In this model, the desired power output and shaft speed are set. The system then stabilizes, and the output power follows the desired power. The parameters $\mathrm{K}_{\mathrm{e}}$ and $\mathrm{K}_{\mathrm{x}}$ are easily obtained through experimentation. $\mathrm{K}_{\mathrm{e}}$ is the ratio between no-load voltage and no-load shaft speed. $\mathrm{K}_{\mathrm{x}}$ can be determined using $\mathrm{K}_{\mathrm{e}}$ and one other operation point.

$$
\begin{array}{r}
\mathbf{K}_{\mathrm{e}}=\frac{\mathbf{V}_{\text {DCno-load }}}{\omega_{\text {no-load }}} \\
\mathbf{K}_{\mathbf{x}}=\frac{\frac{\mathbf{V}_{\text {DC1 }}-\mathbf{K}_{\mathbf{e}}}{\frac{-\omega_{1}}{\mathbf{V}_{\text {DC1 }}}}}{}
\end{array}
$$

From these parameters, voltage, power and torque can be found. These equations are used in the model of the microturbine.

$$
\begin{aligned}
& \mathrm{V}_{\mathrm{dc}}=\mathrm{K}_{\mathrm{e}} \cdot \omega-\mathrm{K}_{\mathrm{x}} \cdot \omega \cdot \mathrm{I}_{\mathrm{dc}} \\
& \mathrm{P}_{\mathrm{dc}}=\mathrm{K}_{\mathrm{e}} \cdot \omega \cdot \mathrm{I}_{\mathrm{dc}}-\mathrm{K}_{\mathrm{x}} \cdot \omega \cdot \mathrm{I}_{\mathrm{dc}}{ }^{2} \\
& \tau=\mathrm{K}_{\mathrm{e}} \cdot \mathrm{I}_{\mathrm{dc}}-\mathrm{K}_{\mathrm{x}} \cdot \mathrm{I}_{\mathrm{dc}}{ }^{2}
\end{aligned}
$$


The other parameters, such as the shaft inertia, J; the throttle gain; and the time constant can be obtained through calculation or experimentation. This simulation used constants from a Honeywell microturbine from a University of Wisconsin paper [2]. The values are shown below.

Table 3. Microturbine parameters

\begin{tabular}{ll}
\hline $\mathrm{K}_{\mathrm{e}}$ & 0.092 \\
$\mathrm{~K}_{\mathrm{x}}$ & $8.594 \mathrm{e}-5$ \\
$\mathrm{~J}$ & 0.085 \\
$\mathrm{t}$ & $10 \mathrm{~s}$ \\
\hline
\end{tabular}

The DC link capacitor current is the difference between the microturbine current $\left(\mathrm{I}_{1}\right)$ and the output current $\left(\mathrm{I}_{2}\right) . \mathrm{I}_{2}$ is the ratio between the output power and the DC link voltage. The voltage in the capacitor can then be calculated with the capacitor differential equation.

$$
\begin{aligned}
& \mathrm{I}_{2}=\frac{\mathrm{P}_{\text {out }}}{\mathrm{V}_{\text {DCLink }}} \\
& \frac{\partial \mathrm{V}_{\text {DCLink }}}{\partial \mathrm{t}}=\frac{1}{\mathrm{C}}\left(\mathrm{I}_{1}-\mathrm{I}_{2}\right)
\end{aligned}
$$

The modulation factor that controls the inverter is given by:

$$
m=K_{p} \cdot e r r+\int K_{i} \cdot e r r
$$

The inverter converts the DC voltage from the microturbine into AC voltage to be connected to the $\mathrm{AC}$ grid. The output $\mathrm{AC}$ voltages are calculated using the equations:

$$
\begin{aligned}
& V_{a}=m \frac{V_{d c}}{2} \sin (2 \pi 60 t) \\
& V_{b}=m \frac{V_{d c}}{2} \sin \left(2 \pi 60 t-120^{\circ}\right) \\
& V_{c}=m \frac{V_{d c}}{2} \sin \left(2 \pi 60 t-240^{\circ}\right)
\end{aligned}
$$

The phase currents are calculated using the electrical equation for voltage across a resistor inductor load. 


$$
\frac{\partial i_{a}}{\partial t}=\frac{1}{L}\left(V_{a}-V_{a g}-R \cdot i_{a}\right)
$$

Finally, the three-phase output power is calculated by:

$$
P_{\text {out }}=V_{a} \cdot i_{a}+V_{b} \cdot i_{b}+V_{c} \cdot i_{c}
$$

\subsection{Simulation Results}

The microturbine model is transformed from a dynamic model into an electrical model using a voltage-controlled voltage source.

Figure 44 shows the entire system.

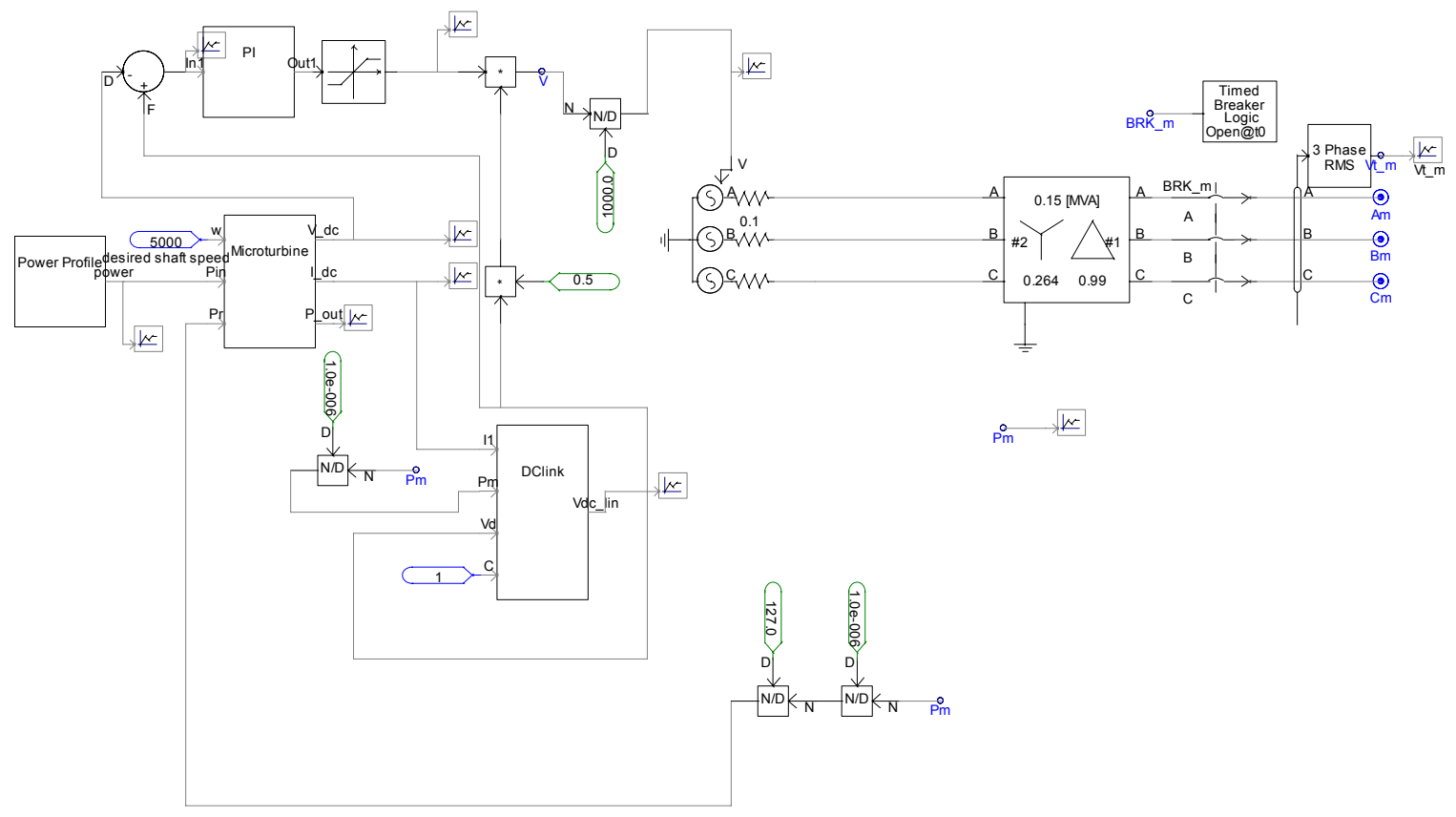

Figure 44. Total system

\subsubsection{Microturbine}

Figure 45 shows the microturbine. The model is based on equations instead of circuit elements. The output voltage is calculated with Equation 9. 


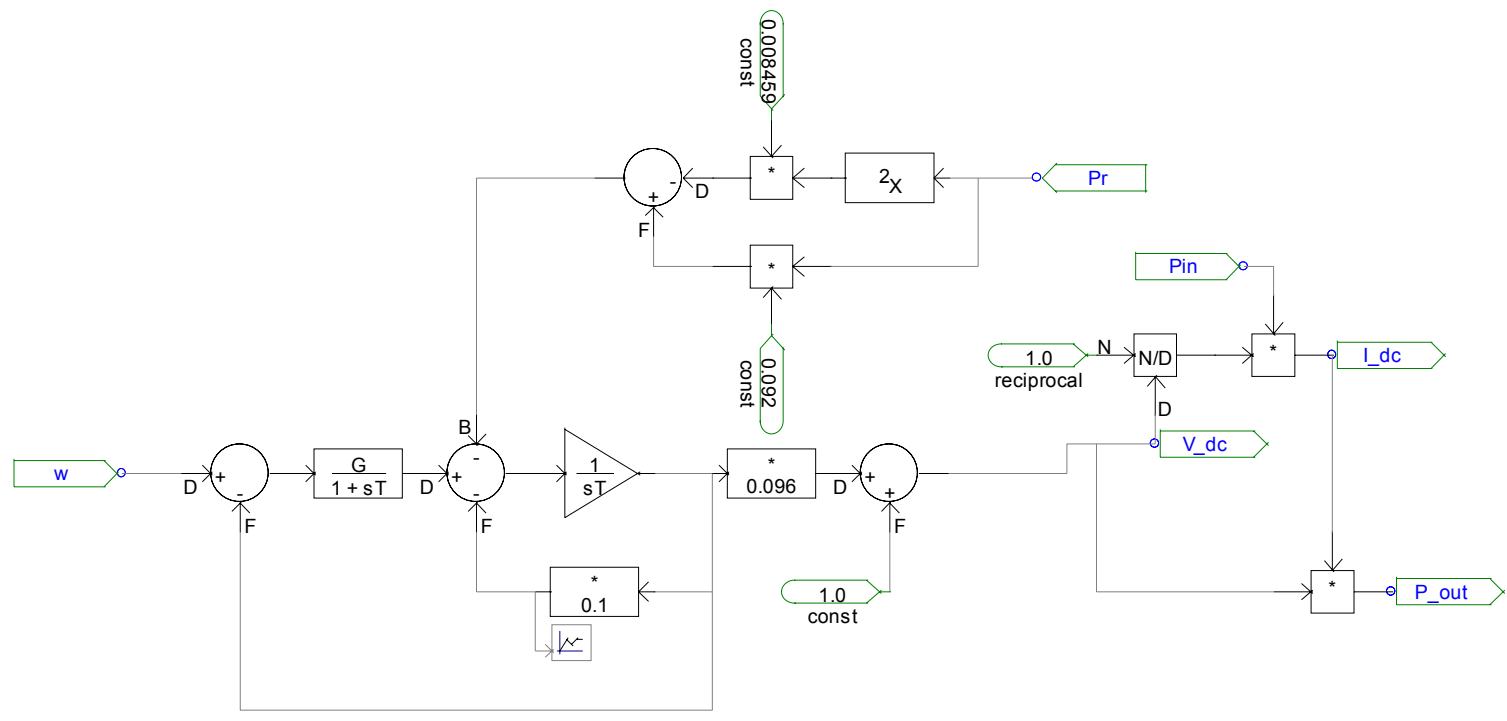

Figure 45. Microturbine

Figure 46, Figure 47, and Figure 48 show the output voltage, current, and power, respectively.

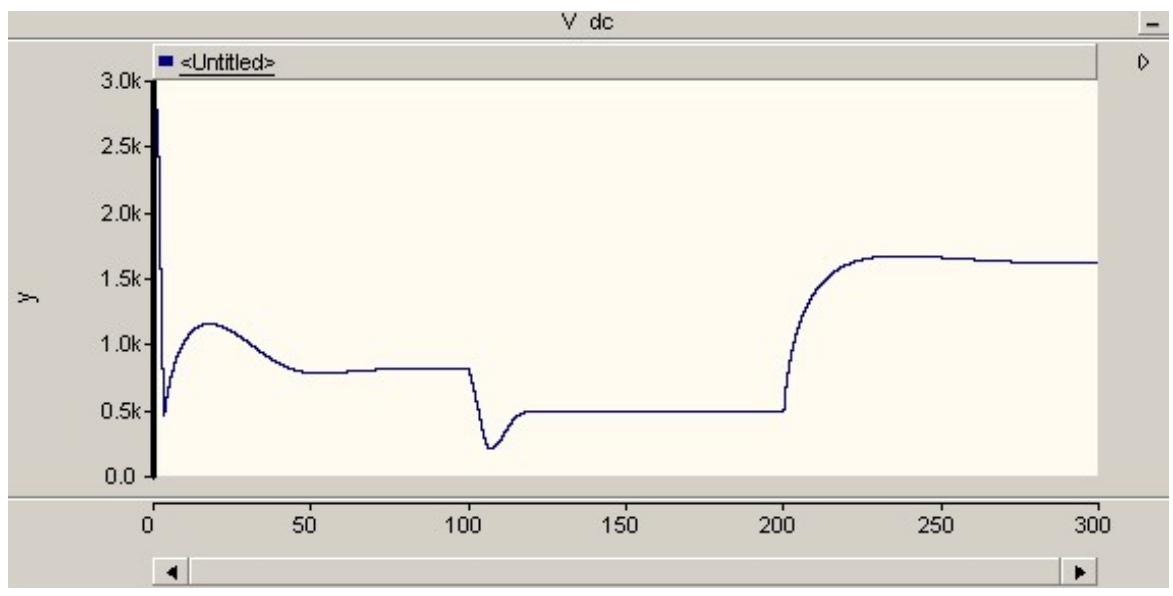

Figure 46. Microturbine output voltage 


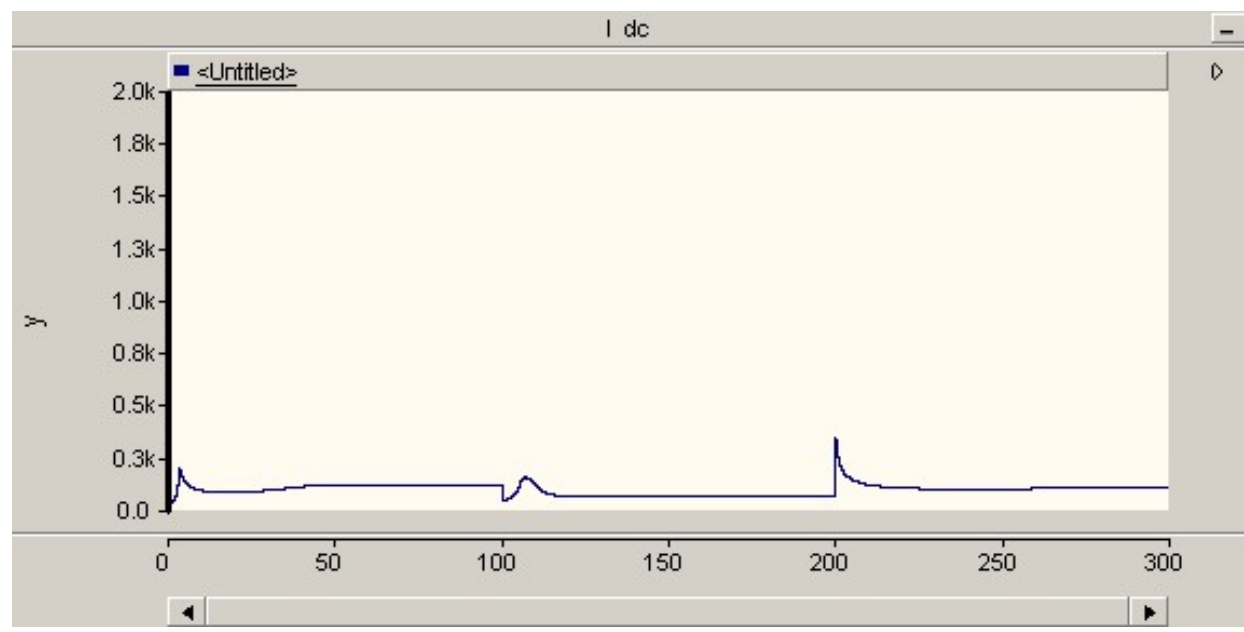

Figure 47. Microturbine output current

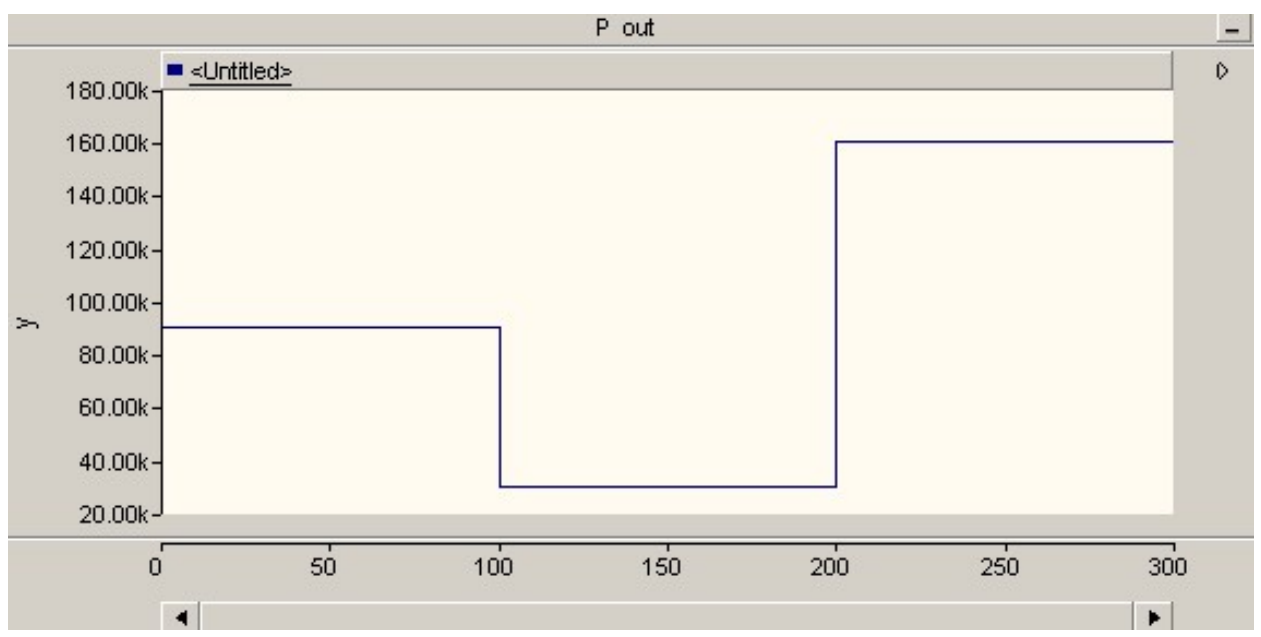

Figure 48. Microturbine output power

\subsubsection{Link}

The DC link capacitor connects the microturbine to the inverter. The voltage level is used to drive the inverter and the error in the capacitor voltage, and the microturbine voltage is used as the input to the PI controller.

The output current and voltage are calculated with Equation 10. Because $\mathrm{I}_{2}$ is in terms of the DC link voltage, a feedback has to be created. It used a capacitance of $1 \mathrm{~F}$.

Figure 49 shows the capacitor block, and Figure 50 shows the capacitor voltage block. 


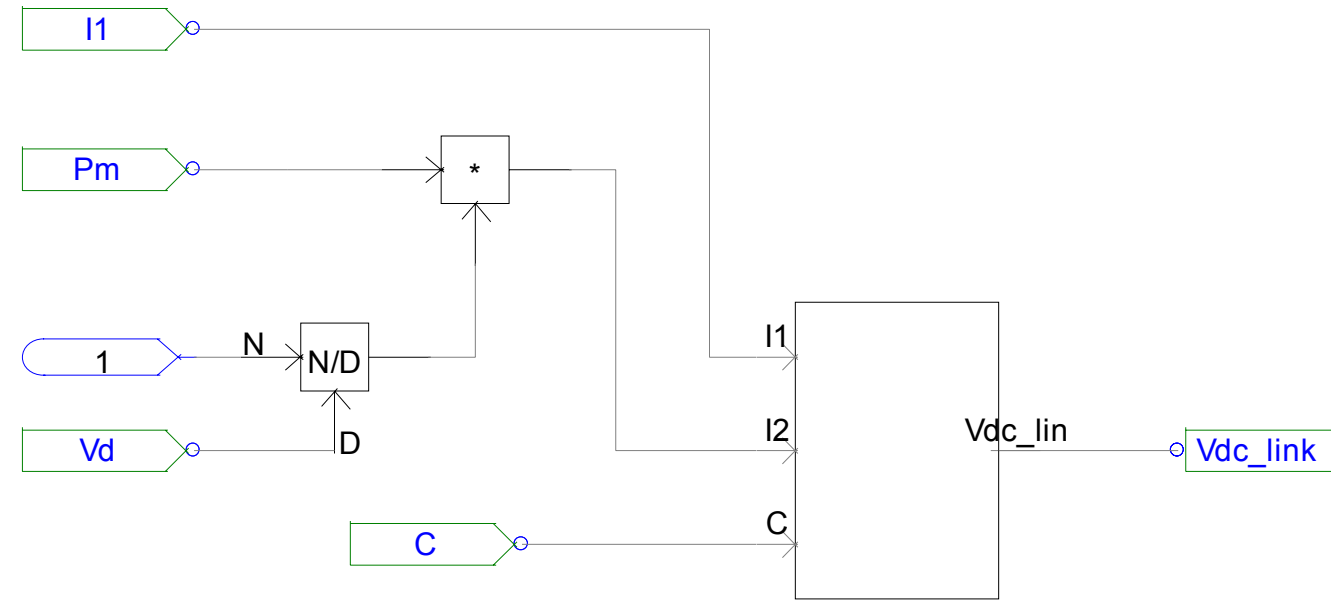

Figure 49. Capacitor block

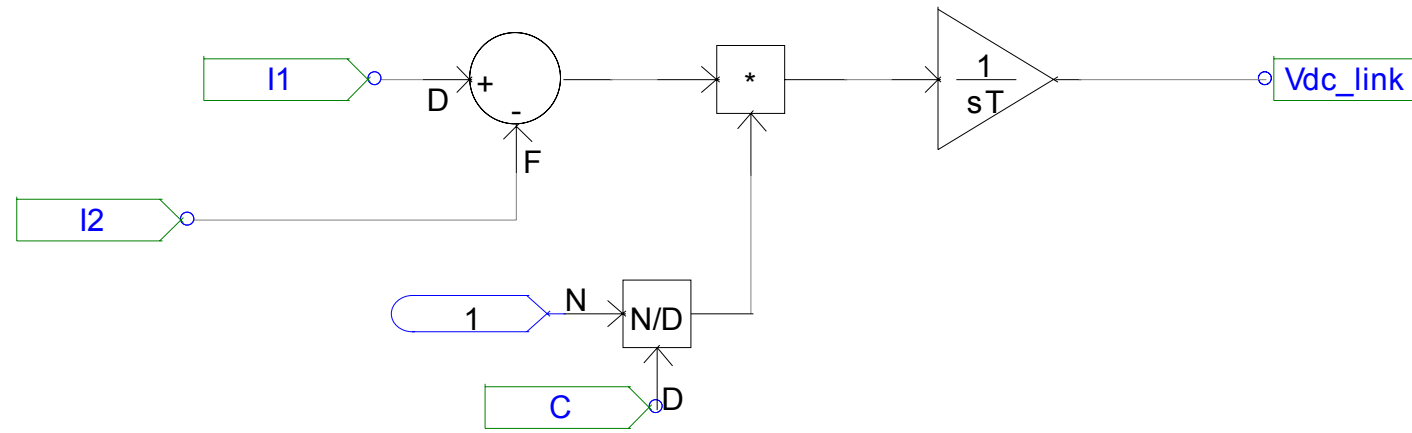

Figure 50. Capacitor voltage block

Figure 51 shows the DC link voltage. It has a constant value of $435 \mathrm{~V}$.

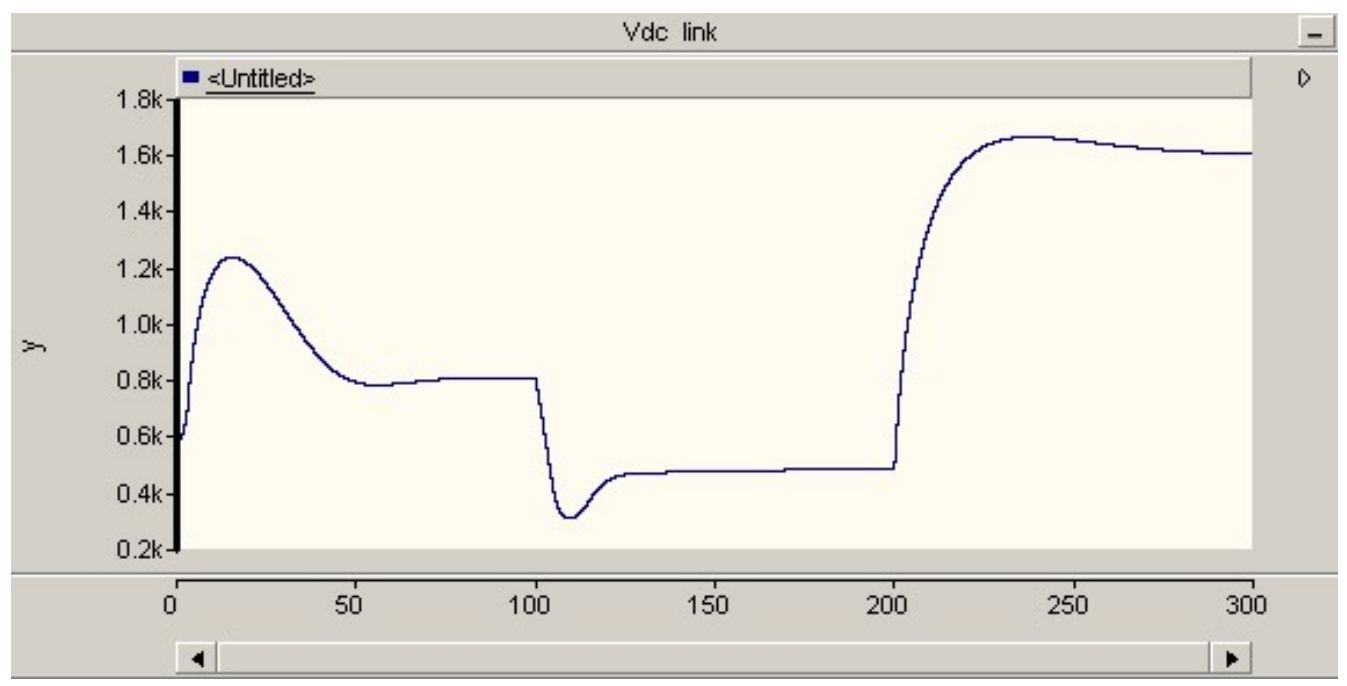

Figure 51. DC link voltage 


\subsubsection{PI Controller}

The PI controller (Figure 52) helps the output power follow the desired power profile. It uses an error from the difference in DC link voltage and the microturbine voltage to create a modulation factor, " $m$ " (Figure 53), that will then drive the inverter. The $\mathrm{m}$ value is put through a saturation limit between 0 and 1, but under normal operations, it should not get to these boundary conditions. They are in place to keep the inverter model from creating voltages it physically could not create.

The proportional and integral gains $\mathrm{K}_{\mathrm{i}}$ and $\mathrm{K}_{\mathrm{p}}$ were determined through a trial-and-error method.

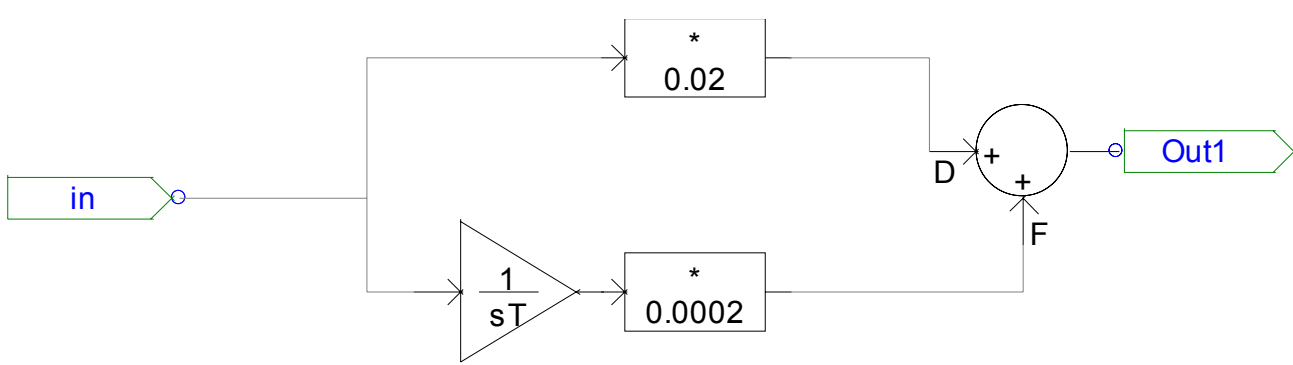

Figure 52. PI control block

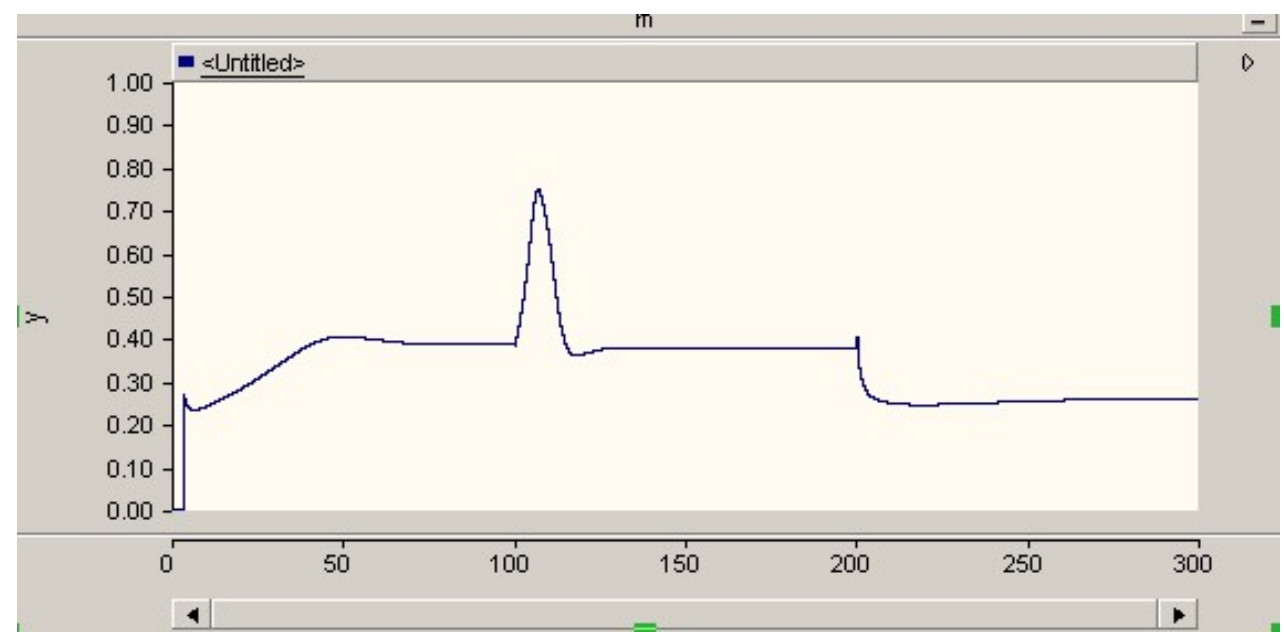

Figure 53. Modulation factor

\subsubsection{Grid Connection}

Figure 54 shows the system connected to the grid through a voltage-controlled voltage source. The $\mathrm{mVdc} / 2$ controls the voltage source. The grid is considered to be $60 \mathrm{~Hz}$, and the $120^{\circ}$ offset produces a balanced three-phase system. The breaker measures the output power. 


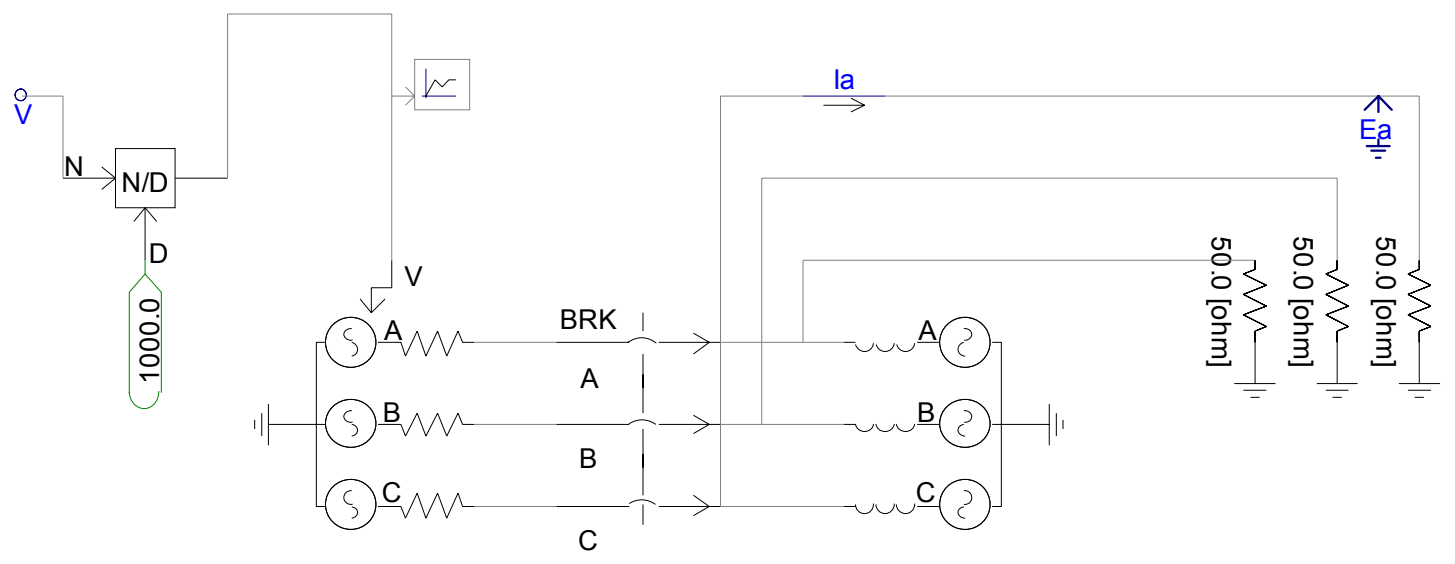

Figure 54. Grid connection

Figure 55 shows the power profile fed into the microturbine to drive the system. This profile can be changed.

Figure 56 shows that the output power follows the reference. (Note that the output power graph is in megawatts but the power reference graph is in watts.) The PI controls the transients of the systems. Changing the proportional and integral gains will change how fast the transients occur and how much the output oscillates. This case uses both gains at 0.002 .

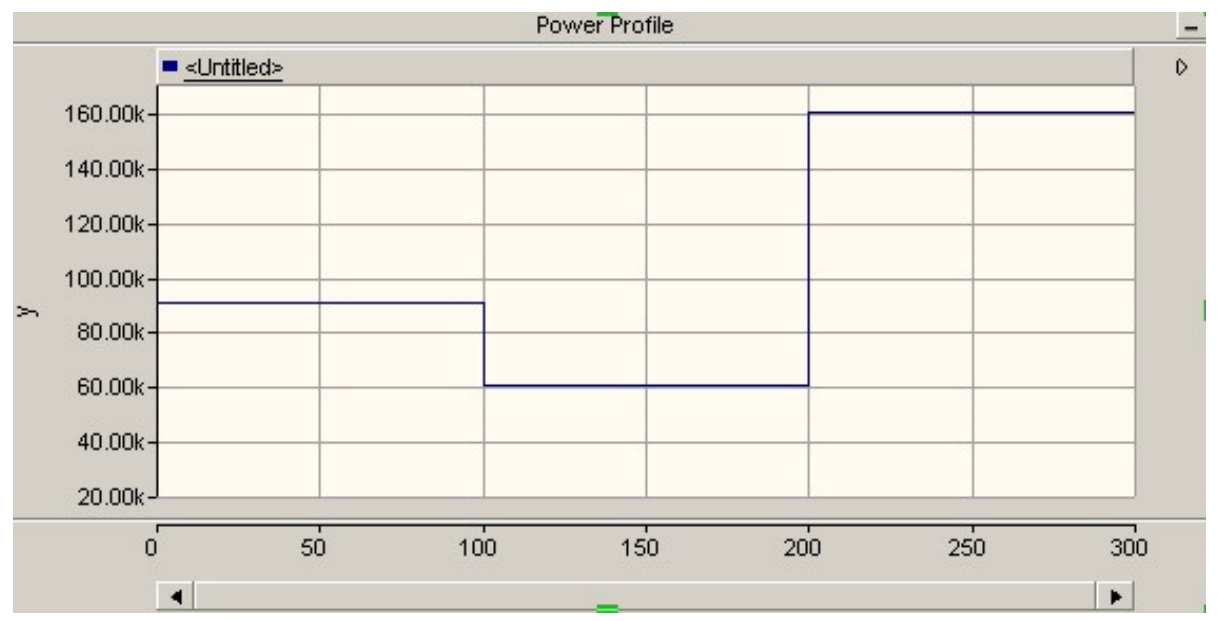

Figure 55. Power profile 


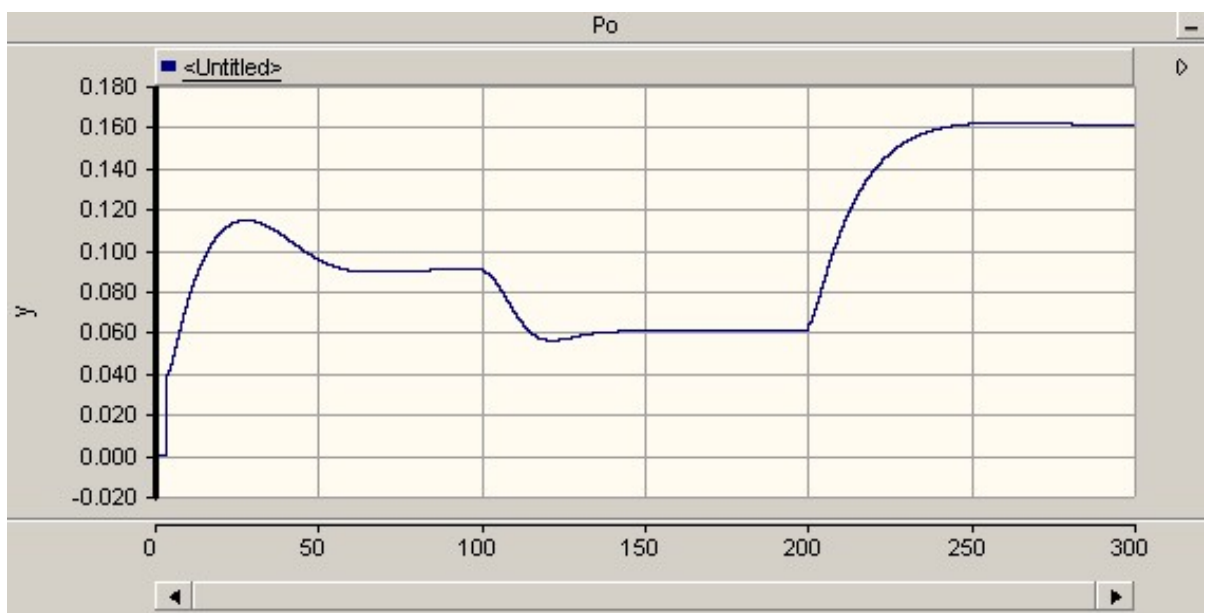

Figure 56. Output power 


\section{$9 \quad$ Backbone Integration}

After the proper functioning of each component was verified, the components were integrated into the backbone.

Figure 57 shows the PSCAD model of the system that has been simulated. The model includes a 62.5-kVA AC grid simulator; a 250-kVA, Y-connected 216.5-V/480-V transformer; variable R-L-C load; a 125-kW diesel generator (represented as a synchronous generator); a $60-\mathrm{kW}$ wind turbine; a PV cell; a 33-kW microturbine; and three $3.5-\mathrm{kW}$ PWM inverters. Each PWM inverter is controlled using the control approaches discussed in earlier sections. Also included in the figure are circuit breakers, at which current, voltage, and power are measured. Other devices, such as a fuel cell, may be added to the grid.

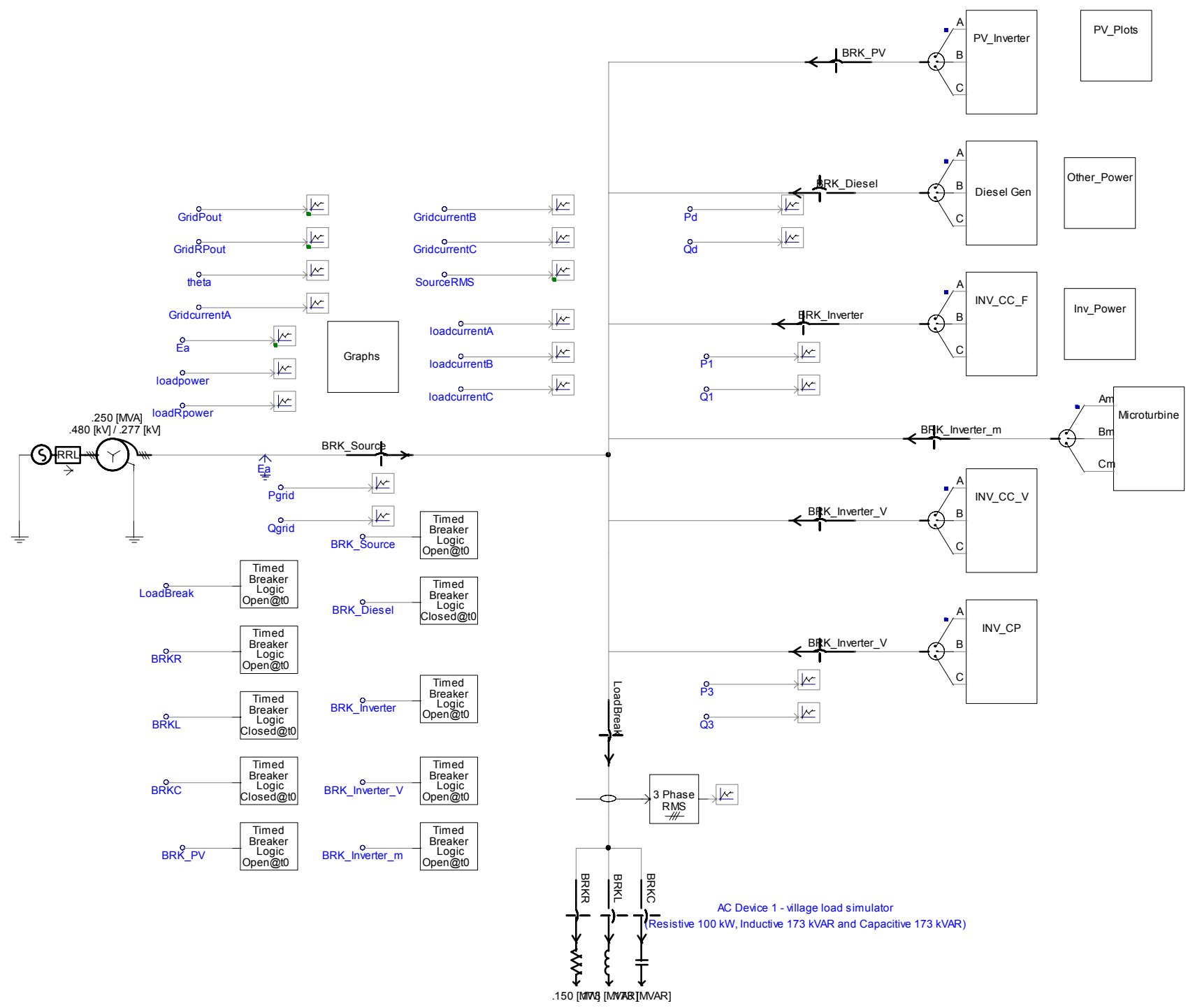

Figure 57. Microgrid backbone - PSCAD 
Figure 58 shows the three-phase bus voltage.

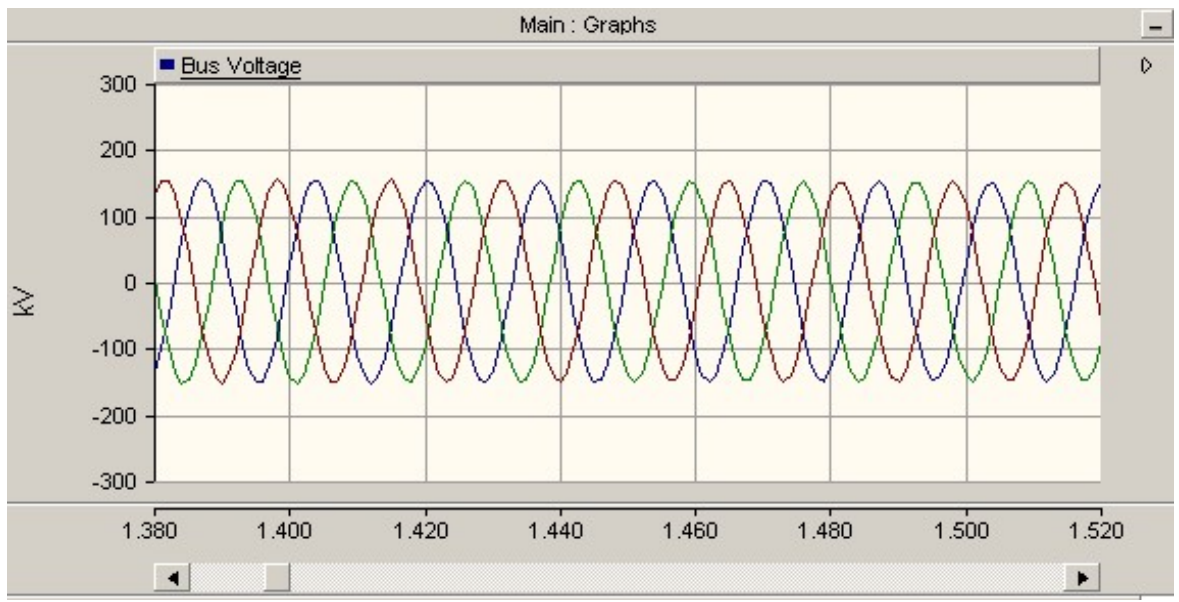

Figure 58. Bus voltage

Figure 59 shows the grid simulator active and reactive powers, current, and voltage.

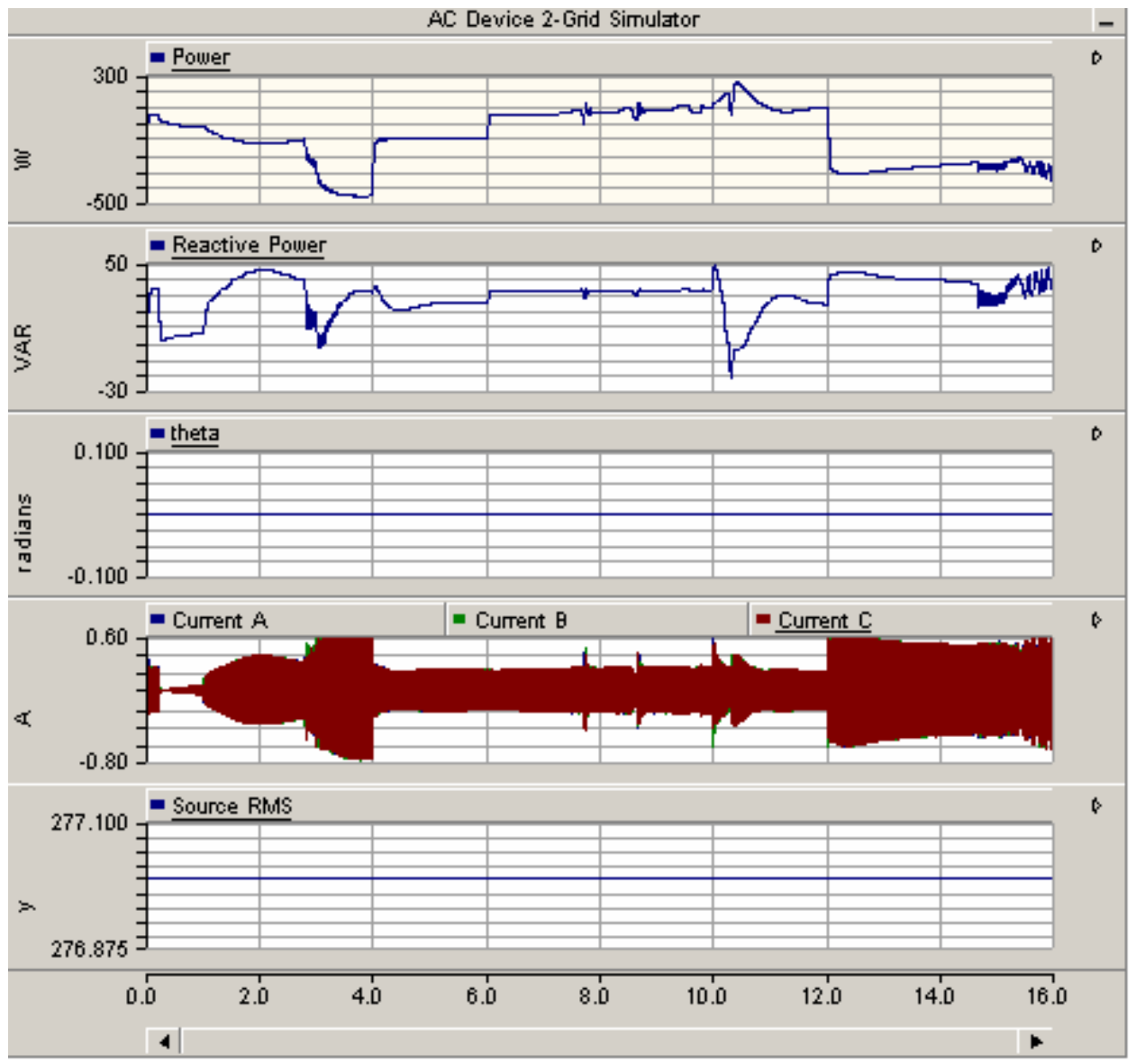

Figure 59. Grid simulator 
Figure 60 shows the load simulator graphs.

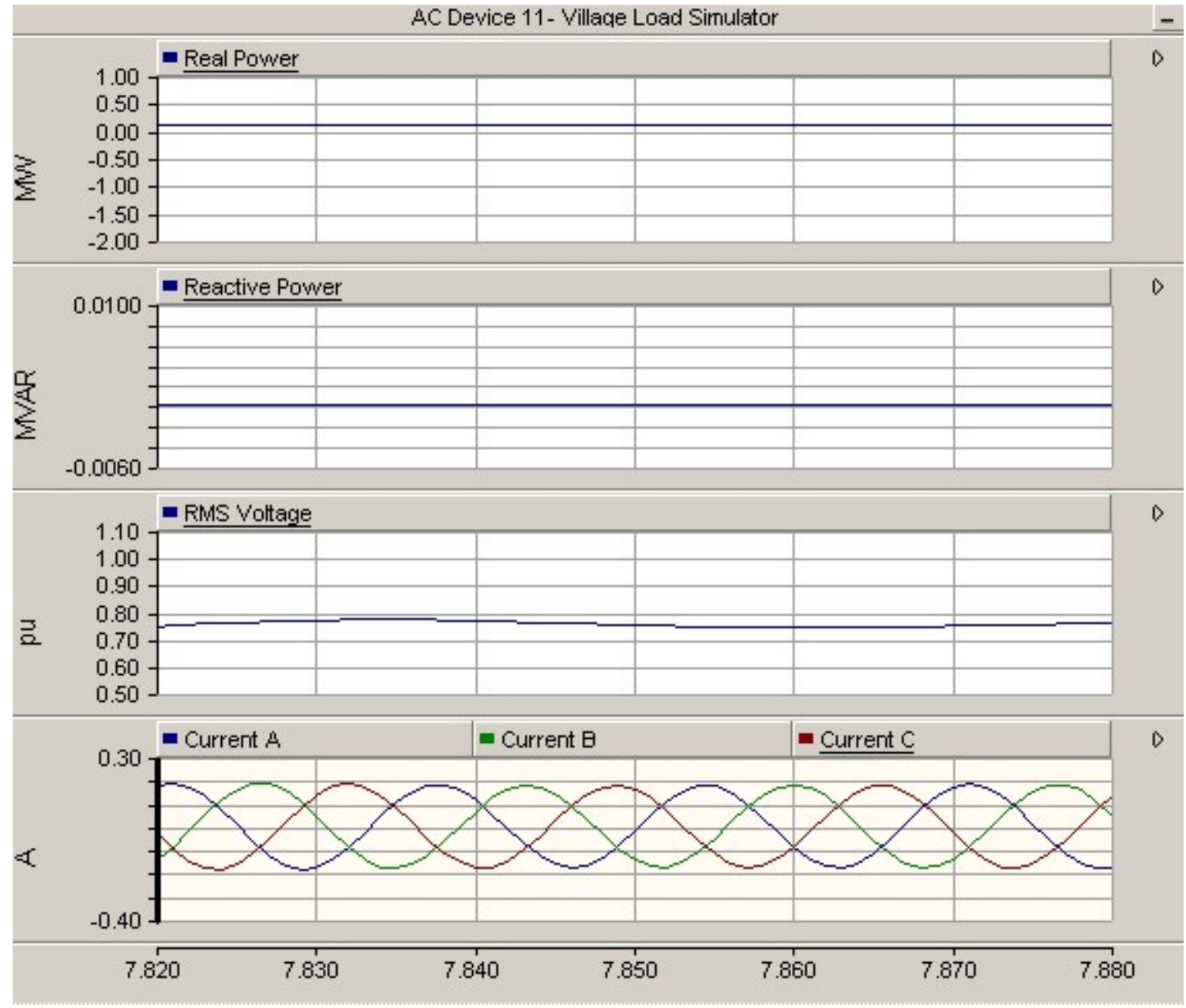

Figure 60. Load simulator

\subsection{Diesel Generator}

Figure 61 and Figure 62 show the outputs of the diesel generator when connected to the backbone. 


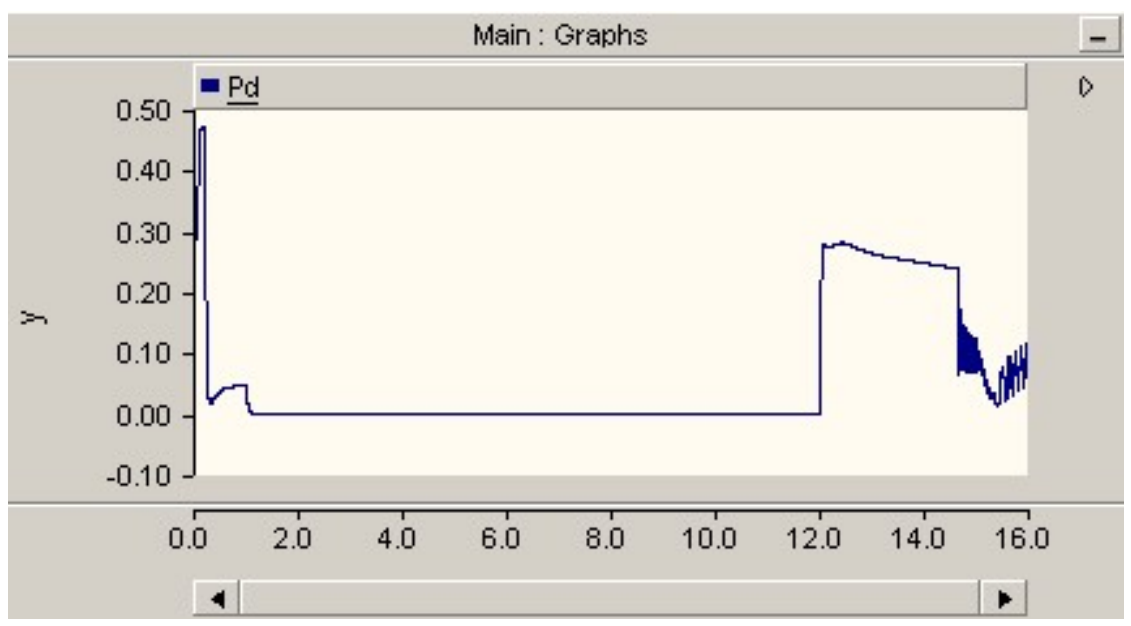

Figure 61. Active power - diesel generator

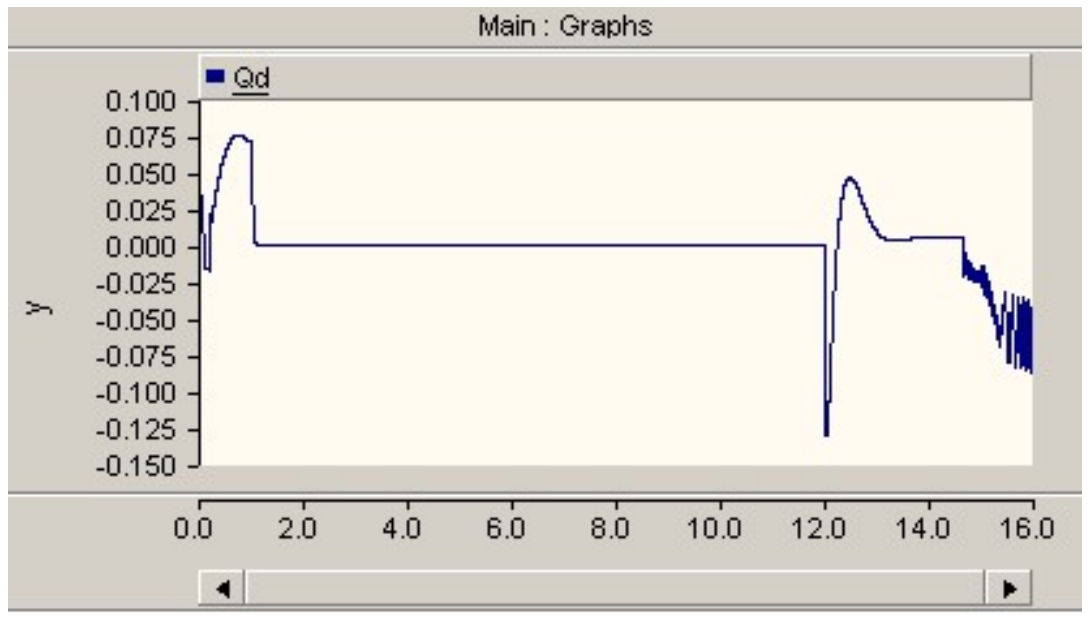

Figure 62. Reactive power - diesel generator

\subsection{PV Cell Grid Connection}

To integrate the PV cell model into the backbone, the GE inverter model is connected at the output of the cell. The PV model is used as the DC source for the current-controlled inverter. The following figures show the simulation results with the inverter model. Anti-islanding schemes were not implemented. The grid connection was removed at $4 \mathrm{~s}$ and connected back at $7 \mathrm{~s}$. Figure 63 shows the PV cell output voltage. The magnitude of the voltage is approximately $680 \mathrm{~V}$. Figure 64 and Figure 65 show the frequency and voltage waveforms at the inverter output. As expected, frequency and voltage vary when the grid is disconnected from the inverter. Figure 66 shows the power injected from the inverter into the grid and the variable R-L-C load. 


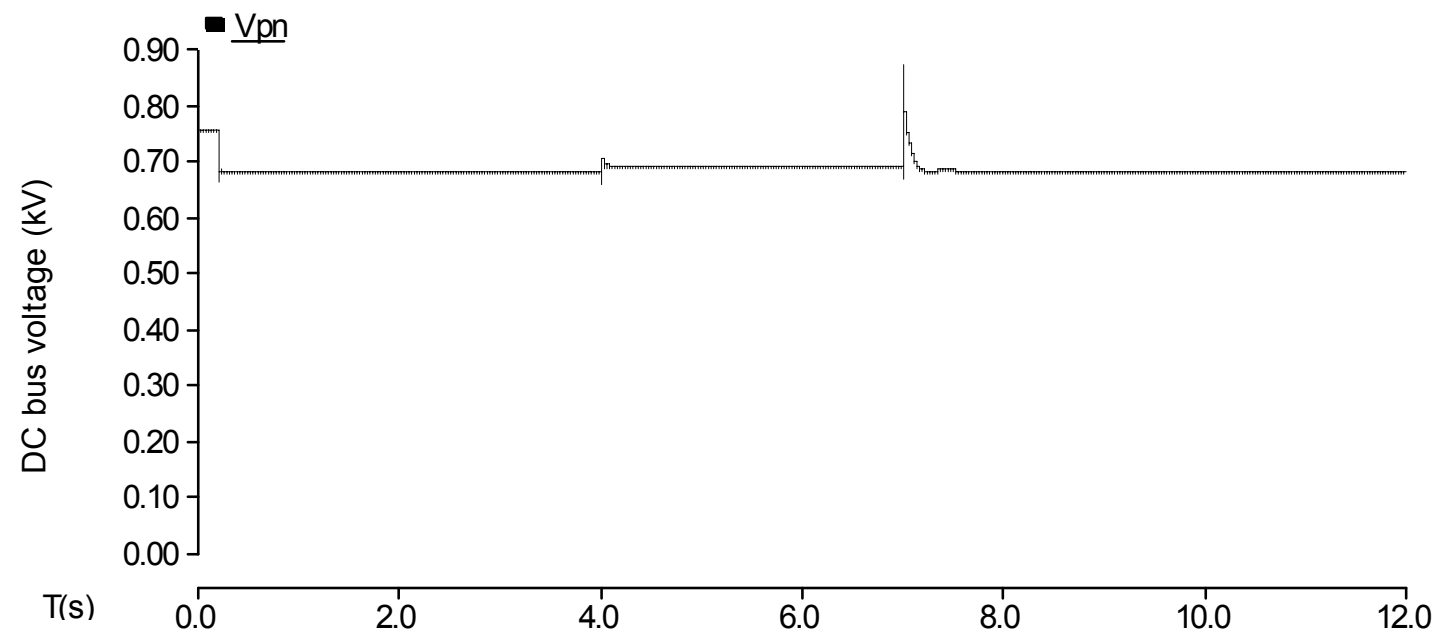

Figure 63. PV output voltage

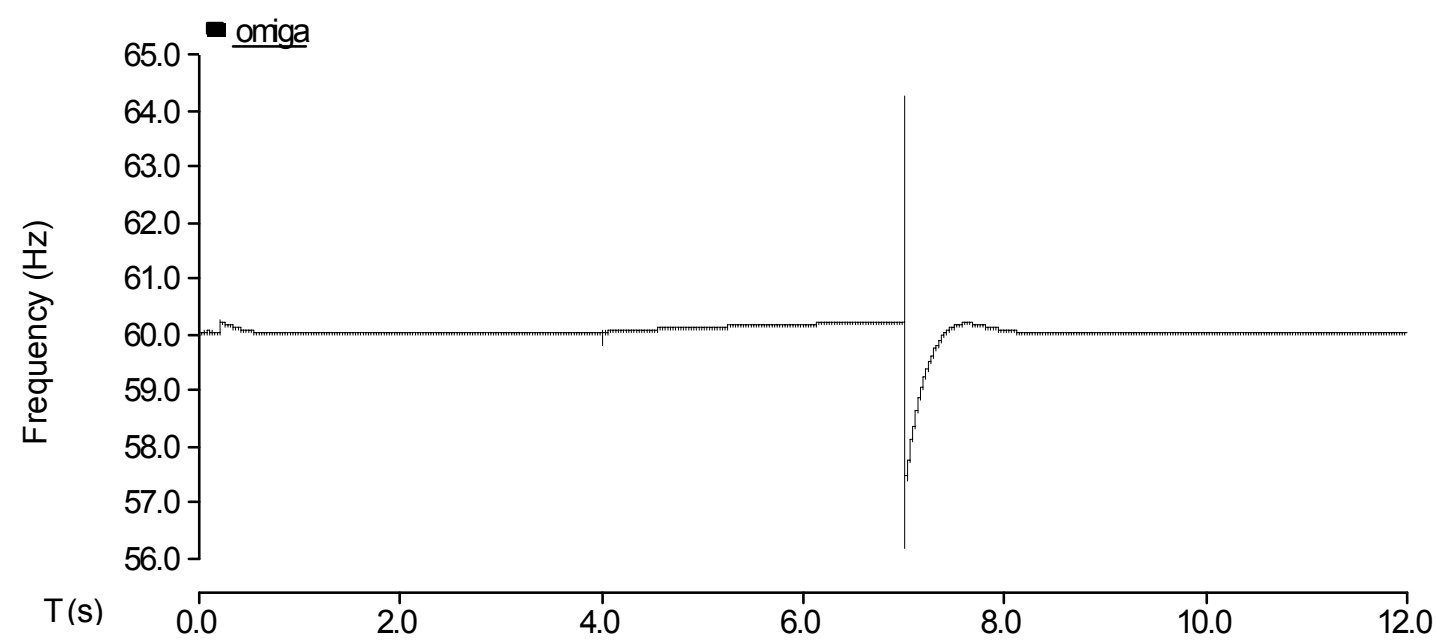

Figure 64. Inverter output frequency

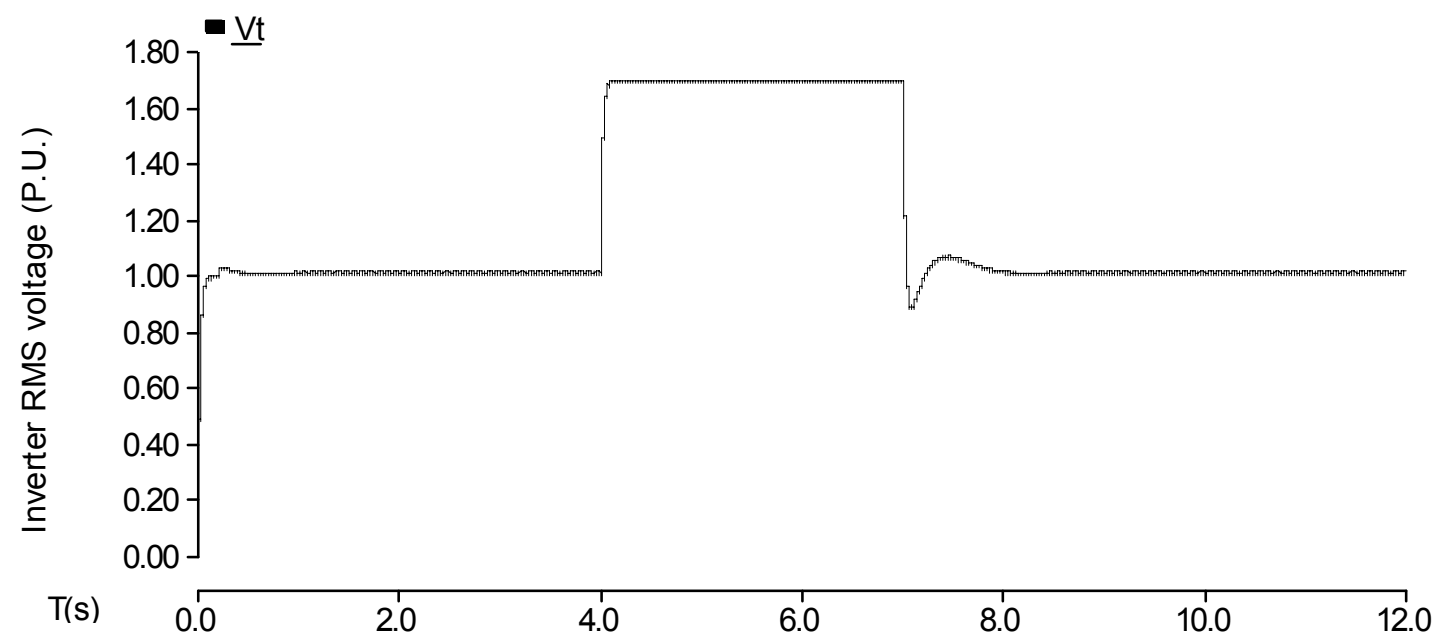

Figure 65. Inverter output voltage 


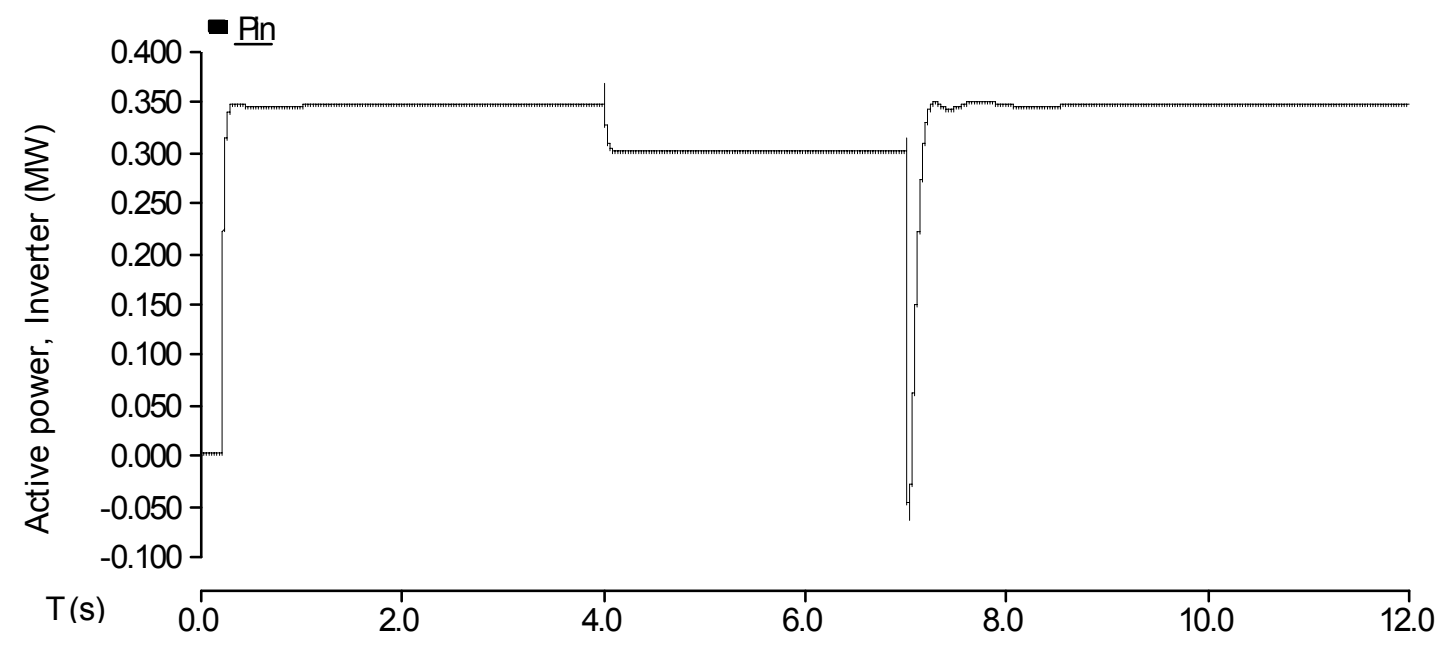

Figure 66. Power injected from the inverter

\subsection{Microturbine Grid Connection}

The microturbine model is integrated into the backbone through an inverter. Figure 67 shows the integration with the backbone. The transformer steps up the voltage to the bus voltage 480 $\mathrm{V}$. When connected to the backbone, the microturbine responds very slowly.

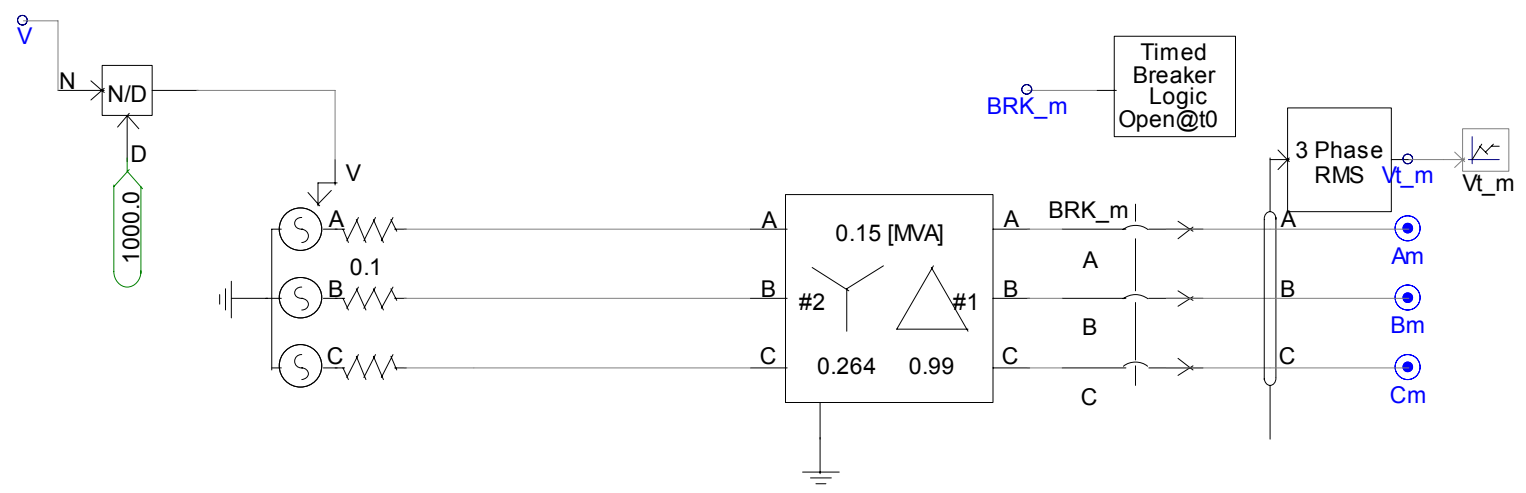

Figure 67. Microturbine grid connection 


\section{Conclusion and Future Work}

DR have an important role in the alleviation of transmission bottlenecks because they are designed to be located at or near the point of end-use and thus avoid the need to transmit electricity through congested wires. Another role of DR is outage response and mitigation. By placement at strategic locations in a networked configuration, DR, operating in "intentional islanding" mode, can provide power to protect critical loads during power failures.

In this project, valid models for DR were created to simulate NREL's DERTF. All of the simulations were run in PSCAD. Models for PWM inverters, microturbines, and PV cells were developed. The diesel generator and wind turbine used models available in the PSCAD library.

Two inverter control methods with two anti-islanding detection schemes were presented. Simulation results showed that the constant current control method works well to track desired d-q axis currents and detect islanding. The inverter simulation with constant power controller is quite stable, but there are problems controlling the reactive power.

Procedures to develop models for a microturbine and a PV suitable for use in electrical engineering were developed. Both models work as expected. The microturbine output power follows the reference power as expected. The PV output voltage is constant at $680 \mathrm{~V}$.

The diesel generator was modeled as a synchronous machine and, therefore, used a model available in PSCAD. The desired output and the desired terminal voltage were achieved. The power is negative because the synchronous machine operates as a generator.

The wind turbine also used a model available in PSCAD. It used an input wind speed and a blade angle pitch dynamics control.

After the models were developed and tested individually, they were connected together to the backbone. Except for the microturbine, all the components worked properly and injected power into the grid. The microturbine worked well by itself, but when connected to the backbone, it became slow and took too long to stabilize.

This project developed electrical models for simulation and analysis of different DR. It can be used to understand the effects of DR on the electric power system. A fuel cell model and the validation of the system have not yet been implemented. 


\section{References}

[1] Simoes, M; Farret, F. Integration of Alternative Sources of Energy. Wiley Press, January 2006.

[2] Gow, J.A.; Manning, C.D. "Development of a Photovoltaic Array Model for Use in Power-Electronics Simulation Studies." Electric Power Applications, IEEE Proceedings, Vol.146, Issue 2, March 1999, pp. 193-200.

[3] PSCAD help file.

[4] Perdana, A.; Carlson, O.; Persson, J. "Dynamic Response of Grid-Connected Wind Turbine With Doubly Fed Induction Generator During Disturbances." Available at http://www.elkraft.ntnu.no/norpie/10956873/Final\%20Papers/054\%20\%20Abram_DynamicResponseDFIG.PDF.

[5] Verhoeven, B. "Probability of Islanding in Utility Networks Due to Grid-Connected Photovoltaic Power Systems.” IEA PVPS T5-07: 2002.

[6] Ye, Z.; Walling, R.; Garces, L.; Zhou, R.; Li, L.; Wang, T. Study and Development of Anti-Islanding Control for Grid-Connected Inverters. NREL/SR-560-36243. Work performed by the General Electric Global Research Center, Niskayuna, NY. Golden, CO: National Renewable Energy Laboratory, May 2004.

[7] Venkataramanan, G.; Illindala, M.S.; Houle, C.; Lasseter, R.H. Hardware Development of a Laboratory-Scale Microgrid Phase 1 - Single Inverter in Island Mode Operation. NREL/SR-560-32527. Work performed by the Wisconsin Power Electronics Research Center, Madison, WI. Golden, CO: National Renewable Energy Laboratory, November 2002, pp. 31-66.

[8] IEEE P1547.4, IEEE Guide for Design, Operation, and Integration of Distributed Resource Island Systems with Electric Power Systems, Draft 1. August 2005.

[9] Davis, M.; Costyk, D. Guide for Design, Operation, and Integration of Distributed Resource Island Systems with Electric Power Systems, Draft 1. August 2005

[10] Chakraborty, S. "D-Q and P-Q Theory: Axis Transformation, Related Mathematics, and Applications." Not published.

[11] Chapman, S. Electric Machinery Fundamentals. 4th edition. McGraw-Hill, 2005; pp. 267-342.

[12] Mohan, N.; Undeland, T.; Robbins, W. Power Electronics. 3rd edition. New York: Wiley, 2003, pp. 16-30.

[13] Flannery, P.; Venkataramanan, G.; Shi, B. Integration of Distributed Technologies Standard Power Electronic Interfaces. P500-2005-119. California Energy Commission consultant report, April 2004.

[14] Simoes, M.; Farret, F. Renewable Energy Systems: Design and Analysis with Induction Generators. CRC Press, May 2004. 


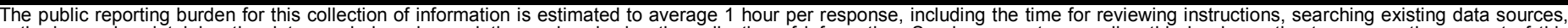

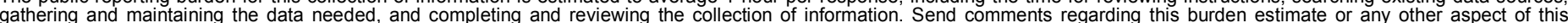

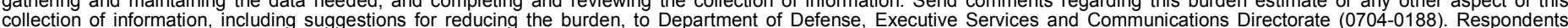

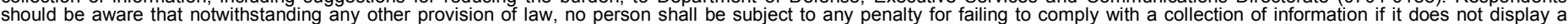

should be aware that notwithstanding

PLEASE DO NOT RETURN YOUR FORM TO THE ABOVE ORGANIZATION.

\begin{tabular}{l|l|l|} 
1. REPORT DATE $(D D-M M-Y Y Y Y)$ & 2. REPORT TYPE & 3. DATES COVERED (FrOm - TO)
\end{tabular}

April 2007

Subcontract report

4. TITLE AND SUBTITLE

Electrical Model Development and Validation for Distributed

Resources

5a. CONTRACT NUMBER

DE-AC36-99-G010337

5b. GRANT NUMBER

5c. PROGRAM ELEMENT NUMBER

6. AUTHOR(S)

M.G. Simoes, B. Palle, S. Chakraborty, C. Uriarte

5d. PROJECT NUMBER

NREL/SR-581-41109

5e. TASK NUMBER

DPE6.1000

5f. WORK UNIT NUMBER
7. PERFORMING ORGANIZATION NAME(S) AND ADDRESS(ES)

Colorado School of Mines

1500 Illinois St.

Golden, CO 80401

9. SPONSORING/MONITORING AGENCY NAME(S) AND ADDRESS(ES)

National Renewable Energy Laboratory

1617 Cole Blvd.

Golden, CO 80401-3393
8. PERFORMING ORGANIZATION REPORT NUMBER

10. SPONSOR/MONITOR'S ACRONYM(S) NREL

11. SPONSORING/MONITORING AGENCY REPORT NUMBER NREL/SR-581-41109

12. DISTRIBUTION AVAILABILITY STATEMENT

National Technical Information Service

U.S. Department of Commerce

5285 Port Royal Road

Springfield, VA 22161

13. SUPPLEMENTARY NOTES

NREL Technical Monitor: Benjamin Kroposki

14. ABSTRACT (Maximum 200 Words)

This project focuses on the development of electrical models for small (1-MW) distributed resources at the National Renewable Energy Laboratory's Distributed Energy Resources Test Facility.

\section{SUBJECT TERMS}

distributed energy; distributed resources; DE; DR; models; modeling; National Renewable Energy Laboratory; NREL

16. SECURITY CLASSIFICATION OF:
\begin{tabular}{|l|l|l|}
\hline a. REPORT & b. ABSTRACT & c. THIS PAGE \\
Unclassified & Unclassified & Unclassified \\
& & \\
\hline
\end{tabular}

\begin{tabular}{|c|c|}
\hline $\begin{array}{l}\text { 17. LIMITATION } \\
\text { OF ABSTRACT }\end{array}$ & $\begin{array}{l}\text { 18. NUMBER } \\
\text { OF PAGES }\end{array}$ \\
\hline UL & \\
\hline
\end{tabular}

19a. NAME OF RESPONSIBLE PERSON

19b. TELEPHONE NUMBER (Include area code) 